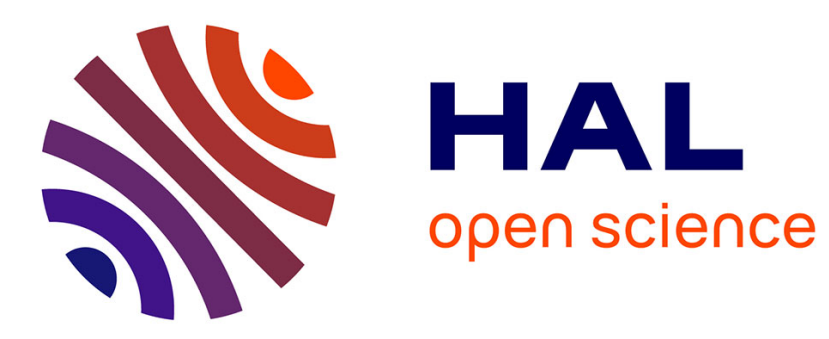

\title{
La contemplation des philosophes selon Thomas d'Aquin Adriano Oliva
}

\section{To cite this version:}

Adriano Oliva. La contemplation des philosophes selon Thomas d'Aquin. Revue des sciences philosophiques et theologiques, 2012. hal-03089044

\section{HAL Id: hal-03089044 https://hal.science/hal-03089044}

Submitted on 7 Jan 2021

HAL is a multi-disciplinary open access archive for the deposit and dissemination of scientific research documents, whether they are published or not. The documents may come from teaching and research institutions in France or abroad, or from public or private research centers.
L'archive ouverte pluridisciplinaire HAL, est destinée au dépôt et à la diffusion de documents scientifiques de niveau recherche, publiés ou non, émanant des établissements d'enseignement et de recherche français ou étrangers, des laboratoires publics ou privés. 


\section{REVUE \\ DES \\ SCIENCES PHILOSOPHIQUES \\ ET \\ THÉOLOGIQUES}

REVUE TRIMESTRIELLE

Publiée avec le concours du Centre National de la Recherche Scientifique

et du Centre National du Livre

ARTICLES :

A. Oliva. - La contemplation des philosophes selon Thomas d'Aquin.

C. König-Pralong. - Découverte et colonisation françaises de la philosophie médiévale (1730-1850)

J. Rousse-Lacordaire. - La cabale au service du christianisme au $\mathrm{XIX}^{\mathrm{e}}$ siècle : le chevalier Drach et le père Perrone.

BULLETIN :

M. Borgo, I. Costa, R. Imbach, M. Millais, A. Oliva. - Bulletin

d'histoire des doctrines médiévales.

\section{P A R I S}

LIBRAIRIE PHILOSOPHIQUE J. VRIN

6, Place de la Sorbonne, V ${ }^{\mathrm{e}}$

2012 



\title{
LA CONTEMPLATION DES PHILOSOPHES SELON THOMAS D’AQUIN
}

\author{
par Adriano OLIVA \\ Commissio Leonina - LEM (CNRS, Paris)
}

\author{
À la mémoire des Pères \\ René Antoine Gauthier, OP \\ Louis facques Bataillon, $O P^{1}$
}

L'enquête présentée ici porte sur la contemplation comme acte de l'intellect spéculatif en tant qu'il est choisi au préalable par la volonté : il s'agit de la contemplation qui «devient une affaire de vie » (contemplatio accipit rationem uite), pour le chrétien comme pour «le païen et l'infidèle». Dans le cas de la contemplation purement philosophique, cet acte est suscité par un désir naturel que Thomas a une fois identifié avec l'amour de soi $^{2}$. Il est nécessaire de donner une interprétation correcte de cette affirmation à la lumière de l'ensemble de la doctrine de Thomas sur ce sujet, car la notion de contemplation

1. Le P. Gauthier, décédé le 27 janvier 1999, n’a pu lire et discuter avec moi que l'édition et les sources du prologue du commentaire des Sentences, dont le premier article m’a inspiré ce travail. Le P. Bataillon, décédé le 13 février 2009, a pu lire une première version de cet article, présentée en 2007 à Andria (Bari), dans le cadre d'un «International Research Workshop » sur « Knowledge and Happiness : Philosophy as a Way of Life in the Middle Ages », organisé par les Prof. Pasquale Porro et Andreas Speer. Le P. Bataillon m'avait fait part alors de ses conseils, non sans les colorer de son humour plein de finesse.

2. Voir In III Sent., dist. 35, q. 1, a. 2, sol. 1 et ad 1 (éd. Maria Fabianus Moos, p. 11771178, cités respectivement dans les notes 36 et 35). - Les œuvres de Thomas sont citées par leur titre, sans indiquer l'auteur. Nous traduisons nous-même tous les textes latins. Je remercie vivement Gilles Berceville, Philippe Büttgen et Daniel Ols qui ont révisé ce texte, ainsi que Luca Bianchi, Marta Borgo, Iacopo Costa et Irene Zavattero. 
philosophique, en particulier celle d'Aristote, lui sert de modèle pour concevoir la contemplation selon la foi chrétienne et joue un rôle déterminant dans sa compréhension de la doctrina theologie. Nous avons mené notre enquête sur l'ensemble des écrits du Docteur angélique, afin de trouver les éléments utiles à notre propos et de fournir une interprétation solide de la notion et du rôle de la contemplation philosophique comme «affaire de vie» chez Thomas d'Aquin. L'ampleur du sujet nous a contraint à laisser de côté plusieurs de ses aspects. Nous avons aussi renoncé à comparer en détail ce que les différents philosophes cités par Thomas disent à ce propos. Et nous n'avons fait appel à l'enseignement d'autres théologiens de l'époque de Thomas, que pour éclairer la doctrine de celui-ci, ce qui est le but de cette étude.

\section{L’EXISTENCE D’UNE CONTEMPLATION DES PHILOSOPHES}

Dans une œuvre de jeunesse rédigée à Paris pendant l'année universitaire 1251-1252 ou 1252-1253 ${ }^{3}$, Thomas d'Aquin dit en toutes lettres qu'il y a selon lui trois genres de contemplation: celle des philosophes, celle des fidèles in via, celle des bienheureux in patria; cette classification demeure valable jusqu'à ses derniers ouvrages ${ }^{4}$.

Au cours de l'automne 1251 ou 1252, en commentant la «Visio » qui ouvre le livre d'Isaïe, Thomas propose de distinguer comme suit la vision

3. Voir Adriano Oliva, Les Débuts de l'enseignement de Thomas d'Aquin et sa conception de la sacra doctrina, avec l'édition du prologue de son Commentaire des Sentences, Paris, J. Vrin («Bibliothèque thomiste» 58), 2006, p. 209 et 223-224; les citations du prologue sont tirées de cette édition, à laquelle nous renvoyons, dans notre texte, en indiquant les lignes du passage cité.

4. Voir $I I^{a}-I I^{a e}$, q. 180 , a. 4, resp. et ad 3 (cités aux notes 11 et 15 ), qui date de 1272 ; et aussi : In Ps., 32, 11 (cité à la note 10), même si la date de ce commentaire pourrait être antérieure à 1273. Pour la datation des œuvres de Thomas, nous suivons généralement la chronologie établie par René Antoine GaUTHIER, dans S. Thomae de Aquino, Opera Omnia, Quaestiones de quolibet, t. 22, 2, cura et studio Fratrum Praedicatorum, Roma Paris, Commissio Leonina - Éd. du Cerf, 1996, p. 479-500; cependant, pour la date du commentaire des Sentences, il faut voir A. OLIVA, Les Débuts..., op. cit., p. 224-253, spéc. p. 241; à propos de la rédaction de la Somme de théologie et d'un second enseignement des Sentences par Thomas, voir : Adriano Oliva, « La Somme de théologie de Thomas d'Aquin. Introduction historique et littéraire », dans Chôra. Revue d'études anciennes et médiévales : philosophie, théologie, sciences 7-8 (2009-2010), p. 217-253 ; ID., «L'enseignement des Sentences dans les Studia dominicains italiens au XIII siècle : l'Alia lectura de Thomas d'Aquin et le Scriptum de Bombolognus de Bologne », dans Philosophy and Theology in the Studia of Religious Orders and at Papal and Royal Court, Acts of the $\mathrm{XV}^{\text {th }}$ Annual Colloquium of the Société Internationale pour l'Étude de la Philosophie médiévale, University of Notre Dame, 8-10 October 2008, Kent EMERY, Jr., William J. COURTENAY and Stephen M. METZGER, Tournhout, Brepols (coll. « Rencontres de Philosophie médiévale » 15), 2012, p. 49-73; à propos de l'Adoro [te] deuote, il faut remarquer que la Commissio Leonina n'a jamais pensé devoir considérer cette composition comme œuvre authentique de Thomas. 
prophétique des autres visions qui sont impliquées de soi dans toute contemplation :

Toutes les visions intellectuelles ne sont pas des visions prophétiques. Il y a un type de vision pour laquelle la lumière naturelle de l'intellect suffit : c'est le cas de la contemplation des réalités invisibles par les principes de la raison, que les philosophes considéraient comme la suprême félicité pour l'homme. Par ailleurs, il y a un autre type de contemplation à laquelle suffit la lumière de la foi pour que l'homme y soit élevé : c'est le cas des saints ici-bas. Il y a encore un type de vision qui est celle des bienheureux dans la Patrie, à laquelle l'intellect est élevé par la lumière de gloire, voyant Dieu par essence en tant qu'il est objet de béatitude ; cela ne se réalise entièrement et parfaitement que dans la Patrie ${ }^{5}$.

La contemplation des philosophes est ici définie comme « vision pour laquelle la lumière naturelle de l'intellect suffit: c'est le cas de la contemplation des réalités invisibles par les principes de la raison ». Elle peut donc, d'une certaine façon, avoir Dieu comme objet. Il s'agit d'une première définition, qui ne vise pas à l'exhaustivité, comme c'est d'ailleurs le cas pour la contemplation des saints ici-bas. Thomas a ici pour seule intention de distinguer la uisio procurée par ces deux contemplations de la uisio prophétique.

De ce texte, on peut retenir qu'il établit d'emblée une catégorie générique de «philosophes », que souvent Thomas identifie à Aristote quand il s'agit de la notion de contemplation philosophique. Parfois, cependant, il distingue les opinions de différents philosophes à ce sujet : Aristote, Alexandre, Averroès (voir $S c G$, III, 48, cité à la note 125), Platon (vu à travers Aristote), Farabi, Avempace, Avicenne (Super IV Sent., d. 49, q. 2, a.1, sol. [ed. Vivès, t. 11, p. 481-484]). Parfois même, il évoque différents courants philosophiques (In Ps., 32, 11, cité à la note 10). Étant donné cette pluralité de contemplations, au sein même de la philosophie, il faut nécessairement tenir compte de la définition ou de l'explication que Thomas donne au cas par cas du mot contemplation ou béatitude. De plus, s'il est vrai que, généralement parlant, le terme felicitas est plutôt

5. « [...] non quelibet uisio intellectualis est uisio prophetalis. Est enim quedam uisio ad quam sufficit lumen naturale intellectus, sicut est contemplatio inuisibilium per principia rationis; et in hac contemplatione ponebant philosophi summam felicitatem hominis. Est iterum quedam contemplatio ad quam eleuatur homo per lumen fidei sufficienter, sicut sanctorum in uia. Est etiam quedam beatorum in patria, ad quam eleuatur intellectus per lumen glorie, uidens Deum per essentiam inquantum est obiectum beatitudinis; et hoc plene et perfecte non est nisi in patria [...]. Nulla autem istarum est uisio prophetalis, quia ad ipsam neque lumen nature neque lumen fidei sufficit; sed eleuatur ad ipsam intellectus prophete per lumen gratie gratis date quod est donum prophetie, nondum tamen attingit ad uidendum Deum prout est obiectum beatitudinis, sed prout est ratio eorum que pertinent ad dispositionem hominum in mundo » In Is., 1, 1 (éd. Leon., t. 28, p. 9, 1. 74-99 ; les italiques sont de nous). 
utilisé pour désigner la contemplation philosophique, alors que beatitudo indique de préférence la contemplation propre, sur cette terre, aux saints ou, dans l'au-delà, aux bienheureux, la lecture des textes de Thomas montre à l'évidence qu'il n'applique aucunement cette distinction de façon rigide et constante ${ }^{6}$.

Exactement un an après avoir commenté le début du livre d'Isaïe, dans l'a. 1 de son prologue au commentaire des Sentences, Thomas reprend la même doctrine. Ici toutefois il précise plusieurs choses : que Dieu est l'objet de la contemplation des philosophes; qu'en cette vie l'ensemble de toutes les connaissances philosophiques est ordonné à cette félicité contemplative (que tamen felicitas est uie) ; et que, puisque celleci procède de la connaissance des créatures, elle est imparfaite, par rapport à la contemplation parfaite que nous aurons de Dieu dans la vision face à face (in patria).

Pour suppléer à l'imperfection des connaissances philosophiques, il y a une autre science, la théologie, qui nous procure une contemplation elle aussi imparfaite, mais par laquelle nous sommes conduits à la contemplation parfaite :

Il faut savoir que tous ceux dont la pensée était juste ont considéré que la fin de la vie humaine consistait en la contemplation de Dieu. Or celle-ci est double. Une contemplation s'effectue par les créatures; elle est imparfaite pour la raison que l'on a dite [voir Ibid., contra 2], et c'est en elle que le Philosophe a reconnu la félicité contemplative. Cette félicité cependant est celle d'ici-bas, et toute la connaissance philosophique qui procède de la considération de ce que sont les créatures lui est entièrement ordonnée. Il est une autre contemplation de Dieu, par laquelle on le voit immédiatement en son essence, et qui est parfaite : elle aura lieu dans la Patrie et selon ce que croit la foi elle est possible à l'homme. Et ainsi il convient que les moyens soient proportionnés à la fin, et que l'homme ici-bas soit conduit à cette contemplation par une connaissance qui n'est pas tirée des créatures, mais qui tire directement son inspiration de la lumière divine. Cela, c'est la doctrine théologique ${ }^{7}$.

6. Voir par exemple In II Sent., d. 4, a. 1, cité à la note 31 ; Q. disp. de uirtutibus, a. 5, ad 8 , cité à la note 34 . On constate cela également chez les commentateurs de l'Éthique à Nicomaque de la première moitié du XIII ${ }^{\mathrm{e}}$ siècle : voir Irene ZAVATTERO, «Le bonheur parfait dans les premiers commentaires latins de l'Éthique à Nicomaque », dans RTP 139 (2007), p. 312.

7. «[...] sciendum est quod omnes qui recte senserunt posuerunt finem humane uite Dei contemplationem. Contemplatio autem Dei est duplex. Vna per creaturas, que est imperfecta ratione iam dicta, in qua contemplatione Philosophus felicitatem contemplatiuam posuit, que tamen felicitas est uie, et ad hanc ordinatur tota cognitio philosophica que ex rationibus creaturarum procedit. Est alia contemplatio Dei, qua uidetur immediate per suam essentiam, et hec perfecta est, que erit in patria et est homini possibilis secundum fidei suppositionem. Vnde oportet ut ea que sunt ad finem proportionentur fini, quatenus homo manuducatur ad illam contemplationem in statu uie 
Il faut remarquer que Thomas ne parle pas ici de la contemplation des saints ici-bas, car elle fait partie de la doctrina theologie : celle-ci étant une manuductio à la contemplation de la Patrie, elle est, elle-même, une participation inchoative à cette contemplation, n'étant pas une connaissance tirée des créatures, mais découlant directement de la lumière divine.

Mais ce dont il faut surtout tenir compte dans ce texte, c'est que la contemplation philosophique, pour Thomas d'Aquin, n'est pas imparfaite par rapport à la sacra doctrina, mais par rapport à la connaissance de Dieu in patria. C'est parce que la philosophie, ordonnée de soi à la contemplation de Dieu, constate le caractère imparfait de la contemplation à laquelle elle peut atteindre, qu'elle est conduite à reconnaître elle-même la nécessité de convenance d'une Révélation et d'une doctrine fondée sur celle-ci, la doctrine théologique, «qui considère les réalités existantes selon les raisons reçues de l'inspiration de la lumière divine $\gg^{8}$. Celle-ci, cependant, est elle aussi une connaissance imparfaite, par rapport non seulement à la science que Dieu a de soi-même, mais aussi à la vision des bienheureux dans la Patrie ${ }^{9}$.

Il faut avoir cette constatation bien présente à l'esprit, car Thomas, dans ses œuvres, ne précise pas toujours s'il entend parler de la contemplation philosophique ou de celle des saints ici-bas. Dans les textes que je citerai, on constate facilement qu'il prend souvent ensemble les deux contemplations ou qu'il passe de l'une à l'autre sans solution de continuité $^{10}$. Si Thomas ne distingue pas explicitement entre les espèces

per cognitionem non a creaturis sumptam, set immediate ex diuino lumine inspiratam. Et hec est doctrina theologie »In I Sent., prol., a. 1 (éd. A. Oliva, Les Débuts..., op. cit., p. 312-313, 1. 31-41 [dorénavant : éd. A. OLIVA]). Voir aussi Summa contra Gentiles [ScG], II, 4 : « Nam in doctrina philosophiae, quae creaturas secundum se considerat et ex eis in Dei cognitionem perducit, prima est consideratio de creaturis et ultima de Deo. In doctrina vero fidei, quae creaturas non nisi in ordine ad Deum considerat, primo est consideratio Dei et postmodum creaturarum. Et sic est perfectior : utpote Dei cognitioni similior, qui seipsum cognoscens alia intuetur. Unde, secundum hunc ordinem, post ea quae de Deo in se in primo libro sunt dicta, de his quae ab ipso sunt restat prosequendum » (éd. Leon., t. 13, p. 279, 1. 14b-25b).

8. « [...] oportet tamen esse aliam < doctrinam $>$ que existentia consideret secundum rationes ex inspiratione diuini luminis acceptas » In I Sent., prol., a. 1, ad 1 (éd. A. OLIVA, p. 313, 1.51-53). Voir aussi le passage de la Somme contre les Gentils, cité à la note précédente.

9. Voir I Pars, q. 12, a. 7, resp. (éd. Leon., t. 4, p. 127) ; In I Sent., prol., a. 3, ad 2.2-B (éd. A. Oliva, p. 323-324, 1.67-90); et In III Sent., d. 23, q. 3, a. 4, sol. 1, ad 2: «Imperfectio quam habet fides respectu visionis, est secundum genus cognitionis; et ideo pertinet ad speciem fidei; et propter hoc visio adveniens fidem evacuat» (éd. M. F. Moos, p. 754, n. 289).

10. En commentant le Psaume 32, 12 : Beata gens cuius est Dominus Deus eius, populus quem elegit in hereditatem sibi, Thomas dit : « Omnes autem desiderant tendere ad beatitudinem, ad quam tamen soli iusti perueniunt, quia eam consequntur in futuro 
de contemplation, c'est que, dans les textes cités, il ne parle pas directement de la contemplation, mais de sa fin : la vision de Dieu. Ce qu'il lui importe d'établir, c'est que la béatitude consiste dans la vision de Dieu et que l'homme la désire naturellement. Ce n'est que dans un second temps, quand on se demande si et comment cette vision se réalise, qu'entrent en jeu les trois degrés que l'on a vus.

Nous croyons pouvoir montrer cela en nous référant à deux textes extraits de la $I I^{a}-I I^{a e}$ de la Somme de théologie, qui appartient à une période de la vie de Thomas (1271-1272) où le débat entre philosophes et théologiens à l'université de Paris, à propos de ces sujets, était parfois difficile - ce qui n'est pas du tout le cas dans les années 1251-1259, comme nous le montrerons ci-dessous (§ III.4). Voici, pour commencer, $I I^{a}-I I^{a e}$, q. 180, a.4, resp. :

Deux choses relèvent de la vie contemplative, l'une à titre principal ; l'autre à titre second et comme disposition. La contemplation de la vérité divine relève de la vie contemplative à titre principal. En effet ce type de contemplation est la fin de la vie humaine [...] Elle sera parfaite dans la vie future, quand nous le verrons face à face [1 Cor 13, 12...]. Mais à présent la contemplation de la vérité divine ne nous revient qu'imparfaitement, comme dans un miroir et en énigme [1 Cor 13, 12], de sorte qu'elle est pour nous comme une amorce de la béatitude, qui commence ici-bas pour se terminer dans le futur. C'est pourquoi le Philosophe, au livre X de l'Éthique, fait consister la félicité ultime de l'homme dans la contemplation du suprême intelligible. Mais puisque nous sommes conduits à la contemplation de Dieu par les effets de son action, selon Romains I : ce qu'il y a d'invisible en Dieu se laisse voir à l'intellect par ses ouvres [tâche qui revient à l'homme en tant qu'homme], la contemplation des ouvres divines relève en second lieu elle aussi de la vie contemplative, dans la mesure où c'est à partir d'elle que l'homme est conduit à la connaissance de Dieu. Augustin dit ainsi,

perfecte, nunc uero inchoatiue et in spe. Ergo dignitas iustorum est magna. Circa eorum beatitudinem hic inchoatam et in futuro perficiendam, duo tangit : materiam scilicet et causam, ibi, populus. Dicit ergo, Beata gens. De beatitudine diuersi diuersa senserunt. Et secundum diuersas opiniones de hac diuerse sunt secte philosophorum. Quidam enim posuerunt eam in bonis corporalibus, sicut Epicurus. Quidam in operibus actiue uite, ut Stoyci. Quidam in ueritatis contemplatione, ut Peripatetici. Querere beatitudinem in eo quod est infra nos, est uanum, quia beatitudo est supra nos. Quod autem est supra nos, hoc est Deus. Ergo beatitudo hominis est inherere Deo. Vnumquodque enim perfectum est, quando inheret proprio bono. Proprium autem bonum hominis est Deus. Ps. $\left[72_{28}\right]$ : Mihi autem adherere Deo bonum est. Deo autem potest quis inherere mente, scilicet intellectu et uoluntate, non sensu, quia hic etiam [est add. cod. et seclusi] brutis est communis. Dupliciter ergo inheret homo Deo : scilicet per intellectum contemplando et cognoscendo, et per affectum amando. Et quia hec imperfecta sunt in uia, perfecta uero in patria, ideo hic beatitudo est imperfecta, ibi perfecta » In Ps., 32, 12 [11] (Bologna, Univ. $1655^{15}$, f. 50va ; voir éd. Vivès, t. 18, p. 413-414; les italiques sont dans l'édition; les soulignements sont de nous). 
dans son livre Sur la vraie religion qu'il ne faut pas s'adonner à la considération des créatures dans une curiosité vaine et périssable, mais qu'il faut en faire une étape vers les réalités immortelles et permanentes. Donc, d'après ce que nous venons de dire, il ressort que quatre éléments participent de la vie contemplative. Dans l'ordre : premièrement, les vertus morales; deuxièmement, les actes autres que la contemplation elle-même, troisièmement, la contemplation des œuvres divines ; quatrièmement, la contemplation même de la vérité divine ${ }^{11}$.

Ce qui frappe dans ce texte, c'est que Thomas, quand il envisage le troisième degré de la contemplation, c'est-à-dire la contemplation des œuvres divines, ne se sent pas obligé de distinguer la contemplation de Dieu dans ses effets selon la philosophie, d'un côté, et selon qu'elle est inspirée par la foi, de l'autre. Il le faisait cependant quelques lignes auparavant lorsqu'il posait, d'une part, la connaissance comme dans un miroir et en énigme (1 Cor 13, 12) - qui désigne traditionnellement la connaissance dans la foi par rapport à la vision face à face -, associée à l'enseignement du Philosophe, et, d'autre part, la connaissance naturelle dont parle saint Paul dans l'épître aux Romains 1, 20-2112. Il faut

11. «[...] ad vitam contemplativam pertinet aliquid dupliciter, uno modo principaliter; alio modo secundario vel dispositive. Principaliter quidem ad vitam contemplativam pertinet contemplatio divinae veritatis : quia huiusmodi contemplatio est finis totius humanae vitae. [...] Quae quidem in futura vita erit perfecta, quando videbimus eum facie ad faciem $[1$ Cor 13,12 ; ...]. Nunc autem contemplatio divinae veritatis competit nobis imperfecte, videlicet per speculum et in aenigmate [1 Cor 13, 12], unde per eam fit nobis quaedam inchoatio beatitudinis, quae hic incipit ut in futuro terminetur. Unde et Philosophus, in X Ethic., in contemplatione optimi intelligibilis ponit ultimam felicitatem hominis. Sed quia per divinos effectus in Dei contemplationem manuducimur, secundum illud Rom. 1, invisibilia Dei per ea quae facta sunt, intellecta, conspiciuntur: inde est quod etiam contemplatio divinorum effectuum secundario ad vitam contemplativam pertinet, prout scilicet ex hoc manuducitur homo in Dei cognitionem [...]. Unde Augustinus dicit, in libro de Vera Relig., quod in creaturarum consideratione non vana et peritura curiositas est exercenda, sed gradus ad immortalia et semper manentia faciendus. Sic igitur ex praemissis patet quod ordine quodam quatuor ad vitam contemplativam pertinent : primo quidem, virtutes morales ; secundo autem, alii actus praeter contemplationem; tertio vero, contemplatio divinorum effectuum; quarto vero contemplativum [completivum éd. Parmensis, t. 3, p. 602] est ipsa contemplatio divinae veritatis $\gg I I^{a}-I I^{a e}$, q. 180, a. 4, resp. (éd. Leon., t. 10, p. 427-428; les italiques sont dans l'édition; les soulignements sont de nous).

12. «Invisibilia enim ipsius a creatura mundi per ea que facta sunt, intellecta conspiciuntur : sempiterna quoque virtus eius et diuinitas ita vt sint inexcusabiles. Quia cum cognouissent Deum non sicut Deum glorificauerunt 》(Biblia latina cum Glossa ordinaria, éd. Adolph RusH, t. 4, p. 276). Thomas commente ainsi ce verset : « Fuit enim in eis [= in sapientibus gentilium] quantum ad aliquid uera Dei cognitio quia quod notum est Dei, id est quod cognoscibile est de Deo ab homine per rationem, manifestum est in illis, id est manifestum est eis ex eo quod in illis est id est ex lumine rationis intrinseco. [...] cognouerunt Deum sicut ultimum finem in quod omnia tendunt »In Rom., 1, lect. 6 (texte provisoire de la Commission Léonine, préparé par Gilles DE GRANDPRÉ ; voir éd. Marietti, 1953, p. 21-22, n. 114-117) ; voir aussi : In Is., 1 , 1 (éd. Leon., t. 28, p. 9, 1. 7579 , cité à la note 5 ). 
toutefois remarquer immédiatement deux choses. En premier lieu, la connaissance comme dans un miroir et en énigme ne désigne pas exclusivement la connaissance selon la foi, mais aussi la capacité humaine que la foi vient perfectionner : «Connaître les réalités divines par le miroir des créatures et énigmatiquement par ressemblance est un mode de connaissance connaturel à la nature humaine $\gg^{13}$. En second lieu, la citation de Romains 1, 20 renvoie directement à la considération des effets divins par la seule raison. Il faut donc souligner que Thomas, dans le texte de la Somme que nous examinons, considère sans aucun doute de façon globale la contemplation des effets divins selon la raison et la contemplation des effets divins selon la foi, et il les considère ordonnées toutes deux à la contemplation future de la Patrie ${ }^{14}$.

Cette union des deux sortes de contemplation des effets divins ne signifie pas que Thomas néglige leur différence : dans la réponse ad 3 de ce même article 4 de la q. 180, il l'expose avec précision, en montrant comment la contemplation selon la foi est en continuité avec celle de la Patrie. En commentant un texte de Grégoire, qui a énuméré six degrés dans la vie contemplative, Thomas exprime ainsi cette continuité :

Ces six réalités désignent les degrés par lesquels on s'élève depuis les créatures jusqu'à la contemplation de Dieu [...] au cinquième degré correspond la contemplation des réalités intelligibles qui ne peuvent être découvertes par les réalités sensibles mais qui peuvent être saisies par la raison; au sixième degré correspond la considération des réalités intelligibles que la raison ne peut ni découvrir ni comprendre, ce qui relève de la contemplation sublime de la vérité divine, achèvement ultime de la contemplation ${ }^{15}$.

13. « Connaturalis enim modus humanae naturae est ut divina non nisi per speculum creaturarum et aenigmate similitudinum percipiat; et ad sic percipienda divina perficit fides » In III Sent., d. 34, q. 1, a. 1, resp. (éd. M. F. Moos, p. 1114, n. 37). Il faut remarquer que chez Guillaume d'Auxerre on trouve déjà ce double usage : voir surtout GulLLELMI AltissiodoRENSIS Summa aurea, III, tr. 12, c. 4 (éd. Jean RiBAILLER, III, 1, p. 208, 1. 58-59), mais aussi Ibid., tr. 13, c. 5 (éd. J. Ribailler, III, 1, p. 250, l.62-63) et Ibid., tr. 12, c. 8 (éd. J. RibaILLER, III, 1, p. 235, l. 79-81).

14. L'ad 4 de ce même article de la Somme dit: «[...] ultima perfectio humani [humani om. éd. Parm.] intellectus est veritas divina : aliae autem veritates perficiunt intellectum in ordine ad veritatem divinam »II ${ }^{a}-I I^{a e}$, q. 180, a. 4 ad 4 (éd. Leon., t. 10, p. 428b).

15. «Ad tertium dicendum quod per illa sex designantur gradus quibus per creaturas in Dei contemplationem ascenditur. Nam in primo gradu ponitur perceptio ipsorum sensibilium ; in secundo vero gradu ponitur progressus a sensibilibus ad intelligibilia; in tertio vero gradu ponitur diiudicatio sensibilium secundum intelligibilia ; in quarto vero gradu ponitur absoluta consideratio intelligibilium in quae per sensibilia pervenitur; in quinto vero gradu ponitur contemplatio intelligibilium quae per sensibilia inveniri non possunt, sed per rationem capi possunt; in sexto gradu ponitur consideratio intelligibilium quae ratio nec invenire nec capere potest, quae scilicet pertinent ad 
Le sixième degré concerne la contemplation qui est « directement inspirée par la lumière divine » (pourrait-on dire avec In I Sent., prol. a. 1, 1. 40), que la seule raison ne peut ni découvrir ni comprendre. Celle-ci est, pour Thomas, en continuité avec la contemplation de la Patrie, achèvement ultime de la contemplation: elle est « une amorce de la béatitude, qui commence ici-bas pour se terminer dans le futur $\gg\left(I I^{a}-I I^{a e}\right.$, q. 180, a.4, cité à la note 11). Il reste cependant un point à approfondir, à savoir si la contemplation philosophique, dont il est question ici dans le cinquième degré, peut être considérée elle aussi en continuité avec la contemplation de Dieu dans la Patrie et en quelle mesure. Le fait que Thomas ait réuni dans la responsio ces deux contemplations selon les créatures et le fait que dans l'ad 3 la contemplation philosophique soit ordonnée à la contemplation finale, le laisse supposer. Pour l'expliquer il faudrait toutefois entrer dans la conception du désir naturel de voir Dieu, dont nous parlerons ci-dessous ${ }^{16}$.

\section{LA CONTEMPLATION IMPARFAITE DE DIEU PER CREATVRAS}

Après avoir présenté quelques caractères qui distinguent la contemplation des philosophes de celle des saints et avoir montré que toutes les deux, selon Thomas, ont pour fin la vision de Dieu, il faut étudier les raisons pour lesquelles il dit constamment que la contemplation per creaturas est imparfaite.

Revenons à l'a. 1 du prologue du commentaire des Sentences. Thomas y explique, dans le contra 2 , que la raison de cette imperfection consiste dans le fait qu'il s'agit d'une contemplation per creaturas, et dans ce cas : «L'effet qui n'est pas proportionné à la cause ne permet qu'une connaissance imparfaite de sa cause $\gg^{17}$. Il est difficile de retrouver ce principe exprimé sous cette forme dans les sources philosophiques de Thomas. On pourrait cependant trouver dans les Seconds Analytiques les principes de cette doctrine, en particulier au chapitre 13 du livre $\mathrm{I}$, où Aristote explique que « la connaissance du fait diffère de la connaissance du pourquoi $»$, en précisant que «cette différence peut avoir lieu dans une même science, et cela de deux façons : la première, c'est quand le syllogisme procède par des prémisses non immédiates (car alors la cause

sublimem contemplationem divinae veritatis, in qua finaliter contemplatio perficitur » Ibid., ad 3 (p. 428b ; les italiques sont de nous).

16. Voir $\S$ V.2. Autre aspect commun à la contemplation philosophique et à la contemplation de la foi : l'une et l'autre disparaissent avec la vision de Dieu facie ad faciem, comme on peut le lire par exemple In III Sent., d. 23, q. 3, a.4, sol. 1, ad 2 (éd. M. F. Moos, p. 754, n. 289, cité à la note 9).

17. «Effectus non proportionatus cause imperfecte ducit in cognitionem sue cause » In I Sent., prol., a. 1, contra 2 (éd. A. OlivA, p. 311, 1. 25-26). 
prochaine ne s'y trouve pas assumée, alors que la connaissance du pourquoi est celle de la cause prochaine); la seconde, c'est quand le syllogisme procède bien par des prémisses immédiates, mais au lieu que ce soit par la cause, c'est par celui des deux termes réciproques qui est le plus connu: rien n'empêche, en effet, que des deux prédicats réciprocables le mieux connu ne soit parfois celui qui n'est pas la cause, de telle sorte que c'est par son intermédiaire qu'aura lieu la démonstration $\gg^{18}$. Cet intermédiaire est précisément l'effet, qui permet d'aboutir à la connaissance du quia de la cause. Dans le Livre II des Seconds Analytiques cette différence de syllogismes est appliquée ou bien à l'étude du rôle du moyen terme (« nous nous demandons soit s'il y a un moyen terme, soit quel est le moyen terme $\gg^{19}$ ) ou bien à celle des rapports de cause à effet et vice versa; la connaissance produite par cette démonstration est ou bien celle du quia est de la cause ou bien celle du quid est, en déterminant le genre auquel une chose appartient, soit par sélection soit par analogie ${ }^{20}$, grâce à la recherche des «termes moyens les plus rapprochés de chaque espèce prise séparément $»^{21}$.

La doctrine des Seconds Analytiques est sous-jacente au raisonnement de Thomas, qui, dans cet a. 1 du prologue du commentaire des Sentences, dans le contra 2, commence précisément par dire que si le rapport entre effet et cause n'est pas «proportionné », la connaissance de l'effet permet une connaissance limitée de la cause, car l'existence de l'effet peut conduire à l'affirmation de la cause (une fois qu'on a déterminé une connexion entre ces deux réalités), mais elle ne conduit pas nécessairement à la connaissance du quid de la cause.

Thomas explique bien cette doctrine dans le Super Boetium De Trinitate, q. 1, a.2. La disproportion entre le créateur et la créature a son fondement dans la distance infinie qui les sépare. Bien que le créateur ait le rôle de principe par rapport à la création et fonde ainsi les genres des êtres en celle-ci, il demeure cependant au-delà de tout genre. Il faut toutefois remarquer que dans le contra 2 de l'a.1 du prologue des Sentences Thomas, plus brièvement, se borne à nier la proportion entre la créature et le créateur, tandis que, dans le Super Boetium, il développe

18. ARIstote, Organon. IV. Les Seconds Analytiques, I, 13 (78a22-31), trad. Jules TRICOT, Paris, J. Vrin (coll. « Bibliothèque des textes philosophiques »), 2000, p. 72-73; voir Aristoteles Latinus, transl. Iacobi (AL IV.1-4, p. 29-30). L'exemple donné ici est celui $\mathrm{du}$ « scintillement des planètes ». Il est intéressant de remarquer que la fin de ce chapitre est consacrée à la connaissance du quia et du propter quid, respectivement par les sciences subalternées et subalternantes. 1. 7-8).

19. Ibid., II 2, (90a6), trad. J. TRICOT, op. cit., p. 164 ; transl. Iacobi (AL IV.1-4, p. 70,

20. Voir Ibid., II 14 (98a1-20), transl. Iacobi (AL IV.1-4, p. 98-99). 1. 4-5).

21. Ibid., II 18, (99b13), trad. J. TRICOT, op. cit., p. 240 ; transl. Iacobi (AL IV.1-4, p. 104, 
cette même idée en insistant non seulement sur le fait que l'effet créé n'est pas en mesure de recevoir «totam uirtutem [creatoris]», mais aussi sur une «proportio ut causati ad causam, et cognoscentis ad cognoscibile », qui permet une vraie connaissance de l'existence de la cause elle-même, aussi bien que de quelques-unes de ses qualités ${ }^{22}$.

Ainsi, même la connaissance par la causalité reste imparfaite quand il s'agit de connaître la cause première. Connaître les effets de celle-ci ne permet pas de jeter un pont sur l'abîme. Bien que cet enseignement, de soi, relève de la seule spéculation philosophique, il ne fait pas de doute qu'il n'ait été suscité par la réflexion sur la doctrine théologique de la création. Ce serait sortir des limites de notre étude que de vouloir l'approfondit en relation avec la métaphysique d'Aristote ${ }^{23}$. Il faut cependant relever une autorité, attribuée au Moyen Âge à Aristote, très utile pour comprendre l'interprétation du Philosophe par Thomas. Ce passage, absent du texte grec du De celo, se lit en revanche dans la traduction de Gérard de Crémone : « Nous nous sommes employés à magnifier le Dieu glorieux et créateur de toutes choses, dont la grandeur surpasse les propriétés des créatures ${ }^{24}$. Cette phrase est citée par Albert le Grand, qui, dans son commentaire des Sentences, attribue à Aristote d'avoir lui aussi reconnu que Dieu «surpasse les créatures». Albert continue cependant en disant que par la seule raison le Philosophe n'a pas pu saisir la «raison de l'éminence, la différence et la propriété de l'être divin ». Il est ainsi nié que la seule raison naturelle de l'homme puisse atteindre le propter quid de l'« éminence » de Dieu, aussi bien que les éléments qui fondent sa différence avec la créature ou les «propriétés» de son être. Albert s'empresse toutefois de dire qu'à

22. In Boet. De Trin., q. 1, a. 2, resp. et ad 3, ad 4 (éd. Leon., t. 50, p. 84-85; voir, cidessous, la note 141).

23. Dans certains ouvrages d'Aristote, il est question de la disproportion entre fini et infini, mais dans un autre contexte et avec des solutions qui ne conviennent pas à notre propos: Aristoteles, De celo, I, 274a7-8, transl. Gerardi (éd. Ilona Opelt, in : Alberti Magni, De caelo et mundo, éd. Col., t. 5-1, 1971, p. 39, 1. 62-63) : « non est inter gravitatem finitam et gravitatem infinitam relatio neque proportio» et Ibid., 275a13-14, transl. Gerardi (op. cit., p. 46, 1.69-70) : «non est inter corpus finitum et corpus infinitum proportio neque propinquitas neque comparatio » ; voir aussi: ID., Physica, VIII, 1, 252a13, transl. Iacobi (AL VII.1.2, p. 282, 1. 13-14, avec l'apparat) : «Infinitum autem ad $<$ in>finitum nullam rationem habet ». Dans cette ligne se trouve aussi l'affirmation suivante : «infiniti uero atque finiti nulla umquam poterit esse collatio » BOETHIUS, Philosophiae consolatio, II, 7, 17 (éd. Claudio MORESCHINI, p. 52, 1. 57-58; CCSL 94², p. 33, 1. 52-53). Voir Louis-Bertrand GEIGER, « Dissimilitude, transcendance et perfection du principe divin, apories et solutions », dans Dialogues I (1962-1963), p. 17-35, repris dans Louis-Bertrand GEIGER, Penser avec Thomas d'Aquin. Études thomistes de Louis-Bertrand Geiger OP, présentées par Ruedi IMBACH, Paris - Fribourg $(\mathrm{CH})$, Éd. du Cerf - Éditions Universitaires (coll. « Vestigia » 26), 2000, p. 213-232.

24. «Adhibuimus nosipsos magnificare Deum gloriosum creatorem omnium, eminentem proprietatibus eorum quae sunt creata » ARISTOTELES, De celo, I, 268a14-15, transl. Gerardi (éd. I. OPELT, 1971, p. 6, u. 87). 
propos de l'existence de Dieu, quia est, et du fait qu'il est un seul, peu de philosophes dignes de ce nom se sont trompés ${ }^{25}$.

Thomas, ensuite, ne fera donc que reprendre ces mêmes thèmes, pour conclure, par exemple dans l'a.1 du prologue du commentaire des Sentences, par cette affirmation: «Puisque donc la philosophie ne procède que par des raisons tirées des créatures, elle ne suffit pas à faire connaître ce qu'est Dieu $»^{26}$.

On pourrait alors se demander comment il est possible que Thomas affirme que la contemplation de Dieu est la fin de la vie humaine et de toute connaissance philosophique ${ }^{27}$, et qu'en même temps il dise que la connaissance philosophique, puisqu'elle procède «ex creaturis », n'est pas en mesure de donner une connaissance de Dieu «suffisante », c'està-dire correspondant aux exigences mêmes de la nature humaine.

Thomas résout cette incohérence en affirmant qu'une autre doctrina est nécessaire, nécessaire non en vue de quelque perfectionnement accessoire, mais pour permettre à l'homme d'atteindre sa fin même. Cette exigence, pour Thomas, est inscrite dans la nature humaine ellemême, parce que «la fin correspond au principe » et «pour chaque chose il est désirable de se réunir à son principe, en quoi consiste sa perfection $\gg^{28}$. Mais ces affirmations sont lourdes de conséquences et nous allons y revenir.

25. «Unde patet quod cognovit quod eminet super creata; sed rationem eminentiae, et differentiam, et proprietatem sui esse non potest per rationem aliquis investigare. Unde etiam circa talia attributa inveniuntur Philosophi multos errores dixisse : circa esse vero Deum, sive quia est, et quod unus est, pauci Philosophi qui vere erant Philosophi, erraverunt » Albertus Magnus, In I Sent., d. 3, A, a. 1 (éd. Augustus Borgnet, t. 25, p. 92). Albert nous semble dépendre surtout des développements qu'Augustin, dans les livres VIII et IX du De civitate Dei, consacre aux opinions des philosophes anciens. Quelques-uns de ces philosophes «potuerunt aciem mentis ultra omnem creaturam transmittere et lucem incommutabilis ueritatis quantulacumque ex parte contingere, quod christianos multos ex fide interim sola uiuentes nondum potuisse derident » Augustinus, De Trinitate, IV, XV, 20 (CCSL 50, p. 186, 1. 12-15; les italiques sont dans l'édition).

26. «Cum igitur philosophia non procedat nisi per rationes sumptas ex creaturis, insufficiens est ad Dei cognitionem faciendam» In I Sent., prol., a. 1, contra 2 (éd. A. Oliva, p. 312, 1. 27-29).

27. Cette doctrine est constante chez Thomas : voir $I I^{a}-I I^{a e}$, q. 180 , a. 4 , ad 3 et ad 4 (éd. Leon., t. 10, p. 428 cités aux notes 15 et 14); et aussi le commentaire du Psaume $32,11:$ : [...] Omnes autem desiderant tendere ad beatitudinem [...]. De beatitudine diversi diversa senserunt. Et secundum diversas opiniones de hac sunt diversae sectae philosophorum » In Ps., 32, 11 (éd. Vivès, t. 18, p. 413, cité à la note 10).

28. « Finis respondet principio » voir $I I^{a}-I I^{a e}$, q. 180, a. 7, ad 1 (éd. Leon., t. 10, p. 433) et «Unicuique rei desiderabile est, ut suo principio coniungatur; in hoc enim uniuscuiusque perfectio consistit » In Metaph., I, lect. 1 (éd. Marietti, 1950, p. 6, n. 4). 


\section{L'ACTE DE CONTEMPLATION SELON THOMAS : « UNE AFFAIRE DE VIE »}

III.1 La contemplation : acte de l'intelligence, choisi au préalable par la volonté

Afin de déterminer en quoi consiste la contemplation des philosophes selon Thomas d'Aquin, commençons par analyser en quoi consiste, selon lui, l'acte de contemplation. Dans celui-ci, il faut considérer trois choses : la faculté de l'homme qui le pose; l'objet de cet acte; et, enfin, sa modalité. Au long de la carrière professorale de Thomas, on peut repérer plusieurs textes, dans lesquels il apparaît clairement que la définition de la contemplation qu'il considère est toujours celle donnée par Aristote au livre X de l'Éthique à Nicomaque :

Mais, si le bonheur est une activité selon la vertu, ce doit être normalement selon la plus haute ; or, la vertu la plus haute doit être celle de ce qu'il y a de meilleur. Donc, que ce qu'il y a de meilleur, ce soit l'intellect ou que ce soit quelque autre chose, - celle évidemment qui, de l'aveu de tous, par nature commande et dirige et a pour rôle de penser ce qui est beau et divin, qu'elle soit quelque chose de divin elle-même, ou qu'elle soit, de tout ce qui est en nous, ce qu'il y a de plus divin, l'activité de ce qu'il y a de meilleur suivant sa vertu propre doit être le bonheur parfait ${ }^{29}$.

Cette définition correspond à la conception de la contemplation aussi bien selon les saints que selon les philosophes, comme Thomas l'affirme dès le début de son enseignement sur les Sentences ${ }^{30}$. Elle s'applique aussi bien à la contemplation imparfaite qu'à la contemplation parfaite :

Réponse. On doit dire que : la béatitude ou félicité consiste en l'opération la plus parfaite de celui qui est doté de raison et d'intellect. L'opération la plus parfaite de l'intellect consiste dans la contemplation du suprême intelligible, qui est Dieu. Ainsi, tant pour Dieu que pour l'ange et pour

29. ARISTOTE, L'Éthique à Nicomaque, introduction, traduction et commentaire par René Antoine GAUTHIER et Jean Yves JoLIF, $2^{\mathrm{e}}$ édition avec une introduction nouvelle, t. I, deuxième partie, Traduction, Louvain - Paris, Publications Universitaires - BéatriceNauwelaerts (coll. «Aristote. Traductions et études »), 1970, p. 303. Voir ARISTOTELES, Ethic. Nic., X, 1177a12-16, transl. R. Grosseteste, rec. pura : «Si autem est felicitas secundum virtutem operacio, racionabile secundum optimam. Hec autem utique erit, optimi. Sive utique intellectus hoc sive aliud quid, quod utique secundum naturam videtur principari et dominari et intelligentiam habere de bonis et divinis, sive divinum et ipsum sive eorum que in nobis divinissimum, huius operacio secundum propriam virtutem erit utique perfecta felicitas » (AL XXV.1-3, p. 358, 1. 25 - p. 359, 1. 2).

30. Voir In III Sent., d. 35, q. 1, a. 2, qla 3, set c. 2 (éd. M. F. Moos, p. 1177, n. 30); Ibid., d. 35, q. 1, a. 2, sol. 3 (p. 1179, n. 44, cité à la note 110). 
l'homme, la félicité et la béatitude ultime est la contemplation de Dieu, non seulement de l'avis des saints mais aussi selon les philosophes ${ }^{31}$.

\section{Et encore :}

Le plaisir de la contemplation n'est pas causé par l'exclusion d'une peine, mais parce que la contemplation est délectable en elle-même : elle ne consiste pas en une génération, mais elle est une opération parfaite ${ }^{32}$.

L'homme agit en tant qu'homme selon deux facultés intellectuelles, qui sont l'intellect et la volonté. C'est selon les actes de ces deux facultés que la définition de la béatitude attribuée par Thomas au Philosophe correspond à celle que le théologien élabore ${ }^{33}$. À la volonté, Thomas attribue deux actes concomitants à l'acte essentiellement intellectuel de la contemplation :

On doit dire que certaines choses sont exigées comme dispositions préalables à la félicité : il en est ainsi des actes des vertus morales, par lesquels les empêchements à la félicité sont écartés, à savoir le trouble de l'âme causé par les passions et les perturbations venant de l'extérieur. Mais il est un acte vertueux qui, quand il est accompli, est essentiellement la félicité elle-même : l'acte de la raison ou de l'intellect. En effet la félicité contemplative n'est rien d'autre que la contemplation parfaite de la vérité suprême, alors que la félicité active est l'acte de la prudence, par lequel l'homme se gouverne lui-même et les autres. Ce qui dans la félicité la conduit à son achèvement est le plaisir qui perfectionne la félicité comme la beauté perfectionne la jeunesse, ainsi qu'il est dit au dixième livre de l'Éthique. Et cela relève de la volonté. C'est la charité

31. « Responsio. Dicendum, quod beatitudo siue felicitas est in perfectissima operatione habentis rationem et intellectum, intellectus autem perfectissima operatio est in contemplatione altissimi intelligibilis, quod Deus est. Vnde tam Dei quam angeli quam etiam hominis ultima felicitas et beatitudo est Dei contemplatio, non solum secundum sanctos set etiam secundum philosophos » In II Sent., d. 4, a. 1 (texte provisoire de la Commission Léonine, préparé par Pierre-Marie GILS et Adriano Oliva; voir éd. P. MANDONNET, p. 133). Dans la définition des béatitudes évangéliques Thomas reprend implicitement la définition d'Aristote: «[Beatitudines] sunt operationes virtutum perfectarum ex adiunctione donorum, sive potius operationes ipsorum donorum. Et hoc consonat dictis Sanctorum [...]. Consonat etiam ipsi Evangelio [...]. Consonare etiam videtur ad hoc Magister [...]. Consonat etiam Philosophorum dictis, qui felicitatem dicunt etiam esse operationem secundum perfectam virtutem » In III Sent., d. 34, q. 1, a. 4, resp. (éd. M. F. Moos, p. 1126, n. 105-109).

32. «Delectatio enim contemplationis non causatur ex hoc quod excluditur aliqua molestia, sed ex hoc quod est secundum seipsam delectabilis, non est enim generatio, sed operatio quaedam perfecta » $I^{a}-I^{a e}$, q. 35, a. 5, resp. (éd. Leon., t. 6, p. 244a).

33. Voir Ruedi IMBACH, «Vie active et vie contemplative dans la perspective de Thomas d'Aquin », dans Ruedi IMBACH, Alain de Libera, Michel Hulin, Jules VullLemin, Gilbert Boss, Gerhard SeEL, Fernand BRunNer, Le Dépassement de soi dans la pensée philosophique, Actes du colloque des 19 et 20 octobre 1990 pour les soixante-dix ans de Fernand Brunner, [...] avec une bibliographie de Fernand Brunner, Neuchâtel, Éditions de la Baconnière (coll. « Langages »), 1994, p. 11-25, spéc. p. 16. 
qui perfectionne la volonté à cet égard, s’il est question de la félicité céleste, promise aux saints. Mais s'il est question de la félicité contemplative dont ont traité les philosophes, alors la volonté est ordonnée à une délectation de ce genre par le désir naturel ${ }^{34}$.

Il est important d'observer que Thomas n'a rien à reprocher au Philosophe quant aux contenus essentiels de sa conception de la contemplation ; tout au contraire, Thomas considère qu'elle convient parfaitement à la définition qu'on peut donner de la contemplation et donc de la béatitude selon les Évangiles. Il ne s'agit cependant pas de la même béatitude, ou felicitas, et pour voir les différences principales il convient de considérer la vita contemplativa.

Quand on parle de pratiquer la contemplatio, quand la contemplatio accipit rationem uite, pour les philosophes aussi bien que pour les saints, alors « la vie contemplative tient en un acte de la faculté connaissante, choisi au préalable par la volonté ${ }^{35}$. La volonté, comme on vient de le lire, dans le cas des saints est informée par la charité ; dans le cas des philosophes, elle est ordonnée par le désir naturel. Or, si dans la Questio disp. de uirtutibus (citée à la note 34), quand il étudie le rôle de la volonté dans l'acte de contemplation, Thomas s'exprime dans un langage très clair, dans le Super III Sent., dist. 35, q. 1, a.2, sol. 1, «Quod vita contemplativa consistat tantum in actu cognitivae », on trouve un exposé un peu succinct, qui ne doit cependant pas nous tromper. Thomas écrit, à propos de la contemplation des saints :

34. «Dicendum quod ad felicitatem quedam preexiguntur sicut dispositiones, sicuti actus uirtutum moralium, per quos remouentur impedimenta felicitatis, scilicet inquietudo mentis a passionibus et ab exterioribus perturbationibus. - Aliquis autem actus est uirtutis, qui est essentialiter ipsa felicitas quando est completus, scilicet actus rationis uel intellectus. Nam felicitas contemplatiua nichil est aliud quam perfecta contemplatio summe ueritatis ; felicitas autem actiua est actus prudentie, quo homo et se et alios gubernat. - Aliquid autem est in felicitate sicut perfectiuum felicitatis, scilicet delectatio, que perficit felicitatem sicut decor iuuentutem, ut dicitur in X Ethicorum. Et hoc pertinet ad uoluntatem. Et in ordine ad hoc perficit uoluntatem caritas, si loquamur de felicitate celesti, que sanctis repromittitur. Si autem loquamur de felicitate contemplatiua de qua philosophi tractauerunt, ad huiusmodi delectationem uoluntas naturali desiderio ordinatur » Q. disp. de uirtutibus, a. 5, ad 8 (d'après le texte provisoire de la Commission Léonine, établi par Émile DERONNE ; les italiques sont de nous ; voir éd. Marietti, 1965, p. 721); pour la référence à Aristote: ARISTOTELES, Ethic. Nic., Lib. X, 1174b31-34, transl. R. Grossateste, rec. recognita (AL XXVI, fasc. 4, p. 570, 1. 27-28).

35. In III Sent., d. 35, q. 1, a. 2, sol. 1 (éd. M. F. Moos, p. 1177, n. 31, cité à la note suivante). À la première objection, qui dit : « [...] contemplationis finis est ueritas. Sed ueritas tantum ad cognitionem pertinet. Ergo uita contemplativa tantum in operatione cognitive consistit», Thomas répond: «Ad primum igitur dicendum, quod finis contemplationis, in quantum contemplatio, est ueritas tantum, set secundum quod contemplatio accipit rationem uite, sic induit rationem affectati et boni, ut dictum est » Ibid., arg. 1 et ad 1 (texte provisoire de la Commission Léonine, préparé par Frederick HiNNEBUSCH ; voir éd. M. F. MoOs, p. 1174, n. 22 et p. 1178, n. 34 ; les italiques sont de nous). 
Une opération se trouve, pour ainsi dire, à mi-chemin entre le sujet qui l'accomplit et son objet : elle perfectionne le sujet et elle est perfectionnée par l'objet qui la spécifie. Ainsi l'opération de la faculté cognitive peut être modifiée des deux côtés. D'une part, en tant qu'elle est la perfection du connaissant: et une telle modification provient de l'amour de soi, comme c'était le cas dans la vie contemplative des philosophes. L'opération est modifiée d'une autre manière en tant qu'elle a pour terme l'objet : et ainsi le désir de la contemplation provient de l'amour de l'objet, car, là où se trouve l'amour, là est le regard ; et Matthieu VI [21] : « Où est ton trésor, là aussi est ton cœur »; et tel est le désir dans la vie contemplative des saints, dont nous parlons. Cependant la contemplation consiste essentiellement dans l'acte de la faculté cognitive, la charité étant requise au préalable, pour la raison que nous venons de dire ${ }^{36}$.

En affirmant qu'à l'origine de l'acte de contemplation des saints il y a l'amour de charité, Thomas n'entend certes pas nier que ce même acte ne comporte de soi la perfection de son sujet, qui s'unit à Dieu (ou à l'objet aimé) dans la charité. Il veut ici mettre en évidence ce qui est le propre de l'action de la volonté dans l'acte de contemplation des saints : l'amour gratuit, infus, et qui n'évacue pas l'amour de soi. Pareillement, en précisant le rôle préalable de la volonté dans l'acte de contemplation des philosophes, et en disant que ceux-ci sont mus d'un amor sui, Thomas ne veut certes pas nier leur capacité d'aimer l'objet de cet acte même de contemplation! Il l'avait dit explicitement au début de cette solutio 1 : «La volonté, puisqu'elle est le moteur de toutes les puissances de l'âme,

36. «Responsio. Dicendum ad primam questionem, quod uita, secundum quod nunc loquimur, consistit in operatione cui aliquis principaliter mancipatur, cuius ratione omnia que impedire possunt dimittit, que autem adiuuant querit et prosequitur. Hoc autem non potest esse nisi per uoluntatem, cuius est inter opera humana unum pre aliis acceptare, quicquid sit illud. Voluntas autem, cum sit motor omnium potentiarum anime, oportet quod ad obiecta et actus omnium potentiarum se habeat, prout habent rationem boni, quia unusquisque actus debitus, cuiuscumque potentie, est bonum eius. Et ideo uita contemplatiua consistit in actu cognitiue uirtutis, preacceptate per affectiuam. Set cum operatio sit quodammodo media inter operantem et obiectum, uelud perfectio ipsius operantis et perfecta per obiectum a quo speciem recipit, ex duplici parte potest operatio cognitiue affectari. Vno modo in quantum est perfectio cognoscentis, et talis affectatio operationis cognitiue procedit ex amore sui. Et sic erat affectio in uita contemplatiua philosophorum. Alio modo in quantum terminatur ad obiectum, et sic contemplationis desiderium procedit ex amore obiecti, quia ubi amor, ibi oculus, et Mat. VI, "Vbi est thesaurus tuus, ibi est et cor tuum". Et sic habet affectionem uita contemplatiua sanctorum, de qua loquimur. Set tamen contemplatio essentialiter in actu cognitiue consistit, praeexigens caritatem ratione predicta » In III Sent., d. 35, q. 1, a. 2, sol. 1 (texte provisoire de la Commission Léonine, préparé par F. HinNEBUSCH ; voir éd. M. F. Moos, p. 1177, n. 31-33; les italiques sont de nous). La question 1 de cette distinction 35 a fait l'objet d'une très belle étude récente : Massimiliano D'ALESSANDRO, Vita contemplativa $e$ attiva in Tommaso d'Aquino. Saggio di lessicografia su 3SN 35.1 del Commento alle Sentenze, Roma, Aracne (coll. «Aii» 314), 2008 ; l'A., p. 133, dit qu'il ne veut pas analyser la différence entre la contemplation des saints et celle des philosophes et se concentre sur les éléments essentiels de l'acte de contemplation selon Thomas d'Aquin. 
doit se rapporter aux objets et aux actes de toutes ses puissances » (voir la note 36).

En effet, si cela n'était pas le cas, le début de ce raisonnement («Une opération se trouve, pour ainsi dire, à mi-chemin entre le sujet qui l'accomplit et son objet: elle perfectionne le sujet et elle est perfectionnée par l'objet qui la spécifie»), qui commande tout le développement qui suit, serait vain.

Rappelons un texte de la Somme, où Thomas dit comment les fidèles, dans leur amour surnaturel pour Dieu, s'aiment aussi eux-mêmes d'amour de charité. Il distingue d'abord une manière de s'aimer soimême qui est plus forte que l'amitié : cet amour est la forme et la racine de l'amitié. Deuxièmement, selon que l'amour de charité est une amitié entre l'homme et Dieu, on s'aime aussi soi-même dans cette relation à $D_{i e u}{ }^{37}$. L'amour de charité n'exclut donc pas l'amour naturel de soi. Thomas, nous venons de le voir, dit que, dans la contemplation, l'opération de la faculté cognitive peut être modifiée en tant que perfection du sujet connaissant : « une telle modification provient de l'amour de soi» (voir la note 36): l'emploi de l'indicatif présent «provient » (« prouenit ») indique que cela est toujours valable. Thomas ajoute: «comme c'était le cas dans la vie contemplative des philosophes » et ici l'imparfait renvoie aux philosophes du passé qui ne vivaient pas sous le régime de la foi chrétienne. Thomas ne veut pas dire que seule la contemplation des philosophes provient de l'amour de soi, mais que la contemplation de purs philosophes ne provient que de l'amour de soi ${ }^{38}$.

37. «Cum caritas sit amicitia quaedam, sicut dictum est, dupliciter possumus de caritate loqui. Uno modo, sub communi ratione amicitiae. Et secundum hoc dicendum est quod amicitia proprie non habetur ad seipsum, sed aliquid maius amicitia : quia amicitia unionem quandam importat, dicit enim Dionysius quod amor est virtus unitiva; unicuique autem ad seipsum est unitas, quae est potior unione. Unde sicut unitas est principium unionis, ita amor quo quis diligit seipsum, est forma et radix amicitiae : in hoc enim amicitiam habemus ad alios, quod ad eos nos habemus sicut ad nosipsos; dicitur enim in IX Ethic. quod amicabilia quae sunt ad alterum veniunt ex his quae sunt ad seipsum. Sicut etiam de principiis non habetur scientia, sed aliquid maius, scilicet intellectus. Alio modo possumus loqui de caritate secundum propriam rationem ipsius, prout scilicet est amicitia hominis ad Deum principaliter, et ex consequenti ad ea quae sunt Dei. Inter quae etiam est ipse homo qui caritatem habet. Et sic inter cetera quae ex caritate diligit quasi ad Deum pertinentia, etiam seipsum ex caritate diligit »II ${ }^{a}-I I^{a e}$, q. 25, a. 4, resp. (éd. Leon., t. 8, p. 200 ; les soulignements sont de nous). Voir aussi : Q. disp. de caritate, a. 7, resp. : «Diligendus est ex caritate Deus ut radix beatitudinis ; quilibet autem homo debet se ipsum ex caritate diligere ut participat beatitudinem; proximum autem ut socium in participatione beatitudinis; corpus autem proprium secundum id quod ad ipsum redundat beatitudo » (d'après le texte provisoire de la Commission Léonine établi par É. DERONNE ; voir éd. Marietti, 1965, p. 771).

38. À propos de l'amor sui chez Thomas d'Aquin, on peut voir : Louis-Bertrand GeIger, Le problème de l'amour chez saint Thomas d'Aquin, Montréal - Paris, Institut d'Études Médiévales - Vrin (coll. «Conférences Albert le Grand » 1952), 1952 ; 
En vérité, dans cette solutio 1 des Sentences que nous examinons, Thomas prend encore une fois ensemble la contemplation naturelle ou des philosophes et la contemplation des saints, non pour les opposer, mais pour montrer, grâce à l'exemple de la contemplation des philosophes, la complétude de l'acte de contemplation. Il parle de l'amor sui pour indiquer le perfectionnement du sujet («perfectio ipsius operantis », «perfectio cognoscentis ») et il prend l'exemple de la contemplation des saints pour indiquer la perfection de l'acte de contemplation de la part de l'objet qui l'informe («perfecta per obiectum »). Les deux types de contemplation ne sont pas ici comparés, mais pris ensemble, pour montrer toute la richesse de l'acte de contemplation, tant pour ses composantes naturelles (dont l'amor sui), que pour ses composantes surnaturelles (dont la charité).

Rappelons à nouveau trois textes, datés du second enseignement parisien de Thomas, qui montrent premièrement la nécessité de l'amour et de la délectation dans l'acte même de contemplation : « Le plaisir de la contemplation n'est pas causé par l'exclusion d'une peine, mais parce que la contemplation est délectable en elle-même : elle ne consiste pas en une génération, mais elle est une opération parfaite $\gg^{39}$. À deux reprises, Thomas invoque à ce propos l'autorité d'Aristote, dans l'In Matthaeum: « [...] selon le Philosophe, deux choses sont requises pour que les actes de contemplation rendent bienheureux: l'une relève de la substance même de l'acte, à savoir que l'acte porte sur le suprême intelligible, c'està-dire Dieu. L'autre touche à sa forme, à savoir l'amour et le plaisir : la délectation en effet perfectionne la félicité comme la beauté la jeunesse $\gg^{40}$; et dans le De uirtutibus, a. 5 , ad 8 , où il met en parallèle les saints, dont la delectatio est procurée par la charité qui informe la

Roger DE WeISS, Amor sui. Sens et fonctions de l'amour de soi dans l'ontologie de Thomas d'Aquin, Genève, Éd. du Belvédère, 1977; Ruedi IмBACH, Iñigo ATUCHA, Amours plurielles. Doctrines médiévales du rapport amoureux de Bernard de Clairvaux à Boccace, présentation et commentaires par R. IMBACH et I. ATUCHA, bilingue latin/italien-français, Paris, Éd. du Seuil, 2006; Thomas M. OsBORNE, Jr., Love of Self and Love of God in Thirteenth-Century Ethics, Notre Dame (IN), University of Notre Dame Press, 2005 : cette étude, ample et bien documentée, ne rend cependant pas toujours correctement la doctrine de Thomas d'Aquin, notamment lorsqu'elle oppose une fin naturelle et une fin surnaturelle de l'homme et lorsqu'elle affirme une différence entre les textes du commentaire des Sentences et ceux des ouvrages postérieurs sur l'amour de Dieu plus que soi-même (p. 73 et 85 ; voir nos paragraphes III.2 et V.2).

39. $I^{a}-I I^{a e}$, q. 35, a. 5, resp. (éd. Leon., t. 6, p. 244, cité à la note 32).

40. «[...] secundum Philosophum, ad hoc quod actus contemplativi faciant beatum, duo requiruntur : unum substantialiter, scilicet quod sit actus altissimi intelligibilis, quod est Deus ; aliud formaliter, scilicet amor et delectatio : delectatio enim perficit felicitatem, sicut pulchritudo iuventutem » In Matth., 5, lect. 2 (éd. Marietti, 1951, n. 408). 
volonté, et les philosophes, dont la volonté est ordonnée à la delectatio par le désir naturel ${ }^{41}$.

\section{III.2. L'amour de Dieu dans la contemplation des philosophes : une vraie amitié}

En analysant la solutio 1, on pourrait objecter que Thomas n'envisage pas que les philosophes, dans l'acte le plus haut de leur contemplation, puissent aimer Dieu. On ne niera cependant pas que la delectatio se réfère non seulement à la faculté dont elle est issue, mais aussi à l'objet de l'acte de contemplation, qui, même pour les philosophes, selon Thomas, peut être Dieu: non seulement en tant qu'objet ultime de la contemplation finale (voir In I Sent., prol., a.1, cité à la note 7), mais aussi, de quelque manière, en tant qu'objet de la contemplation philosophique en cette vie, comme l'affirme le commentaire sur Matthieu $^{42}$.

Il faut revenir à la distinction 29 , a.3, de ce même commentaire au III Livre, pour être certain que Thomas, dès le commentaire des Sentences, refuse d'enfermer en elle-même la contemplation des philosophes, sous prétexte qu'elle procèderait de l'amor sui, de telle sorte que le philosophe ne pourrait aimer que soi-même. Au contraire, «c'est par sa nature même que l'homme aime Dieu plus que soi-même d'un amour d'amitié $\gg^{43}$.

Dans le Super III Sent., d. 29, a.3, qui répond à la question de savoir si l'on doit aimer Dieu plus que toute autre chose par amour de charité, Thomas commence par distinguer l'amor concupiscentiae, selon lequel nous aimons quelque chose pour quelque chose d'autre, de l'amor benevolentiae, qui consiste à aimer une chose pour elle-même, et qui, selon le Philosophe, est le principe de l'amitié. Ensuite, il affirme que « etiam naturali amore pars plus tendit ad conservationem sui totius quam sui ipsius », en dépassant, en un certain sens l'amor sui. Enfin, après avoir dit que par nature, en vertu de l'amour d'amitié, l'homme aime Dieu plus que soi-même, Thomas se fonde sur cet argument de la raison naturelle pour dire : «Et puisque la charité perfectionne la nature,

41. Cité à la note 34. Pour une comparaison entre la doctrine de la volonté chez Aristote et chez les auteurs du XIII ${ }^{\mathrm{e}}$ siècle : R. A. GAUTHIER, J. Y. JOLIF, dans ARISTOTE, L'Éthique à Nicomaque, op. cit., t. II, Commentaire, première partie, livres I-V, p. 192-194 et p. 210 ; Ibid., t. I, première partie, Introduction par R. A. GAUTHIER, op. cit., p. 255-266.

42. Voir ci-dessus, note 40 . Voir aussi $I I^{a}-I I^{a e}$, q. 180, a. 4, resp., ad 3 et ad 4 (cités aux notes 11,14 et 15); $I^{a}-I^{a e}$, q. 4, a. 2, resp. (éd. Leon., t. 6, p. 38).

43. «Amore amicitiae naturaliter Deus ab homine plus quam seipso diligitur » In III Sent., d. 29, a. 3, resp. (éd. M. F. Moos, p. 929, n. 39), avec notre explication ci-dessous. Voir aussi I Pars, q. 60, a. 5, resp. (éd. Leon., t. 5, p. 104). Voir Jorge LAPORTA, « Pour trouver le sens exact des termes appetitus naturalis, desiderium naturale, amor naturalis, etc. chez Thomas d'Aquin », AHDLMA 40 (1973), p. 37-95. 
c'est aussi selon la charité que l'homme aime Dieu plus que soimême » ${ }^{44}$. Il évoque ensuite une seconde opinion, selon laquelle «c'est en vertu de sa nature que l'on aime d'un amour de convoitise Dieu plus que soi-même, dans la mesure où le bien divin est plus délectable; mais c'est d'un amour d'amitié que l'on s'aime soi-même plus que Dieu, quand on veut davantage exister, vivre, posséder tel ou tel bien qu'on ne le veut pour Dieu. Cependant, la charité élève la nature, et ainsi on aime d'amitié Dieu plus que soi-même». Mais Thomas ne manque pas de prendre position: «mais c'est la première opinion qui est la plus probable $\gg^{45}$.

$\mathrm{Si}$, dans le corpus de cet article, une seule autorité est citée, tirée de l'Éthique à Nicomaque, il est important d'observer que deux objections sur cinq se fondent sur cette même Éthique. Il s'agit de deux citations d'Aristote qui concernent notre propos. La deuxième objection commence ainsi : «Le Philosophe dit au huitième livre de l'Éthique que l'on aime tout ce qui est bon pour soi»; et la troisième : «Au neuvième livre de l'Éthique, le Philosophe dit que les sentiments d'amitié qu'on éprouve envers son prochain procèdent des sentiments qu'on éprouve envers soi-même». Dans les deux réponses ${ }^{46}$ Thomas montre que ces deux affirmations ne sont pas en contradiction avec la réponse pour laquelle il a opté dans le corpus de l'article.

Ce procédé de Thomas me semble revêtir une importance toute particulière. En effet, d'une part, dans le corpus de l'article il n'attribue pas directement à Aristote sa conception de l'amour naturel de Dieu et il semble plutôt développer lui-même sa propre doctrine sur le sujet; en même temps, dans les réponses aux objections, Thomas cherche à montrer que l'enseignement d'Aristote n'est pas en contradiction avec son propre enseignement.

44. «Et quia caritas naturam perficit, ideo etiam secundum caritatem Deum supra se ipsum homo diligit » Ibid. (éd. M. F. Moos, p. 929, n. 37-38).

45. «Aliquis naturaliter amore concupiscientiae Deum plus seipso diligit, inquantum divinum bonum est sibi delectabilius ; sed amore amicitiae plus seipsum naturaliter quam Deum diligit, dum plus se vult esse et vivere et habere aliqua bona quam Deum; sed caritas ad hoc naturam elevat ut etiam per amicitiam aliquis plus Deum diligat quam seipsum. Sed prima opinio probabilior est » In III Sent., d. 29, a. 3, resp. (éd. M. F. Moos, p. 929, n. 39-40). La position de Thomas est beaucoup plus radicale que celle d'Albert le Grand, de la Summa fr. Alexandri et de Bonaventure : AlberTus MAgnus, In III Sent., d. 29, A, a. 5, ad 1 et ad 2 (éd. A. Borgnet, t. 28, p. 551-552) ; Summa fratris Alexandri, II, inq. 2, tract. 3, sect. 2, q. 2, tit. 1, d. 2, m. 1, c. 1, a. 2, part. 2 et a. 3, probl. 1 (éd. Quaracchi, t. 2.1, p. 218, n. 166 et p. 222, n. 169); BonAVENTURA DE BALNEOREGIO, In III Sent., d. 29, a. un., q. 2, ad 1 et ad 2 (éd. Quaracchi, t. 3, p. 642). Bien que nous ne partagions pas toutes les interprétations de ce livre, on peut voir: T. M. OsBorne, Jr., Love of Self..., op. cit., p. 45-68.

46. In III Sent., d. 29, a. 3, ad 2 et ad 3 (éd. M. F. Moos, p. 930, n. 42-43; voir la note 66). 
Il faut ensuite considérer le commentaire de Thomas à l'Éthique d'Aristote. Nous nous bornons à rappeler deux passages qui illustrent bien la conception qu'a Thomas de la contemplation des philosophes. Quand au chapitre $11 \mathrm{du}$ livre $\mathrm{X}$ il explique la raison pour laquelle l'homme ne peut pas trouver la plus grande félicité dans la vie civile et politique, il dit: «puisque la fin ultime ne réside pas en ces choses, comme on l'a montré au premier livre, il est plus convenable qu'on se limite à vouloir, dans l'action politique, acquérir le bien-être pour soi et pour ses concitoyens $\gg^{47}$. En revanche, l'opération selon laquelle l'homme obtient la félicité la plus haute est une opération de l'intellect qui est spéculative et elle est « à soi-même sa propre fin, de sorte qu'elle ne vise aucune autre fin qu'elle-même; cette opération a son propre plaisir qui provient d'elle-même et qui la fait progresser $\gg^{48}$. Ensuite, en commentant le chapitre 13, Thomas dit qu'Aristote «montre comment le bienheureux se rapporte aux réalités supérieures, c'est-à-dire à Dieu »: Dieu est ici posé explicitement comme objet! Il continue en affirmant que le bienheureux ( «felix»), puisqu'il opère selon l'intellect en contemplant la vérité (et donc Dieu) et en s'appliquant à réaliser le bien de l'intellect, est dans sa meilleure disposition, car il est au maximum du meilleur bien que l'homme puisse atteindre et il est aussi amantissimus Deo. Il dit encore : «Il est raisonnable de tenir que Dieu montre sa bienveillance surtout à ceux qui aiment et honorent l'intellect, plaçant au-dessus de tout le bien de l'intellect, de même que les dieux ont souci de ceux qui sont leurs amis ${ }^{49}{ }^{4}$. L'existence d'une amitié du bienheureux

47. « [...] quia in his non est ultimus finis ut in I ostensum est, magis est decens quod per civilem conversationem aliquis velit acquirere felicitatem sibi ipsi et civibus 》In Ethic. Nic., X (1177b4), lect. 11 (éd. Leon., t. 47, 2, p. 587, 1. 40-43).

48. «Operatio intellectus que est speculativa videtur a praemissis operationibus differre secundum rationem studii, quia scilicet homo vacat huiusmodi operationi propter seipsam, ita quod nullum alium finem propter ipsam appetit; habet etiam huiusmodi operatio propriam delectationem ex ipsa procedentem quae auget eam » Ibid., lect. 11 (éd. Leon., t. 47, 2, p. 587, 1. 60-66).

49. «Deinde cum dicit : Secundum intellectum autem etc., ostendit quomodo felix se habeat ad superiora, scilicet ad Deum. Et dicit quod felix felicitate speculativa, quia operatur secundum intellectum contemplando veritatem et curam suam apponit ad bonum intellectus, videtur esse optime dispositus, in quantum excellit in eo quod est optimum hominis, et etiam amantissimus Deo. Supposito enim, sicut rei veritas habet, quod Deus habeat curam et providentiam de rebus humanis, rationabile est quod delectetur circa homines de eo quod est optimum in eis et quod est cognatissimum, id est simillimum, Deo, quod quidem est intellectus, ut ex praemissis patet; et per consequens rationabile est quod Deus maxime benefaciat his qui amant intellectum et honorant, ipsum bonum intellectus omnibus praeferentes, quasi ipsi dii curent de his qui sunt eis amici; rationabile etiam est quod beneficia conferant his qui recte et bene operantur. Manifestum est autem quod omnia praedicta conveniunt sapienti ; sapiens enim diligit et honorat intellectum, qui maxime amatur a Deo inter res humanas, sapiens etiam et recte et bene operatur. Relinquitur ergo quod ipse sit Deo amantissimus. Ille autem est felicissimus qui maxime amatur a Deo, qui est fons omnium bonorum. Relinquitur igitur 
(«felix ») avec Dieu et les dieux est affirmée non dans l'abstrait, mais dans l'exercice même de contemplation du philosophe, du sage, selon Thomas.

Deux questions cependant se posent. Les sages païens peuvent-ils vraiment être «amis » («amici ») de Dieu et des dieux sans le secours de la grâce? Dans cet amour d'amitié aiment-ils Dieu plus qu'euxmême? Les deux questions sont intimement liées et nous commençons par répondre à la seconde.

Le commentaire du livre $\mathrm{X}$ de l'Éthique à Nicomaque, que nous venons de présenter, laisse supposer que le sage païen aime Dieu plus que soi-même, car on y affirme que le sage, en se référant « aux réalités supérieures, c'est-à-dire à Dieu », « est au maximum du meilleur bien qu'il puisse atteindre [...], plaçant au-dessus de tout le bien de l'intellect » par lequel il s'unit d'amitié à Dieu et aux dieux. Cela suppose non seulement que l'homme aime Dieu pour lui-même, mais aussi qu'il reconnaisse que Dieu est le summum bonum, fons omnium bonorum et donc aimable plus que soi-même. Est-ce que l'homme, par ses seules forces naturelles peut aimer Dieu plus que soi-même? À ce propos Thomas a eu des positions qui peuvent sembler, à une première lecture, opposées, mais je crois qu'elles ne le sont pas, si on les interprète dans le mouvement de sa pensée sur ce sujet.

Thomas tient que, par nature, l'homme peut aimer Dieu plus que soimême, comme il le dit à la dist. 29, a.3, du Super III Sent. et à la q. 109, a.3, de la $I^{a}-I^{a e}$. Dans ces textes, Thomas prouve que l'homme est par nature capable d'aimer Dieu plus que soi-même afin de montrer que l'amour de charité, qui nous fait aimer Dieu plus que nous-mêmes, ne porte pas atteinte à l'amour naturel de l'homme pour Dieu, mais le perfectionne: sinon l'amour de charité détruirait l'amour naturel de l'homme ${ }^{50}$. Tant dans les Sentences que dans la Somme, Thomas considère cet amour pour Dieu plus que soi-même comme un caractère originaire de la nature de l'homme, que la charité vient perfectionner.

Dans la Somme, cependant, Thomas ajoute que «dans l'état de la nature corrompue, l'homme, par l'appétit de la volonté rationnelle, n'est plus capable (deficit) d'aimer Dieu plus que soi-même, car cet appétit, à cause de la corruption de la nature, suit son bien privé, à moins qu'il ne

quod, etiam secundum hoc quod felicitas hominis dicitur esse per hoc quod amatur a Deo, sapiens est maxime felix » Ibid., X (1179a22), lect. 13 (éd. Leon., t. 47, 2, p. 595, 1. 109-137; les italiques sont de nous).

50. « [...] sequitur quod naturali dilectione etiam angelus et homo plus et principalius diligat Deum quam seipsum. - Alioquin, si naturaliter plus seipsum diligeret quam Deum, sequeretur quod naturalis dilectio esset perversa; et quod non perficeretur per caritatem, sed destrueretur » I $I^{a}$ Pars, q. 60, a. 5, resp. (éd. Leon., t. 5, p. 104). 
soit rectifié par la grâce (nisi sanetur per gratiam Dei) ${ }^{51}$. Cette affirmation, prise telle quelle, pose plusieurs problèmes.

En effet, premièrement, Thomas enseigne que l'homme, par la chute originelle, n'a pas perdu la capacité d'aimer Dieu plus que soi même, car « cela est naturel pour toute nature créée » $\left(I^{a}-I I^{a e}\right.$, q. 109, a.3, ad 2 ; voir aussi : ibid., q. 85, a.2). En outre, la perte de la grâce originelle ne porte pas atteinte aux puissances naturelles en tant que telles et, en particulier, ne porte atteinte ni à l'intelligence, ni à la volonté : c'est l'exercice des puissances qui devient difficile pour l'homme ${ }^{52}$. Enfin, l'inclination de l'homme à la vertu n'est pas éliminée par le péché, quant à son enracinement dans la nature ${ }^{53}$.

Deuxièmement, dans le commentaire des Sentences nous lisons un texte où Thomas s'exprime différemment :

La charité, comme il apparaît de ce qui vient d'être dit, comporte une amitié, un amour et un désir. Or, le désir naturel ne peut porter que sur une chose qui peut être atteinte par nature. Par conséquent, le désir naturel du bien suprême est inscrit en nous par nature, car le bien suprême est participable par nous à travers les effets naturels. Pareillement l'amour est causé par la similitude. Partant, on aime le bien suprême par-dessus tout, car nous possédons une similitude avec lui par les biens naturels.

Mais puisque la nature ne peut pas parvenir aux opérations qui sont sa vie et sa béatitude, à savoir la vision de son essence [scil. de Dieu], par

51. «Homo in statu naturae integrae dilectionem sui ipsius referebat ad amorem Dei sicut ad finem, et similiter dilectionem omnium aliarum rerum. Et ita Deum diligebat plus quam seipsum, et super omnia. Sed in statu naturae corruptae homo ab hoc deficit secundum appetitum voluntatis rationalis, quae propter corruptionem naturae sequitur bonum privatum, nisi sanetur per gratiam Dei. Et dicendum est quod homo in statu naturae integrae non indigebat dono gratiae superadditae naturalibus bonis ad diligendum Deum naturaliter super omnia; licet indigeret auxilio Dei ad hoc eum moventis. Sed in statu naturae corruptae indiget homo etiam ad hoc auxilio gratiae naturam sanatis » $I^{a}-I I^{a e}$, q. 109, a. 3, resp. (éd. Leon., t. 7, p. 295).

52. «Bona naturalia prout in esse nature absolute considerantur remanent integra post peccatum, tamen peruertuntur quantum ad rectum ordinem quem habebant in gratiam uel uirtutem. Et hanc rectitudinem consequebatur super omnia Deum diligere » In II Sent., d. 3, q. 4, a. unic., ad 5 (texte provisoire de la Commission Léonine, préparé par P.-M. Gils et A. Oliva ; voir éd. P. MANDONNET, p. 128) ; « Nulla potentia naturalis tollitur per peccatum »I I Pars, q. 83, a. 2, arg. 3 (éd. Leon., t. 5, p. 309).

53. « Naturalis inclinatio ad virtutem ... ex parte radicis ... non diminuitur per peccatum : eo quod peccatum non diminuit ipsam naturam. Sed diminuitur inquantum scilicet ponitur impedimentum pertingendi ad terminum ... non tamen potest totaliter consumi, quia semper manet radix talis inclinationis $\gg I^{a}-I^{a}$, q. 85, a. 2, resp. (éd. Leon., t. 7, p. 111-112) ; «Rectitudo enim gratie non est sine rectitudine nature $Q$. disp. de malo, q. 4, a. 2, III, ad 1 (éd. Leon., t. 23, p. 113, 1. 502-503). Voir Bernard QuELQUEJEU, « Naturalia manent integra. Contribution à l'étude de la portée, méthodologique et doctrinale, de l'axiome théologique Gratia praesupponit naturam», Rev. Sc. ph. th. 49 (1965), p. 640-655. 
conséquent [la nature] ne peut pas atteindre l'amitié qui fait que les amis ont vie commune et activités communes. Il convient donc que la charité soit surajoutée, par laquelle nous pouvons avoir une amitié avec Dieu $[\ldots]^{54}$.

Dans ce passage, Thomas distingue entre le désir naturel, l'amour et l'amitié que nous pouvons avoir par rapport à Dieu et, alors qu'il affirme la nécessité de la grâce pour qu'il y ait amitié entre l'homme et Dieu, il enseigne que l'homme, de ses seules forces naturelles, « aime le bien suprême par-dessus tout, car nous possédons une similitude avec lui par les biens naturels ».

Troisièmement, dans le Quodlibet I nous lisons : «Quelqu'un, d'amour naturel, peut aimer Dieu par-dessus tout plus ou moins, mais quand il l'aime à son maximum, alors il atteint le plus haut degré de préparation à recevoir la grâce $\gg^{55}$. Thomas conçoit donc que tout homme, après la chute et sans la grâce sanctifiante, puisse aimer Dieu par-dessus tout de ses seules forces naturelles et cela selon certains degrés ordonnés (« magis et minus »), qui comportent un sommet.

Si l'on se bornait à une lecture superficielle de ces trois textes, on pourrait dire que, dans la $I^{a}-I I^{a e}$ (datée de 1271), Thomas a changé d'avis par rapport aux distinctions 27 et 29 (datées de l'hiver 1254 ou 1255) et au Quodlibet I (daté du Carême 1269). Nous ne le croyons pas : à notre avis,

54. « Ad quartum dicendum, quod caritas, ut ex predictis patet, amicitiam et amorem et desiderium includit. Desiderium autem naturale non potest esse nisi rei que naturaliter haberi potest. Vnde desiderium naturale summi boni inest nobis secundum naturam, in quantum summum bonum participabile est a nobis per effectus naturales. Similiter amor ex similitudine causatur. Vnde naturaliter diligitur summum bonum super omnia, in quantum habemus similitudinem ad ipsum per bona naturalia. Set quia natura non potest peruenire ad operationes eius, que sunt sua uita et sua beatitudo, scilicet uisio sue essentie, ideo etiam ad amicitiam non pertingit, que facit amicos conuiuere et in operibus communicare. Et ideo oportet superaddi caritatem, per quam amicitiam ad Deum habeamus [sic Pamplona, Cabildo 51, f. 132ra ; « habeamus ad Deum » autographe: Vat. lat. 9851, f. 71rb], et ipsum amemus, assimilati ei per participationem spiritualium donorum, et desideremus ut participabilem per gloriam ab amicis suis » In III Sent., d. 27, q. 2, a. 2, ad 4 (voir texte provisoire de la Commission Léonine, préparé par F. HinNEBUSCH ; éd. M. F. MoOs, p. 879, n. 129).

55. « Naturali dilectione qua Deus super omnia naturaliter diligitur potest aliquis magis et minus uti, et quando in summo fuerit, tunc est summa preparatio ad graciam habendam »Qdl. I, q. 4, a. 3 [8], ad 2 (éd. Leon., t. 25, 2, p. 189, 1. 91-95); voir aussi : «Vnde donum gratie nullo modo sub merito cadere potest eius qui in puris naturalibus est, et multo minus eius qui peccato deprimitur. Set tamen opera bona ante donum gratie facta premio suo sibi proportionato non carent : causant enim quandam habilitatem ad gratiam, et secum etiam quandam honestatem et iocunditatem et pulcritudinem habent, in quibus precipue eorum premium consistit. Et aliqua etiam per accidens causant, ut bonorum temporalium affluentiam aut aliquid huiusmodi, quia frequenter, ut Gregorius dicit, Deus in hoc mundo remunerat quod premium future glorie non meretur, ut sic nullum bonum irremuneratum inueniatur» In II Sent., d. 27, q. un., a. 4, resp. (texte provisoire de la Commission Léonine, préparé par P.-M. GILS et A. OlIVA; voir éd. P. MANDONNET, p. 704-705 ; les soulignements sont de nous). 
dans la $I^{a}-I I^{a e}$, Thomas apporte plutôt un complément aux textes antérieurs.

Pour bien comprendre ce passage de la $I^{a}-I I^{a e}$, il faut considérer que la corruption de l'appétit rationnel de la volonté concerne l'exercice de cet appétit et non la racine elle-même de cet appétit qui, comme on vient de le montrer, selon Thomas reste intègre après la chute. Ce passage de la $I^{a}-I I^{a e}$ n'exclut donc pas absolument que l'homme, même après la chute, puisse, bien que difficilement, user correctement de l'appétit naturel de la volonté et ce, d'autant plus que « l'inclination naturelle de l'homme à la vertu, quant à sa racine, n'est pas diminuée par le péché ». Nous croyons donc que Thomas, dans la q. 109, a.3, de la $I^{a}-I^{a e}$, entend préciser que normalement, ut in pluribus, «dans l'état de la nature corrompue, l'homme, par l'appétit de la volonté rationnelle, n'est plus capable (deficit) d'aimer Dieu plus que soi-même, car cet appétit, à cause de la corruption de la nature, suit son bien privé »: il s'agit d'un fait lié à l'exercice de la volonté et non à sa capacité radicale, qui n'est pas atteinte par la chute, comme Thomas le dit dans l'a.3, ad 1 et ad 2, de cette même q. 109. Absolument parlant, il faut donc garder à l'homme la capacité originelle d'aimer Dieu plus que soi-même de ses seules forces naturelles, sans le secours de la grâce : dès que, par son intellect, il reconnaît en Dieu le summum bonum, fons omnium bonorum, l'homme ne peut que l'aimer plus que soi-même, comme Thomas l'enseigna dans la dist. 27 du Super III Sent. et comme il le soutint publiquement dans le Quodlibet $I$, de quelques mois seulement antérieur à la $I^{a}-I^{a e}$ : si l'on comprend le texte de la q. 109 en un sens absolu, on met en cause l'intégrité, après la chute, de l'intellect et de la volonté quant à leur racine même, chose que Thomas exclut.

Si Thomas dans la $I^{a}-I I^{a e}$, q. 109, a.3 avait changé d'avis par rapport aux ouvrages précédents, toute sa doctrine sur le péché originel en aurait été subvertie, ce qui n'est pas le cas. Entre la q. 109 et le traité sur le péché originel ( $I^{a}-I I^{a e}$, q. 82-86), ainsi que la Q. disp. de malo (q. 16, a. 6, resp. ; a. 5, arg. 1, 16 et 18), peu de temps s'est écoulé. Par ailleurs, même dans ces derniers textes on trouve parfois des expressions, pour ainsi dire, générales, qui ne rendent pas compte des précisions de l'ensemble de l'enseignement de Thomas sur ce sujet (voir $I^{a}-I I^{a e}$, q. 83, a.4, resp. : «Et ideo cum omnes partes animae dicantur esse corruptae per peccatum originale...»). Ainsi, nous croyons que même dans la q. 109, quand Thomas parle de «corruptionem naturae» et de «naturae corruptae », il entend simplement désigner un état par rapport à un autre, celui de la nature intègre, et il n'entend pas nier l'intégrité, « ex parte radicis », de l'appétit de la volonté, mais seulement du côté de l'exercice. Par ailleurs, dans la $I I I^{a}$ Pars, q. 27, a.3, resp., Thomas affirme qu'Adam, avant le péché, n'avait pas le fomes peccati, grâce à la « justice 
originelle » (per originalem iustitiam) et l'on sait que, par originalis iustitia, Thomas entend la grâce sanctifiante donnée au premier homme et qui faisait que ses puissances inférieures étaient parfaitement soumises à sa raison, «Deo per gratiam supplente id quod ad hoc deerat per naturam» (voir ScG, IV, 52). Saint Thomas, après la question 109, continue donc à penser qu'Adam, dans l'état de nature pure, aurait eu le fomes concupiscentiae et que c'est la justice originelle (qui comporte la grâce sanctifiante) à l'en avoir préservé, ce qui revient à dire que la situation d'Adam après le péché ne se distingue de l'état de nature pure que par la culpabilité, mais que Dieu n'a introduit alors dans la nature humaine aucune corruption : la nature humaine d'Adam après le péché est identiquement la nature pure. Ce fait montre que la q. 109 (ainsi que quelques autres expressions occasionnelles) ne reflète qu'imparfaitement la pensée du Docteur angélique. On peut supposer que cela est dû à une insuffisante révision (par Thomas ou par ses secrétaires) de passages écrits un peu à la hâte et qui sont plutôt conformes à l'enseignement courant, au moyen âge, inspiré à saint Augustin.

De plus, la doctrine soutenue dans le Quodlibet I interdit de penser que Thomas conçoive cette capacité originelle de l'homme d'aimer Dieu plus que soi-même comme une capacité morte, inefficace : le texte du Quodlibet I implique directement l'exercice de cette capacité, selon des degrés («magis et minus »), jusqu'à un sommet («maximum»), et cela sans le secours de la grâce, car cet exercice même est une préparation à recevoir la grâce (la même doctrine se trouve exprimée non seulement dans l'In II Sent., d. 27, q. un., a.4 [cité à la note 55], mais aussi dans la $I^{a}-I I^{a e}$, q. 89 , a. 6 [cité à la note 56], chronologiquement très proche de la q. 109). Par rapport à la lettre de l'article 3 de la q. 109, de la $I^{a}-I I^{a e}$, l'enseignement du Quodlibet I et celui de la dist. 27, q. 2, a.2, ad 4, du Super III Sent. me semblent plus cohérents avec la doctrine constante de Thomas à propos de l'exercice des facultés naturelles de l'homme après la chute, ce qui nous autorise à interpréter le passage de la $I^{a}-I I^{a e}$ q. 109, a. 3 comme un complément aux autres textes, concernant le constat qu'habituellement, ut in pluribus, l'homme sans le secours de la grâce, n'est pas capable («fallit») d'aimer Dieu plus que soi-même.

Rappelons ici que, selon Thomas, Dieu peut donner la grâce sanctifiante même à des infidèles, s'il le juge opportun. Cela en considération de leur comportement droit, que Thomas considère comme une préparation à recevoir la grâce (nous retrouvons ici la doctrine du Quodlibet I, cité à la note 55). Â propos du péché originel, il écrit : «Une fois qu'il a commencé à avoir l'usage de la raison [...], la première chose qui se présente alors à la réflexion de l'homme, c'est de délibérer de soimême. Et s'il s'ordonne donc à la juste fin, par la grâce il reçoit la 
rémission du péché originel $»^{56}$. On voit bien, dans ce texte, que Thomas pense qu'à l'infidèle qui, tout en ayant le péché originel, s'ordonne de soi («faciens quod in se est») à la juste fin, Dieu peut offrir la grâce sanctifiante, qui le justifie en lui remettant le péché originel. Il ne dit pas qu'il donne à l'infidèle la grâce sanctifiante pour qu'il s'ordonne à la juste fin, car cela, selon Thomas, le sage païen peut le faire à partir de ses capacités naturelles: «omnes qui recte senserunt posuerunt finem humane uite Dei contemplationem » (In I Sent., Prol., a.1, resp., cité à la note 7 ; voir aussi, ci-dessous, les textes cités aux paragraphes V.1 et V.2). Dans la $I^{a}-I I^{a e}$, q. 89, a. 6, l'expression «cum usum rationis habere inceperit » ne se rapporte pas à un enfant qui aurait acquis l'usage de la raison, mais à un homme, qui a atteint un âge suffisant pour réfléchir (« cogitare », « capax discretionis ») et pour « délibérer de soi-même ». On ne sera donc pas surpris du fait que Dieu donne sa grâce au sage païen qui agit droitement et bien (« et recte et bene operatur »), autant qu'il le peut, afin qu'il puisse, par la gratia sanans naturam, aimer Dieu plus que soi-même d'une manière plus parfaite de celle qu'il peut atteindre par l'exercice, difficile, de ses facultés naturelles. Si l'homme, par les seuls principes de la nature, ne peut pas atteindre sa fin, sans la grâce de la foi, cependant «à la place de tout ce que la nature a donné aux autres animaux, à l'homme a été donnée la raison, par laquelle il peut se procurer ce qui est nécessaire à sa vie ici-bas et se disposer à recevoir de Dieu (divinitus) les aides pour la vie future $\gg^{57}$. Cette

56. «Cum vero usum rationis habere inceperit [...] primum quod tunc homini cogitandum occurrit, est deliberare de seipso. Et si quidem seipsum ordinaverit ad debitum finem, per gratiam consequetur remissionem originalis peccati. Si vero non ordinet seipsum ad debitum finem, secundum quod in illa aetate est capax discretionis, peccabit mortaliter, non faciens quod in se est » $I^{a}-I^{a e}$, q. 89, a. 6, resp. (éd. Leon., t. 7, p. 146). Sur le sens de « usum rationis » voir : Augustinus, De beata vita, I, 2 (CCSL 29, p. 65, 1. 15-21). À propos des doctrines médiévales sur le salut des infidèles, en plus de l'étude classique de Louis CAPÉRAN, Le Problème du salut des infidèles : Essai historique, Nouvelle édition, revue et mise à jour; Essai théologique, nouvelle édition, revue et augmentée, Toulouse, Grand Séminaire, $1934^{2}$, on peut voir Ruedi IMBACH, «De salute Aristotelis. Fussnote zu einem nebensächlichen Thema», dans Claudia BRINKER, Urs Herzog, Niklaus Largier, Paul Michel (éd.), Contemplata aliis tradere, Studien zum Verhälntis von Literatur und Spiritualität, Für Alois M. Haas, Bern..., Peter Lang, 1995, p. 157-173 ; Peter VON Moos, «La Quaestio de Lambert du Mont sur le salut éternel d'Aristote », dans Religiosità e civiltà Conoscenze, confronti, influssi reciproci tra le religioni (secc. X-XIV), Milano, Vita e Pensiero ( Le Settimane internazionali della Mendola », Nuova Serie, Brescia 15-17 settembre 2011), sous presse, avec l'abondante bibliographie.

$57 . \ll[\ldots]$ loco omnium quae natura aliis animalibus providit data est homini ratio per quam et necessaria huius vitae sibi praeparare potest et disponere se ad recipienda divinitus auxilia futurae vitae » De uer., q. 14, a. 10, ad 5 (éd. Leon., t. 22, 2, p. 468, 1. 263267). Pour interpréter le texte de la $I^{a}-I I^{a e}$, q. 109, a. 3 comme un complément à la doctrine exposée auparavant par Thomas, on pourrait se référer à son enseignement sur la nécessité que soient révélées certaines vérités naturelles, de soi accessibles à l'homme par sa seule raison: $I I^{a}-I{ }^{a e}$, q. 2, a. 4 (éd. Leon., t. 8, p. 30-31), avec les lieux parallèles. 
doctrine de Thomas, sur l'action de la grâce divine dans le monde, en particulier celle de la $I^{a}-I I^{a e}$, q. 89 , a. 6, est d'une importance capitale pour démêler le complexe débat autour de la question dite « de auxiliis »; elle trouve, heureusement, un écho dans la constitution Lumen gentium de Vatican II ${ }^{58}$.

Ayant ainsi expliqué la position de Thomas à propos de la possibilité pour l'homme, par ses seules forces naturelles, d'aimer Dieu par-dessus tout et plus que soi-même, une autre question, comme je le disais, surgit spontanément à propos du commentaire de Thomas au chapitre $13 \mathrm{du}$ livre X de l'Éthique à Nicomaque: les sages païens peuvent-ils vraiment être «amis» («amici») de Dieu et des dieux sans le secours de la grâce?

Il va de soi que, dans ce commentaire, Thomas ne parle pas de la grâce car il est en train d'interpréter la doctrine d'Aristote. Ce faisant, Thomas attribue à celui-ci d'avoir envisagé une vraie amitié entre le sage et Dieu et les dieux : il faut donc penser que Thomas considère cette amitié réellement possible. Il ne fait pas de doute que, dans le commentaire de l'Éthique, Thomas envisage l'amour entre le sage païen et Dieu comme une vraie amitié, qui comporte une certaine réciprocité : « Il est raisonnable de tenir que Dieu montre sa bienveillance surtout à ceux qui aiment et honorent l'intellect, plaçant au-dessus de tout le bien de l'intellect, de même que les dieux ont souci de ceux qui sont leurs amis »; le sage est «souverainement aimé de Dieu» («amantissimus Deo »), ce qui le rend vraiment bienheureux («sapiens est maxime felix »).

Or, dans la dist. 27, q. 2, a.2, ad 4, du Super III Sent., nous lisons qu'envers Dieu, l'homme, par ses seules forces naturelles, « ne peut pas atteindre l'amitié qui fait que les amis ont vie commune et activités communes » : pour cela, l'homme a besoin de la charité, donc de la grâce (note 54). En effet, comme il est dit encore dans cette distinction 27, dans le Quolibet $I$ et dans $I^{a}-I I^{a e}$, q. 109, a.3, ad 1, à la rigueur l'homme peut s'efforcer, par ses seules forces naturelles et selon un minus, un magis et un maximum, d'aimer Dieu plus que soi-même : mais quand Dieu aime l'homme, son amour ne peut pas être inefficace, il ne peut pas ne pas

58. Voir tout le n. 16, et en particulier : « Nec divina Providentia auxilia ad salutem necessaria denegat his qui sine culpa ad expressam agnitionem Dei nondum pervenerunt et rectam vitam non sine divina gratia assequi nituntur. Quidquid enim boni et veri apud illos invenitur, ab Ecclesia tamquam praeparatio evangelica aestimantur et ab Illo datum qui illuminat omnem hominem, ut tandem vitam habeat »Constitutio dogmatica De Ecclesia, «Lumen gentium», n. 16, dans Sacrosanctum Oecumenicum Concilium Vaticanum II. Constitutiones, Decreta, Declarationes, Cura et studio Secretariae generalis Concilii Oecumenici Vaticani II, In Civitate Vaticana, Typis Polyglottis Vaticanis, 1966, p. 120-122, pour la citation : p. 121. 
rendre l'homme «aimable ${ }^{59}$. Dieu ne peut pas aimer le pécheur, enseigne Thomas, et donc, s'il aime le sage païen, c'est qu'il lui donne la gratia gratum faciens, qu'il lui pardonne le péché originel, qu'il le justifie et qu'il le gratifie du partage « de ses opérations, qui sont sa vie et sa béatitude ».

Nous pouvons considérer un texte de la $I^{a}-I I^{a e}$, q. 110, a.1, qui permet de comprendre pourquoi cette amitié ne peut se réaliser que par la grâce : «La dilection de Dieu pour une créature peut être de deux sortes. Une dilection commune, selon laquelle Dieu aime tout ce qui est, comme il est dit en Sagesse 11 [25] ; dilection selon laquelle Dieu donne aux choses créées l'être naturel». L'amour dont parle Thomas en commentant l'Éthique, ne peut pas être de cette sorte, car il implique une réciprocité, qui rend les sages païens «amis » («amici ») de Dieu. « Il est une autre dilection, spéciale, continue Thomas, selon laquelle Dieu élève la créature rationnelle au-dessus de la condition de la nature, à la participation du bien divin $»^{60}$. Si Dieu aime quelqu'un d'amitié, par là même, il l'élève « à la participation du bien divin » et il lui offre de « communier à sa vie et à ses activités », qui sont surnaturelles.

Alors que dans le cas de l'amitié entre le sage païen et Dieu, selon l'enseignement de Thomas, il faut affirmer la nécessité de la grâce, dans le cas de l'amour de Dieu par-dessus tout et plus que soi-même, je crois que, toujours selon l'enseignement de Thomas, nous ne sommes pas autorisés à affirmer la nécessité absolue de la grâce, qui porterait atteinte à l'intégrité des facultés de l'âme dans leur racine, mais seulement une nécessité pratique, quant à l'exercice de ces facultés.

Cet excursus sur la nature et la grâce dans la contemplation du philosophe montre comment au sommet de cette contemplation, dans l'amitié que Dieu instaure entre le sage païen et lui-même, la nature et la grâce se rejoignent harmonieusement, de même que la théologie rejoint la philosophie, pour la conduire à sa fin, comme nous le montrons cidessous $(\S \mathrm{V})$. En effet, la relation entre la nature et la grâce, telle que Thomas la conçoit, se fonde sur la conviction que l'homme n'a pas été

59. Voir tout l'article 2 de la $I I I^{a}$ Pars, q. 86, et en particulier : « Sicut autem habitum est in Secunda Parte $\left[I^{a}-I I^{a e}\right.$, q. 110, a. 1], hoc interest inter gratiam Dei et gratiam hominis, quod gratia hominis non causat, sed praesupponit bonitatem, veram vel apparentem, in homine grato : sed gratia Dei causat bonitatem in homine grato, eo quod bona voluntas Dei, quae in nomine gratiae intelligitur, est causa boni creati» (éd. Leon., t. 12 , p. 308 ; c'est nous qui soulignons).

60. «Differens consideratur dilectio Dei ad creaturam. Una quidem ommunis, secundum quam diligit omnia quae sunt, ut dicitur Sap. 11 [25] ; secundum quam esse naturale rebus creatis largitur. Alia autem est dilectio specialis, secundum quam trahit creaturam rationalem supra conditionem naturae, ad participationem divini boni. [...] Sic igitur per hoc quod dicitur homo gratiam Dei habere, significatur quiddam supernaturale in homine a Deo proveniens $\gg I^{a}-I I^{a e}$, q. 110, a. 1, resp. (éd. Leon., t. 7, p. 311). 
créé « in puris naturalibus » et ensuite surélevé à l'état de grâce, mais qu'il a reçu le don de la grâce avec celui de la nature et « il a été ordonné à la fin de la béatitude non comme si c'était une fin due à l'homme selon sa nature, mais seulement en raison de la libéralité divine ${ }^{61}$. Dieu, en donnant la grâce sanctifiante aux infidèles, poursuit ainsi son dessein originel.

Pour en revenir à la distinction $35 \mathrm{du}$ Super III Sententiarum, l'acte de contemplation des saints commence inspiré par la charité et se termine directement à Dieu qui l'inspire ${ }^{62}$. Comme celui des philosophes il comporte lui aussi l'amour du sujet qui contemple, donc l'amour de soi : « procedit ex amore sui ». Cet amour est nécessaire, car il est la forme et la racine de toute union amoureuse (voir $I I^{a}-I I^{a e}$, q. 25, a.4, resp., cité à la note 37). Informé par la charité, cet amour est surélevé dans une sorte d'amitié avec soi-même, qui est infusée par Dieu et orientée vers lui. C'est ainsi que l'acte de contemplation des saints ici-bas a en lui-même sa delectatio. De même, l'acte de contemplation des philosophes commence ex amore sui et se termine à l'objet aimé. Et comme cet objet est Dieu, l'homme est capable de l'aimer plus que soi-même, puisque « la partie tend plus à la conservation de l'ensemble dont elle est partie que d'elle-même ». Le philosophe qui contemple Dieu ex creaturis, aime Dieu pour lui-même et non seulement pour soi. Ainsi son acte a en luimême sa delectatio. Dans la solutio 1 que nous examinons, Thomas joint l'analyse de la contemplation des philosophes et celle de la contemplation des saints ici-bas. Il montre dans la contemplation des saints la dimension naturelle de l'amor sui, que l'habitus de charité informe; dans la contemplation des philosophes, le dépassement de l'amor sui dans l'amour naturel de Dieu plus que soi-même.

Cette conception, en elle-même, ne comporte de la part des philosophes aucun empiétement par rapport à la foi. Si abus il y a, selon Thomas, il serait plutôt dans la détermination des conditions ou des modalités de réalisation de cette contemplation des sages, « amis de Dieu », comme il apparaît évident dans la suite du commentaire à l'Éthique :

61. « Ab ipsa prima institutione natura humana est ordinata in finem beatitudinis, non quasi in finem debitum homini secundum naturam eius sed ex sola divina liberalitate »De uer., q. 14, a. 10, ad 2 (éd. Leon., t. 22, 2, p. 467, 1. 221-225); voir, en particulier: I Pars, q. 62, a. 3 (éd. Paulinae, 1962, p. 292, avec les notes) ; q. 95, a. 1 (ibid., p. 461) ; II ${ }^{a}-I I^{a e}$, q. 5, a. 1 (ibid., p. 1117) ; Q. disp. de malo, q. 4, a. 2, III, ad 1 (éd. Leon., t. 23, p. 113, 1. 494-497) ; et les lieux parallèles. À propos de l'expression « in puris naturalibus », voir In II Sent., d. 27, q. un., a. 4, resp., cité à la note 55. Pour l'ensemble de ces questions, voir : Jean-Pierre TORRELL, « Nature et grâce chez Thomas d'Aquin », dans $R T 102$ (2001), p. 167-202.

62. Voir $I I^{a}-I I^{a e}$, q. 180, a. 7, resp. (éd. Leon., t. 10, p. 432-433, cité à la note 67). 
Il ressort de cela qu'Aristote fait consister la félicité ultime de l'homme dans l'opération de la sagesse dont il a établi la doctrine plus haut au sixième livre, et non pas dans le contact avec l'intellect agent, comme certains le prétendent. Il faut remarquer aussi que ce n'est pas la félicité parfaite qu'il assigne à cette vie, mais une félicité telle qu'il peut y en avoir dans la vie humaine et mortelle. D'où son expression plus haut, au premier livre : « bienheureux comme des hommes ${ }^{63}$.

On sait qu'au sujet de la conception aristotélicienne de la félicité parfaite Thomas s'est exprimé de différentes façons tout au long de sa carrière, et je tâcherai d'en rendre compte ci-dessous (§ IV et aussi III.5). En outre, en tenant compte du fait qu'il écrit son commentaire de l'Éthique à Paris autour de 1271-1272, on pourrait penser que, dans ce développement final, il ne critique pas seulement Averroès, mais aussi des positions «averroistes ». Cependant, dans l'étude de tous les textes concernant la contemplation des philosophes, nous n'avons trouvé aucun élément explicite qui donnât à penser que Thomas veuille s'opposer à des thèses relevant de ce que l'on a appelé l'aristotélisme intégral ou l'averroïsme ${ }^{64}$.

\section{III.3. L'amor sui des philosophes dans leur acte de contemplation}

Le P. Jean-Pierre Torrell, qui a traduit et commenté la solutio $1 \mathrm{du}$ Super III Sent., dist. 35, q. 1, a.2, a interprété ce texte comme une réaction non seulement à ce qu'on a appelé aussi l'aristotélisme intégral, mais également comme une correction de la conception qu'Aristote luimême a formulée de la contemplation philosophique ${ }^{65}$.

63. «Ex quo patet quod ultimam felicitatem humanam ponit Aristotiles in operatione sapientiae de qua supra in VI determinavit, non autem in continuatione ad intelligentiam agentem, ut quidam fingunt. Attendendum etiam quod in hac vita non ponit perfectam felicitatem, sed talem qualis potest competere humanae et mortali vitae; unde et supra in I dixit : "Beatos autem ut homines" » In Ethic. Nic., X (1179a22), lect. 13 (éd. Leon., t. 47, 2, p. 595, 1. 137-144; les italiques sont de nous).

64. Voir ci-dessous aux notes 111-113, les précisions apportées par le commentaire sur Matthieu, avec notre explication; on peut rappeler que ce commentaire date du second enseignement parisien de Thomas, contemporain des débats relatifs à l'averroïsme.

65. Jean-Pierre Torrell, «Philosophie et théologie d'après le Prologue de Thomas d'Aquin au Super Boetium de Trinitate. Essai d'une lecture théologique », Documenti e studi sulla tradizione filosofica medievale 10 (1999), p. 342-343: « À lire ce passage [de la solutio 1 , citée à la note 36] dans l'ignorance du contexte que nous venons de rappeler, un philosophe chrétien d'aujourd'hui ne peut manquer de le trouver injuste et d'en être choqué ; il admettra peut-être qu'il dénonce une tentation toujours possible de s'arrêter trop tôt, mais il reprochera à son auteur de faire trop peu de cas de l'authentique amour de la vérité qui peut inspirer sa démarche. Même s'il admet que la vérité n'est pas encore complètement connue par lui, il revendique cependant de pouvoir l'aimer pour ellemême de façon désintéressée et non pas commandée par l'amour de soi. Cette attitude est compréhensible, mais ce n'est pas cela que conteste Thomas. "Contemplation selon les philosophes” désigne pour lui non pas la recherche philosophique en général, mais bien une déviation qu'il croit pouvoir identifier chez Aristote et chez ceux qui prétendent le 
Si l'on considère la conception de la contemplation que Thomas attribue à Aristote, telle que nous avons pu la dégager de plusieurs textes du docteur Angélique, et si l'on interprète correctement la solutio $1 \mathrm{du}$ Super III Sent., dist. 35, q. 1, a.2, on constate que celle-ci ne rectifie en aucune manière la conception de la contemplation que Thomas attribue à Aristote.

À l'a. 3 de la d. 29, «Quod Deus non sit supra omnia diligendus ex caritate », Thomas considère une objection formulée à partir de l'Éthique d'Aristote :

$\mathrm{Au}$ neuvième livre de l'Éthique, le Philosophe dit que les sentiments d'amitié qu'on éprouve envers son prochain procèdent des sentiments qu'on éprouve envers soi-même.

Dans sa réponse il écrit :

Il faut dire que les sentiments d'amitié qu'on éprouve envers son prochain procèdent des sentiments qu'on éprouve envers soi-même, non pas comme cause finale, mais comme ce qui précède dans l'ordre de la génération. En effet, on se connaît soi-même avant de connaître l'autre, et de la même manière avant de connaître Dieu ; et encore, on s'aime soimême avant d'aimer autrui, quant à l'ordre de la génération ${ }^{66}$.

La doctrine est ici la même que celle de la solutio 1 du Super III Sent., dist. 35, q. 1, a. 2 .

Tant pour ce qui concerne les philosophes en général (qui procèdent selon la raison à partir des créatures) que pour la philosophie d'Aristote, telle que Thomas l'interprète, j'ai montré que selon Thomas l'acte de

suivre intégralement. Pour Aristote, la plupart du temps, si la contemplation fait le bonheur du philosophe ce n'est pas en raison de l'objet contemplé, mais bien parce que c'est la plus haute activité de l'homme, qui y trouve sa perfection. Activité strictement intellectuelle, elle s'achève dans l'immanence, et non dans un objet transcendant. Thomas ne pouvait apprécier trop sévèrement pareil repliement dans un humanisme clos; et c'est pourquoi ici encore il subvertit Aristote : sans doute la béatitude consistera dans un acte de l'intelligence, mais ce n'est que dans l'autre vie (celle qu'Aristote ignorait et que ses disciples stricts du Moyen Âge laissaient de côté) qu'elle s'accomplira; ici-bas, c'est l'amour qui précède. [...] Comme tel ce passage du troisième livre des Sentences est un texte rare, unique peut-être chez Thomas, et on ne réduira pas à cela ce qu'il pense de la recherche philosophique » (les italiques sont de l'auteur).

66. «Philosophus dicit in IX Eth. quod amicabilia quae sunt ad alterum veniunt ex amicabilibus quae sunt ad seipsum». Dans la réponse Thomas écrit: «Ad tertium dicendum quod amicabilia quae sunt ad alterum, venerunt ex amicabilibus quae sunt ad seipsum, non sicut ex causa finali, sed sicut ex eo quod est prius in via generationis. Quia sicut quilibet sibi prius est notus quam alter, etiam quam Deus; ita etiam dilectio quam quisque habet ad seipsum, est prior ea dilectione quam habet ad alterum, in via generationis » In III Sent., d. 29, a. 3, ad 3 (éd. M. F. Moos, p. 927, n. 31 et p. 930, n. 43). Voir aussi : «[...] spes pertinet ad secundum amorem, quia ille qui sperat aliquid sibi obtinere intendit. Et ideo in via generationis spes est prior caritate »II $I I^{a}$, q. 17, a. 8, resp. (éd. Leon., t. 8, p. 133). 
contemplation le plus haut inclut l'amour de Dieu en tant qu'il peut être l'objet de contemplation à partir des créatures. Le $\mathrm{P}$. Torrell a raison d'affirmer le caractère immanent de l'acte intellectuel de contemplation perfectionnant le sujet, selon Thomas, mais cela n'autorise pas à nier l'altérité de l'objet contemplé. Plus encore : cet objet est aimé en tant qu'il est connu et, dans cet acte d'amour, l'homme se porte au-delà de lui-même vers l'objet qu'il connaît. Quand cet objet est Dieu, le philosophe sage peut aussi devenir ami de Dieu, car selon Thomas la volonté a son terme dans l'objet aimé. Du fait que la contemplation des philosophes procedit ex amore sui il ne s'ensuit pas que l'acte de contemplation se termine à soi-même : l'essence de cet acte étant la considération intellectuelle de l'objet contemplé, dans la mesure où l'objet sera contemplé, il sera aussi aimé, même dans le cas de la contemplation naturelle de Dieu, que l'homme peut aimer plus que soimême, en raison de sa seule nature humaine, mû éventuellement par la grâce, même si inconsciemment (Super III Sent., d. 29, a.3 et $I^{a}-I I^{a e}$, q. 109, a.3, avec notre explication au paragraphe précédent).

Il faut souligner une autre donnée importante : quand Thomas, lors de son second enseignement parisien, écrit l'a. 1 de la q. 180, de la $I I^{a}-I I^{a e}$, il reprend d'une autre façon les idées déjà exposées dans la solutio $1 \mathrm{du}$ Super III Sent., dist. 35, q. 1, a.2. Il dit que deux éléments meuvent la puissance appétitive à voir quelque chose : l'amour de l'objet (« amor rei visae ») et l'amour de la connaissance elle-même («amor ipsius cognitionis quam quis ex inspectione consequitur »). S'il ne reprend pas l'expression amor sui pour désigner un de ces deux moteurs, ce n'est pas pour l'exclure, mais pour en préciser la nature. La connaissance que l'on aime et qui meut le sujet est celle du sujet lui-même qui voit (inspectione consequitur). L'amour de soi qui meut le sujet à contempler n'est pas l'amor sui générique et originel qui est la forme et la racine de toute union amoureuse (voir $I I^{a}-I I^{a e}$, q. 25, a.4, resp., cité à la note 37), mais l'amour de soi connaissant. Par cette précision, Thomas met également en valeur le lien intrinsèque de la contemplation avec l'objet contemplé (amorem rei visae) et donc il n'enferme pas cette connaissance de soi sur elle-même. Cela apparaît clairement dans l'a. 7 de la q. 180 : en traitant de la delectatio, Thomas ne se borne pas à considérer la distinction entre l'acte de voir et le fait de voir tel objet précis (personam amatam), mais il affirme que l'acte et son objet produisent chacun sa propre delectatio : « de même que dans la vision corporelle le plaisir vient non seulement de l'acte même de voir, mais encore du fait de voir une personne que l'on aime ${ }^{67}$.

67. « [...] aliqua contemplatio potest esse delectabilis dupliciter. Uno modo, ratione ipsius operationis, quia unicuique delectabilis est operatio sibi conveniens secundum 
Il faut encore dire que pour Thomas il n'y a pas de confusion possible entre l'amour que les philosophes ont pour Dieu et celui qu'ont les saints dans leur acte respectif de contemplation. Cela tient au fait qu'à l'origine de la contemplation des saints, Thomas l'enseigne, il y a un acte de charité et la charité est une vertu infuse, alors que la contemplation de Dieu qu'ont les philosophes reste dans le domaine des capacités naturelles de l'homme, et quant aux puissances de l'âme impliquées dans la contemplation et quant aux moyens qui permettent l'accès à Dieu. Ces deux contemplations appartiennent à deux ordres différents de relation à Dieu : l'un selon les créatures (« ex creaturis»), l'autre selon la Révélation et la grâce.

Rappelons-le encore : la contemplation de Dieu qu'ont les philosophes n'est pas dite imparfaite par rapport à la contemplation des sancti in uia, mais par rapport à la connaissance de Dieu in patria.

\section{III.4. Le contexte historico-doctrinal de la dist. 35 du Super III Sent.}

Dans son commentaire de la solutio 1 que nous étudions, le P. Torrell croit pouvoir affirmer que Thomas vise une « déviation » de la doctrine d'Aristote et de l'aristotélisme intégral, déviation, je suppose, par rapport à la vérité que la foi nous enseigne ${ }^{68}$. A mon avis, dans cette distinction 35 , qui date du début de 1254 ou de $1255^{69}$, il ne peut nullement être question de cela ${ }^{70}$.

propriam naturam vel habitum. Contemplatio autem veritatis competit homini secundum suam naturam, prout est animal rationale. Ex quo contingit quod omnes homines ex natura scire desiderant, et per consequens in cognitione veritatis delectantur. Et adhuc magis fit hoc delectabile habenti habitum sapientiae et scientiae, ex quo accidit quod sine difficultate aliquis contemplatur. Alio modo contemplatio redditur delectabilis ex parte obiecti, inquantum scilicet aliquis rem amatam contemplatur, sicut etiam accidit in visione corporali quod delectabilis redditur non solum ex eo quod ipsum videre est delectabile, sed ex eo etiam quod videt quis personam amatam. Quia ergo vita contemplativa praecipue consistit in contemplatione Dei, ad quam movet caritas, ut dictum est ; inde est quod in vita contemplativa non solum est delectatio ratione ipsius contemplationis, sed ratione ipsius divini amoris. Et quantum ad utrumque eius delectatio omnem delectationem humanam excedit. Nam et delectatio spiritualis potior est quam carnalis, ut supra habitum est, cum de passionibus ageretur, et ipse amor quo ex caritate Deus diligitur, omnem amorem excedit $\gg I I^{a}-I I^{a e}$, q. 180, a. 7, resp. (éd. Leon., t. 10, p. 432-433 ; les italiques sont de nous). Voir aussi le texte du P. Gauthier et l'article d'I. Zavattero cités aux notes 83 et 84 .

68. " "Contemplation selon les philosophes" désigne pour lui [scil. Thomas] non pas la recherche philosophique en général, mais bien une déviation qu'il croit pouvoir identifier chez Aristote et chez ceux qui prétendent le suivre intégralement» J.-P. Torrell, « Philosophie et théologie... », art. cit., p. 342 (cité à la note 65 ; les italiques sont de nous). 241.

69. À propos de la datation de ce texte, voir A. Oliva, Les Débuts..., op. cit., p. 166 et

70. Voir Ruedi ImBACH, «L'averrö̈sme latin du XIII siècle », dans Ruedi IMBACH, Alfonso MAIERÙ (éd.), Gli studi di filosofia medievale fra Otto e Novecento. Contributo a un bilancio storiografico, Atti del convegno internazionale, Roma, 21-23 settembre 1989, 
Il est possible que le $\mathrm{P}$. Torrell ait été conduit à faire ce rapprochement entre la solutio 1 et l'aristotélisme intégral à partir de textes cités dans un fameux article de R. A. Gauthier ${ }^{71}$ auquel il se réfère, en particulier là où le $\mathrm{P}$. Gauthier cite la question 29 de ce qu'on appelait alors le Commentaire du Vatican. Or, dans cette question, nous lisons un passage qui peut certes être mis en parallèle avec la solutio 1 dont nous parlons, sans qu'on puisse toutefois instaurer une relation directe entre les deux textes :

Cependant, selon le Philosophe, connaître et contempler Dieu est plus noble que l'aimer [...] Et quand on dit que les infidèles peuvent connaître Dieu, je crois que l'on ne peut connaître Dieu sans l'aimer, parce que l'amour suit l'intelligence et la connaissance ${ }^{72}$.

Le même P. Gauthier cependant, dès son article de 1948 avait bien daté de la fin du XIII ${ }^{\mathrm{e}}$ siècle ce commentaire, ainsi que tous ceux qui constituent le corpus qu'il étudie ${ }^{73}$. Depuis, Iacopo Costa, qui a consacré

Roma, Edizioni di Storia e letteratura (coll. «Storia e letteratura. Raccolta di studi e testi » 179), 1991, p. 191-208, spéc. p. 203 ; Luca BIANCHI, « La felicità intellettuale come professione nella Parigi del Duecento », Rivista di Filosofia 78 (1987), p. 181-199 ; Carlos BAZÁN, «Radical Aristotelianism in the Faculties of Arts. The Case of Sigier of Brabant », dans Ludger HonNEFELDER, Rega WoOD, Mechthild DREYER, Marc-Aeilko ARIS (éd.), Albertus Magnus und die Anfänge der Aristoteles-Rezeption im lateinischen Mittelalter. Von Richardus Rufus bis zu Franciscus de Mayronis, Münster, Aschendorff (coll. «Subsidia Albertina» I), p. 585-629; Gianfranco FIORAVANTI, «La felicità intellettuale : storiografia e precisazioni », dans Maria BETTETINI, Francesco D. PAPARELLA (éd.), La felicità nel medioevo, Louvain-la-Neuve (coll. «Fédération Internationale des Instituts d'Études Médiévales. Textes et études du Moyen Âge » 31), 2005, p. 1-12; Ruedi ImBACH, Ide Fouche, «Introduction », dans ThOMAs D’AQUin, BoĖce DE DACIE, Sur le bonheur. Textes introduits, traduits et annotés par R. IMBACH, I. FOUCHE, Paris, J. Vrin (coll. «Translatio. Philosophies médiévales »), 2005, p. 7-41. Pour un bilan des études actuelles sur le sujet, voir la remarquable étude de Marta BORGO, «Between Avicenna and Averroes : Considerations on the Early Aquinas' Aristoteles », à paraître.

71. R. A. GAUTHIER, «Trois commentaires “averroïstes” sur l'Éthique à Nicomaque », AHDLMA 22-23 (1947-1948), p. 187-336. Voir J.-P. TORRELL, «Philosophie et théologie... », art. cit., p. 343.

72. « Tamen secundum Philosophum intelligere Deum et speculari est nobilius quam diligere ipsum [...]. Et cum dicitur quod infideles possunt intelligere Deum, credo quod aliquis non potest Deum intelligere quin ipsum diligat, ita quod dilectio sequitur ad intellectionem et apprehensionem » R. A. GAUTHIER, «Trois commentaires... », art. cit., p. 292, note 1. Édition critique par Iacopo CostA, Le questiones di Radulfo Brito sull'«Etica Nicomachea ». Introduzione e testo critico, Turnhout, Brepols (coll. «Studia Artistarum » 17), 2008 ; la citation se trouve p. 244, 1. 143-149.

73. Le Commentaire dit alors du Vatican avait été daté des années 1290, celui de Gilles d'Orléans à cheval entre XIII ${ }^{\mathrm{e}}$ et XIV ${ }^{\mathrm{e}}$ siècle, celui du Paris, Bnf lat. 14698 postérieur à la condamnation de 1277 ; les commentaires étudiés par Mgr. M. Grabmann avaient été datés également de cette fin du XIII ${ }^{\mathrm{e}}$ s. : R. A. GAUTHIER, «Trois commentaires...», art. cit., p. 222, 224 et 229. Voir aussi R. A. GAUTHIER, compte rendu de Odon LotTin, Psychologie et morale aux XII et XIII e siècles. II-III. problèmes de morale, Louvain, 19481949, dans Bulletin thomiste, VIII (1947-1953), p. 82. Ces dates ont été précisées par I. COSTA (voir la note suivante). Par ailleurs, à propos de l'averroïsme psychologique, le 
de remarquables études aux commentaires de l'Éthique postérieurs à ceux d'Albert le Grand et de Thomas, a définitivement identifié en Radulfus Brito l'auteur de ce qu'on appelait Commentaire du Vatican, et il a confirmé les années 1290 comme date de rédaction ${ }^{74}$.

Le P. Torrell cite un passage de l'article du P. Gauthier de 1948, où celui-ci affirme : «La contemplation philosophique s'oppose donc du tout au tout à la contemplation chrétienne telle que l'avait définie saint Thomas. Dans celle-ci, c'était l'amour qui était le principe et la mesure de la connaissance; dans celle-là, c'est la connaissance qui est le principe de l'amour $\gg^{75}$. Or, la connaissance philosophique dont parle ici le P. Gauthier est celle du commentaire de Radulfus Brito, que nous venons d'évoquer et que le P. Gauthier cite en note, et pas du tout celle dont parle Thomas d'Aquin dans la solutio 1 du Super III Sent., dist. 35, q. 1, a.2. La notion de contemplation philosophique selon Thomas d'Aquin, telle qu'elle se déduit des textes cités dans les pages précédentes, n'a rien à voir avec celle dont parle ici le P. Gauthier. Le P. Torrell rapproche la remarque du P. Gauthier en marge du commentaire de Brito de l'affirmation de Thomas dans la solutio 1 qui nous retient, où Thomas parle du rôle de la volonté et non de l'intellect dans la contemplation : pour cette raison Thomas dit que la contemplation des philosophes commence par l'amour de soi. On comprendrait ce rapprochement si Thomas, dans sa solutio 1, avait reproché aux philosophes la doctrine exprimée dans le commentaire de Brito. Thomas soutient cependant le contraire: même selon les philosophes la contemplation de Dieu commence par l'amour, et il n'y a lieu de leur reprocher aucun intellectualisme.

En outre, si l'on considère l'expression de Thomas dans la solutio 1 en question, «Et sic erat affectio in uita contemplatiua philosophorum » (voir la note 36), on constate que Thomas parle au passé : erat. Thomas n'est pas en train de penser à ses contemporains, mais il discute une

P. Gauthier écrivait en 1984: «Lorsque saint Thomas entreprit à Rome à la fin de 1267 d'écrire son commentaire au De anima, il n'était pas question pour lui de réfuter l'averrö̈sme parisien, qui venait à peine de faire son apparition en 1265 » R. A. GAUTHIER, «Introduction », dans Thomae de Aquino, Sentencia libri De anima, éd. Leon., t. 45, 1, p. $288^{*}$. Voir aussi : ID., « Notes sur les débuts (1225-1240) du premier "averroïsme" », Rev. Sc. ph. th. 66 (1982), p. 335.

74. I. Costa, Le questiones di Radulfo Brito..., op. cit., p. 99-155. Iacopo Costa a également édité le commentaire anonyme de Paris, Bnf lat. 14698, et a confirmé la datation du P. Gauthier: Iacopo CosTA, Anonymi Artium Magistri Questiones super Librum Ethicorum Aristotelis (Paris, Bnf lat. 14698), Turnhout, Brepols (coll. «Studia Artistarum » 23), 2010, p. 119-121. Encore à propos des dates, on peut voir Iacopo COSTA, «L'Éthique à Nicomaque à la faculté des Arts de Paris avant et après 1277 », AHDLMA 79 (2012), p. 71-114.

75. R. A. GAUTHIER, « Trois commentaires... », art. cit., p. 292. 
doctrine philosophique qu'il connaît bien ${ }^{76}$. Quant il parle de ses collègues de la faculté des Arts ou des «philosophes» ses contemporains, Thomas emploie, par exemple, l'expression «sapientes huius mundi », expression qui se réfère à la désignation de la philosophie comme «mundana sapientia $» 77$.

À vrai dire, nous ne pensons pas que la doctrine de Radulfus Brito soit en contradiction avec ce que dit ici Thomas, car ils parlent de deux choses différentes. Brito me semble parler de la connaissance préalable qu'il faut avoir de quelque chose pour l'aimer et, en cela, il est en parfait accord avec Thomas : « Nullus enim desiderio et studio in aliquid tendit nisi sit ei praecognitum $\gg^{78}$. En revanche Thomas, dans la solutio 1, parle de l'amour qui est préalable à toute contemplation d'un objet, une fois qu'on en connaît l'existence et la bonté, sur laquelle se porte proprement l'amour (voir la note 36 et aussi 35). Cette connaissance et cet amour, préalables à deux actes bien distincts, n'entrent pas en conflit.

Ce n'est donc pas vers les commentaires de l'Éthique à Nicomaque écrits à partir des années 1270, mais bien vers ceux qui ont été produits avant 1255, ainsi qu'aux introductions ou divisions de la philosophie élaborées pendant la première moitié du XIII ${ }^{e}$ siècle, qu'il faut que nous nous tournions pour vérifier si dans cette solutio 1 Thomas est en train de se référer à ses collègues de la faculté des Arts.

Comme le P. Gauthier l'a très bien montré, Thomas, dans les années 1246-1248, a étudié profondément les commentaires à l'Ethica noua et à l'Ethica uetus de la première moitié du XIII siècle $^{79}$. Nous connaissons au

76. Voir la note 10 et les textes cités ci-dessous, au paragraphe IV.

77. Responsio ad magistrum Ioannem de Vercellis de 43 articulis (éd. Leon., t. 42, p. 327, 1. 51-58), où Thomas affirme avec force la distinction entre la profession de philosophe et celle de théologien : voir Adriano Oliva, «Philosophy in the Teaching of Theology by Thomas Aquinas », dans The Thomist 76 (2012), sous presse.

78. ScG, I, 5 (éd. Leon., t. 13, p. 14). Déjà Augustin écrivait : « Non enim diligitur quod penitus ignoratur. Sed cum diligitur quod ex quantaculacumque parte cognoscitur, ipsa efficitur dilectione ut melius et plenius cognoscatur » AUGUSTINUS, In Iohannis euangelium, tract. 96, n. 4 (CCSL 36, p. 571, 1. 9-12).

79. On trouve les références aux écrits du P. Gauthier ainsi qu'aux remarques du P. Bataillon, dans Jean-Pierre TORRELL, Initiation à saint Thomas d'Aquin. Sa personne et son oeuvre, Paris-Fribourg $(\mathrm{CH})$, Éd. du Cerf - Éditions universitaires (coll. «Vestigia » 13), Deuxième édition 2002 revue et augmentée d'une mise à jour critique et bibliographique, 2002, p. 29-36, où il faut cependant corriger l'affirmation que Thomas aurait « recopié le De caelesti hierarchia dans un manuscrit qui témoigne du système parisien des "pièces" »(p. 36) : nous avons prouvé dès 2002 que l'indication des pièces dans ce manuscrit n'a rien à voir avec le système parisien de la copie par exemplar et pecie et que le commentaire d'Albert n'a pas été transmis selon ce système; de plus, nous avons montré qu'Albert a commenté tout le corpus dionysien après s'être installé à Cologne : voir A. Oliva, Les Débuts..., op. cit., p. 213-223. Les remarquables travaux de Maria Burger ont confirmé les résultats de notre recherche: voir Maria BURGER, «Thomas Aquinas's Glosses on the Dionysius Commentaries of Albert the Great in Codex 30 of the Cologne Cathedral Library », dans Ludger HonNEFELDER, Hannes MöHLE, 
moins six de ces commentaires ${ }^{80}$. Ici, nous nous bornons à rappeler que leurs auteurs élaborent tous un commentaire de l'Éthique à Nicomaque en se souciant de ne s'éloigner en rien de la doctrine chrétienne. Même Robert Kilwardby, qui se distingue des autres auteurs par un souci de plus grande fidélité à la lettre du Stagirite, ne peut pas s'empêcher d'identifier le bonheur avec Dieu ${ }^{81}$. En outre, ces commentaires admettent que le bonheur ici-bas est imparfait (ou parfait secundum quid) et certains affirment explicitement que ce n'est que dans la vie future que l'homme peut atteindre le bonheur parfait ${ }^{82}$. Ces commentaires partagent l'idée que l'homme, par l'exercice des vertus et de la contemplation amoureuse, ne peut s'unir que de manière imparfaite au Premier principe, le Bonheur subsistant, la Cause première, à savoir Dieu, et c'est plutôt Celui-ci qui peut unir l'homme à soi ${ }^{83}$. « Cognoscere

Susanna BUlLIDO DEL BARRIO (éd), Via Alberti. Texte - Quellen - Interpretationen, Münster, Aschendorff (coll. «Subsidia Albertina » II), 2009, p. 561-581, spéc. p. 574.

80. Ces commentaires ont été étudiés, entre autres spécialistes, d’abord par Odon LotTin et René Antoine GaUthiER ; ensuite par Georg WiELAND, Antony J. CElano ; plus récemment par Martin J. TraceY, Valeria BuffoN et Irene ZaVATtero. Voir la bibliographie dans Irene ZAVATTERO, «Le bonheur parfait dans les premiers commentaires latins de l'Éthique à Nicomaque », RTP 139 (2007), p. 311-327 ; Claude LAFLEUR, Joanne CARRIER, «L'enseignement philosophique à la Faculté des arts de l'Université de Paris en la première moitié du XIII ${ }^{\mathrm{e}}$ siècle dans le miroir des textes didascaliques », dans Laval théologique et philosophique 60 (2004), p. 409-448.

81. Voir I. ZAVATTERO, «Le bonheur parfait...», art. cit., p. 312 et 324 . Pour les contenus du commentaire du ms. d'Avranches, Bibl. mun. 232 f. 90r-123r, on peut voir Georg WIELAND, Ethica - Scientia practica. Die Anfänge der philosophischen Ethik im 13. Fahrhundert, Münster, Aschendorff (coll. « Beiträge zur Geschichte der Philosophie und Theologie des Mittelalters. Texte und Untersuchungen » N. F., 21), 1981, p. 143-146 ; 244248 ; 287-293. Nous avons vérifié le commentaire de Paris bis, Paris, Bnf lat. 3572 f. 186ra$187 \mathrm{vb}$. Le commentaire de Paris sur l'Ethica noua a été édité par René Antoine GAUTHIER, «Le cours sur l'Ethica noua d'un maitre ès Arts de Paris (1235-1240) », AHDLMA 42 (1975), p. 71-141. Le prologue du commentaire de ce même auteur sur l'Ethica uetus a été publié par Irene ZAVATTERO, «Le prologue de la Lectura in Ethicam ueterem du "Commentaire de Paris" (1235-1240). Introduction et texte critique », RTPM 77 (2010), p. 1-33. Le prologue du commentaire du Ps.-Pecham a été édité par Valeria BuFFoN, "Anonyme (Pseudo-Peckham), Lectura cum questionibus in Ethicam nouam et ueterem (vers 1240-1244). Prologue », RTPM 78 (2011), p. 297-382.

82. Voir Irene ZAVATTERO, «Felicità e principio primo. Teologia e filosofia nei primi commenti latini all'Ethica Nicomachea », dans Rivista di storia della filosofia, nuova serie, 61 (2006), p. 132-135 ; et EAD., « Le bonheur parfait... », art. cit., p. 312, 314, 318321. Voir aussi les textes édités par Ruedi Imbach, qui reprennent certaines doctrines des commentaires: Ruedi IMBACH, «Einführungen in die Philosophie aus dem XIII. Jahrhundert. Marginalien, Materialien und Hinweise im Zusammenhang mit einer Studie von Claude Lafleur », dans Freiburger Zeitschrift für Philosophie und Theologie 38 (1991), p. 471-493.

83. Le P. Gauthier écrivait à propos du commentaire de Paris : « Le Bonheur n'est pas à faire, il existe; il n'est pour l'homme que de s'unir à lui et, si le problème d'une opération de l'homme se pose, ce n'est pas qu'en cette opération consiste le Bonheur: non, c'est simplement que cette opération est pour l'homme le moyen de s'unir au Bonheur subsistant » R. A. GAUTHIER, « Le cours sur l'Ethica noua... », p. 78, où est citée la même doctrine chez Arnould de Provence: voir R. A. GAUTHIER, «Arnould de 
primum et diligere sunt opera alicuius cum felicitatem habet $\gg$ : comme le remarque Irene Zavattero, les opérations des bienheureux ne leur servent pas à obtenir la félicité, mais elles caractérisent l'état de félicité, à savoir la condition de celui qui possède la félicité et qui vit l'union avec le Primum $^{84}$. Cela implique que ces auteurs déterminent comment on peut atteindre la félicité et s'unir ou, plutôt, être uni au Primum. Pour cette raison, les maîtres développent des doctrines originales, qui utilisent divers éléments de la psychologie et de la métaphysique grécoarabes. On y trouve aussi l'idée que, sous un certain aspect, l'homme, par un amour délibéré, peut aimer Dieu plus que soi-même ${ }^{85}$, idée que Thomas radicalise ${ }^{86}$. Enfin, si selon ces maitres «l'homme est capable d'œuvrer à un bonheur parfait dans son genre », comme on peut aussi le lire dans l'interprétation que Thomas donne d'Aristote, cela n'est jamais en contradiction avec la foi ${ }^{87}$. Comme le fera Thomas, Robert Kilwardby affirme qu'Aristote n'a pas parlé du bonheur après la mort ${ }^{88}$ : il fait cependant exception parmi ces maîtres qui tendent plutôt à retrouver dans l'Éthique du Philosophe tous les éléments de la doctrine chrétienne sur le bonheur ${ }^{89}$.

On constate, à la lecture de ces commentaires comme aussi des introductions à la philosophie, l'élaboration d'une «théologie

Provence et la doctrine de la fronesis, vertu mystique suprême », dans RMAL 19 (1963), p. 129-170, pour la citation p. 139. Voir, à ce propos, l'étude détaillée d'I. ZAVATTERO, « Felicità e principio primo... », art. cit. p. 109-136, pour l'identification de la félicité avec le Primum, p. 113-123. Voir aussi Cl. LAFleur, J. CARRIER, «L'enseignement philosophique... », art. cit., p. 422.

84. I. ZAVATTERO, «Felicità e principio primo... », art. cit., p. 125, avec la note 96 . Voir Cl. LAFLEUR, J. CARRIER, « L'enseignement philosophique... », art. cit., p. 413.

85. «Duplex est amor hominis : naturalis et deliberatiuus, et naturali amore forte diligimus primam causam ut nos felicitet et ut conseruet nostrum esse, sed non amore deliberatiuo [...]. Sic ergo patet quod simpliciter loquendo magis est finis felicitas increata, plus etiam per amorem deliberatiuum unitur creatura rationalis prime cause, quam sibi ipsi. Et loquor de creatura rationali recte appetente et ordinate » ANONYMI MAGISTRI ARTIVM (PSEVDO-IOHANNIS PECKHAM) <Lectura cum questionibus in Ethicam Novam et Veterem>, letc. 10, q. 3 (éd. Valeria BuFFON, cité à partir d'I. ZAVATTERO, « Felicità e principio primo... », art. cit., p. 125, note 100 ; les italiques sont de nous).

86. «Amore amicitiae naturaliter Deus ab homine plus quam seipso diligitur » In III Sent., d. 29, a. 3, resp. (éd. M. F. Moos, p. 929, n. 44), cité à la note 43; voir aussi la note 45 , où l'on trouve les références aux textes parallèles d'Albert le Grand, de la Summa fr. Alexandri et de Bonaventure.

87. On lit, par exemple, dans le commentaire du Ps.-Peckham : « Non enim sic ponit Philosophus uirtutem in nobis a diuina prouidentia, sicut ponit felicitatem - licet fortassis, secundum theologum et secundum ueritatem, uirtus non sit a nobis set a Prima Causa, secundum illud : "Deus operatur in nobis uelle et perficere" [Ad Phil. 2, 13] » Anonymi Magistri Artivm (Psevdo-IoHAnNIS PecKHAM) < Lectura cum questionibus in Ethicam Novam et Veterem>, Prologus (éd. V. Buffon, « Anonyme Pseudo-Peckham... », art. cit., p. 358, 1. 31-34).

88. I. ZAVATTERO, « Le bonheur parfait... », art. cit., p. 324 ; EAD., « Felicità e principio primo... », art. cit., p. 126-132. Voir les notes 119,120 et 110.

89. I. ZAVATTERO, « Felicità e principio primo... », art. cit., p. 132. 
éthique ${ }^{90}$, plutôt que d'un commentaire littéral de l'Éthique d'Aristote, même si ces auteurs veulent parler secundum philosophos et non secundum theologos ${ }^{91}$. La revendication de leur «profession de philosophes » chez tous ces maîtres ne doit pas nous tromper sur leur doctrine: ils sont imbus d'une formation théologique, surtout augustinienne, qu'ils joignent à la tradition néoplatonicienne médiévale et à celle du Liber de causis, considéré comme un appendice de la Métaphysique d'Aristote, dont ils se servent aussi pour commenter l'Éthique, tout en faisant référence à Avicenne et à la tradition du péripatétisme gréco-arabe ${ }^{92}$.

Il ne faut pas commettre l'erreur d'interpréter cet ensemble de textes, introductions à la philosophie et commentaires de l'Éthique, à la lumière des doctrines qui apparaîtront à la faculté des Arts autour des années $1270^{93}$. À propos de l'enseignement à la faculté des Arts peu avant 1250, dom Lottin écrivait : «Aux années où nous sommes, le conflit n'a pas encore éclaté entre une théologie pétrie de tradition augustinienne et une philosophie novatrice se réclamant d'Aristote $»^{94}$. Le P. Gauthier lui faisait écho vingt ans plus tard : «Cette curieuse harmonisation de la doctrine d'Aristote avec la doctrine chrétienne était vers 1250 chose courante à la faculté des arts de Paris $\gg^{95}$.

Comme nous le rappelions plus haut, le P. Gauthier a montré que Thomas a bien connu ces commentaires de l'Éthique, mais il n'a eu aucune raison de les critiquer : leurs auteurs sont bien conscients de la distance entre la doctrine authentique d'Aristote en matière d'éthique et les exigences de la tradition augustinienne dont ils sont issus. Ce sont plutôt leurs commentaires qui peuvent avoir inspiré la solutio 1 de Thomas d'Aquin que nous examinons, quand il écrit, à propos d'Aristote et des philosophes passés, «Et sic erat affectio in uita contemplatiua philosophorum » : en effet, ces maîtres ès arts se sont beaucoup occupés

90. Georg WIELAND, «L'émergence de l'éthique philosophique au XIII ${ }^{\mathrm{e}}$ siècle », dans Cl. LAFLeUR, J. CARRIER (éd.), L'Enseignement de la philosophie au XIII siècle. Autour du "Guide de l'étudiant" du ms. Ripoll 109, Turnhout, Brepols (coll. «Studia Artistarum » 5), 1997, p. 173.

91. Voir G. WiELAND, Ethica - Scientia practica..., op. cit., p. 172-177 ; Cl. LAFLEUR, J. CARRIER, «L'enseignement philosophique... », art. cit., p. 409-448. Voir, ci-dessus, la note 77 . 436.

92. Voir Cl. LAFLEUR, J. CARRIER, « L'enseignement philosophique... », art. cit., p. 413-

93. Voir I. Zavattero, «Felicità e principio primo...», art. cit., p. 116, avec la bibliographie citée.

94. Odon LotTIN, Psychologie et morale aux XII et XIII siècles, t. I, Problèmes de psychologie, Louvain - Gembloux, Abbaye du Mont César - J. Duculot, 1942, p. 534, cité par R. A. GAUTHIER, « Arnould de Provence... », art. cit., p. 162.

95. R. A. GAUTHIER, « Arnould de Provence... », art. cit., p. 146. 
de la connaissance amoureuse (cognitio cum affectu) du Primum, comme nous l'avons montré.

Sans négliger l'attention constante que Thomas nourrit pour le travail qui se fait à la faculté des Arts, on doit reconnaître que le contexte des doctrines que Thomas discute dans cette distinction 35 est plutôt théologique: c'est dans une tradition d'enseignement de la sacra doctrina que son commentaire s'insère. En laissant de côté les lieux parallèles de la question chez les prédécesseurs de Thomas, je voudrais attirer l'attention sur la question De fine theologiae de Magister Willermus, datée des années 1230, où sont comparés la fin de la philosophie morale et celle de la théologie ${ }^{96}$. Une écho de cette discussion se trouve aussi dans le prologue du commentaire des Sentences d'Albert le Grand ${ }^{97}$, et, sous une autre forme encore, dans le premier article de la Summa fratris Alexandri, qui reprend des questions plus anciennes ${ }^{98}$. Le but de notre article étant de mettre en évidence la doctrine de Thomas à propos de la contemplation des philosophes, nous ne pouvons étudier de façon étendue l'histoire de la doctrine des rapports entre la philosophie morale et la théologie au XIII siècle. Dans les textes que je viens de mentionner, on constate cependant le lien intrinsèque entre la question de la contemplation des philosophes et la définition de la théologie. C'est un lien que l'on retrouve aussi chez Thomas, comme nous avons pu le montrer en citant le premier article de son prologue sur les Sentences.

\section{III.5. La contemplation amoureuse de Dieu chez Aristote, selon Thomas}

Une autre affirmation, dans l'article du P. Torrell, a retenu notre attention: «Activité strictement intellectuelle, elle [scil. la

96. Magister Willermus, De fine theologiae: «Contemplatio secundum quod circa Deum vel mundum ut cognitum simpliciter tendit ad theologiam non pertinet quoad finem, quia hoc habet paganus et infidelis, sed secundum quod est in eum ut desideratum, ut amatum, ut dilectum, hoc fides est ; et sic finis contemplativae in affectu perficitur, quod concedimus » (éd. Leonardo SILEO, Teoria della scienza theologica. Quaestio de scientia theologiae di Odo Rigaldi e altri testi inediti (1230-1250), t. II, Romae, Pontificium Athenaeum Antonianum [coll. «Studia Antoniana cura Pontificii Athenaei Antoniani edita » 27], 1984, p. 123, 1. 130-135); et encore : «Item, moralis philosophiae finis est felicitas quae est virtus virtutum, virtus perfecta ; et dicitur : "tempora felicem faciunt aeterna beatum", quia beatitudo est supra tempus et ultra tempus ; et beatitudo finis summae moralis scientiae theologiae [...] et ita beatitudo, vita eterna finis est. Solutio. In tertio libro Sententiarum, secundum Augustinum : duplex est perfectio, viae et patriae. In via finis essentialis et propinquus, est iustificatio, in patria beatitudo ; et eadem beatitudo est finis remotus perfectionis viae » (Ibid., p. 124-125, 1. 162-174).

97. Voir Albertus Magnus, In I Sent., d. 1, A-B, a. 4 et 15 (éd. A. Borgnet, t. 25, p. 1819 et 34-37). Ce sont surtout des textes d'Albert qui ont été étudiés par Marie-Dominique CHENU, «Les "philosophes" dans la philosophie chrétienne médiévale », dans Rev. Sc. ph. th. 26 (1937), p. 27-40.

98. Summa fr. Alexandri, Tract. introd., q. 1, c. 1, sol. (éd. Quaracchi, t. I, p. 2). Pour les sources, voir [Victorin DoUCET], Prolegomena, dans Summa fr. Alexandri, éd. Quaracchi, t. IV, p. CCXLVII. 
contemplation] s'achève dans l'immanence, et non dans un objet transcendant. Thomas ne pouvait apprécier trop sévèrement pareil repliement dans un humanisme clos; et c'est pourquoi ici encore il subvertit Aristote : sans doute la béatitude consistera dans un acte de l'intelligence, mais ce n'est que dans l'autre vie (celle qu'Aristote ignorait et que ses disciples stricts du Moyen Âge laissaient de côté) qu'elle s'accomplira ; ici-bas, c'est l'amour qui précède ${ }^{99}$. Le fait que l'amour précède ne subvertit pas la conception aristotélicienne de la contemplation telle que Thomas la comprend, lui qui affirme que même ici-bas « la contemplation consiste essentiellement dans l'acte de la faculté cognitive, la charité étant requise au préalable » : cela pour les saints, alors que pour les philosophes, y compris Aristote (voir, par exemple, la citation de l'Éthique aux notes 66 et 37), l'amor sui vient avant. Cette affirmation n'est rien d'autre que la conclusion de la solutio 1 qui nous retient ici et c'est la doctrine constante de Thomas, reprise dans la Somme de théologie, qui n'a pas manqué de susciter des débats parmi les maîtres postérieurs ${ }^{100}$.

Comme cette dernière citation le montre à l'évidence, le P. Torrell, en interprétant la solutio 1 qui nous retient ici, confond la doctrine de l'aristotélisme intégral, l'interprétation thomiste de la contemplation philosophique (en particulier d'Aristote) et l'interprétation d'Aristote luimême au $\mathrm{XX}^{\mathrm{e}}$ siècle, à laquelle il se réfère à travers le merveilleux livre du P. Gauthier La Morale d'Aristote de $1958^{101}$.

Les trois choses sont déjà bien distinguées dans l'article du P. Gauthier de 1948, où il est aussi question d'humanisme, mais pas d'« humanisme clos ». Le P. Gauthier écrivait :

Nous-mêmes, aujourd'hui, en face de l'interprétation albertino-thomiste de l'Éthique à Nicomaque, nous ne pouvons nous défendre d'un certain malaise. C'est que, si saint Albert et surtout saint Thomas ont bien su voir, dans la doctrine aristotélicienne, ce qui en faisait la valeur éternelle, ils n'ont pas su voir ce qui en faisait le sens historique. Dès lors, leurs

99. Voir la note 65. La solutio 1 du Super III Sent., d. 35, q. 1, a. 2 est aussi interprétée de façon, à notre avis, erronée par François-Xavier PUTTALLAZ, « Thomas d'Aquin, Pierre Olivi. Figures enseignantes de la vie contemplative », dans Christian TrotTMANN (éd.), Vie active et vie contemplative au Moyen Âge et au seuil de la Renaissance, Rome, École française de Rome (coll. «Collection de l'École française de Rome» 423), 2009, p. 371384, spéc. p. 374-376.

100. En plus de $I^{a}-I I^{\text {ae }}$, q. 3, a. 4 (éd. Leon., t. 6, p. 29-30), il faut voir : $I I^{a}-I I^{a e}$, q. 180, a. 4 (éd. Leon., t. 10, p. 427-428 ; voir, ci-dessus, la note 11). À propos de la réception et des critiques de la doctrine thomiste, il faut voir I. CostA, Anonymi Artium Magistri..., op. cit., p. 120-121. Et déjà R. A. GAUTHIER, « Trois commentaires... », art. cit., p. 336.

101. René-Antoine Gauthier, La Morale d'Aristote, Paris, Presses Universitaires de France (coll. «Initiation philosophique » 34), 1958, 19632 , p. 101-104 [réimpr. : Paris, Presses Universitaires de France (coll. «SUP - Le philosophe » 34), 1973, p. 107-110], cité par le P. Torrell à la p. 342. 
tentatives de solution se sont maintenues à un plan strictement notionnel. Ils ont essayé de nous montrer comment un humanisme vrai pouvait s'allier à un christianisme authentique, et, à ce plan, leur pensée est irréprochable et leur effort fut grand ${ }^{102}$.

Cette alliance entre « un humanisme vrai » et « un christianisme authentique » le P. Gauthier l'affirme encore dans un de ses derniers travaux de 1993, avec même un certain lyrisme :

Comme elles sont d'accord pour définir le métier du sage, la sagesse humaine qui parle par Aristote et la sagesse divine qui parle par l'Écriture sont d'accord pour en chanter les louanges. Entre tous les métiers des hommes, il est celui où se trouvent rassemblés le plus de perfection, le plus de grandeur, le plus d'utilité et le plus de joie. Le plus de perfection, parce que s'adonner à l'étude de la sagesse, c'est déjà posséder quelque chose de la béatitude céleste (voir Éth. Nic., X, 7, 1177 a 19-21 et 8, 1178 b 8-32). Le plus de grandeur, parce que faire métier de sage, c'est imiter Dieu et entrer dans son amitié (voir Éth. Nic., X, 9, 1179 a 22-32). Le plus d'utilité, parce que la sagesse est la voie qui nous mène au royaume d'immortalité. Le plus de joie, parce que la fréquentation de la sagesse n'entraîne pas d'amertume et sa société pas de dégoût, mais liesse et allégresse (voir Éth. Nic., X, 7, 1177 a 22-27) ${ }^{103}$.

Ce passage du P. Gauthier se clôt avec la fameuse citation de la Somme contre les Gentils, où Thomas parle de sa tâche de théologien : « sapientis officium » $(S c G$ I, 2). Ainsi le P. Gauthier voit-il en Thomas d'Aquin celui qui a réalisé en lui-même cette alliance de deux sagesses, humaine et chrétienne.

102. « Mais ils n'ont pas cherché à nous expliquer, continue le P. Gauthier, comment cet humanisme-là, celui d'Aristote, avait pu naître dans la Grèce païenne du Iv siècle avant Jésus-Christ, et comment, après l'avènement du Christianisme, il était définitivement périmé. Ce dernier problème, historique et non plus notionnel, les franciscains, eux, l'ont vu. Mais eux ils n'ont pas su voir l'autre problème. Dès lors, la pensée chrétienne était condamnée, en face de l'aristotélisme, aux solutions partielles, aux réponses incomplètes, et un drame était fatal. Ce drame, ce fut l'aristotélisme intégral. Certes, les aristotéliciens intégraux, par le plus profond d'eux-mêmes, appartenaient à la même famille d'esprit que les saint Albert et les saint Thomas, ils avaient ressenti l'attrait de ce qu'il y avait dans l'aristotélisme de philosophie éternelle. Mais en même temps, ils avaient senti l'irrémédiable faiblesse de l'interprétation thomiste » R. A. GAUTHIER, « Trois commentaires... », art. cit., p. 335-336 (italiques dans le texte). L'affirmation selon laquelle « cet humanisme-là [...], après l'avènement du Christianisme, était définitivement périmé » exige des précisions que nous nous réservons de formuler dans une prochaine note sur Thomas d'Aquin et les philosophes. Dans la conclusion de cette étude, nous abordons cependant déjà la question.

103. René-Antoine Gauthier, Saint Thomas d'Aquin, Somme contre les Gentils. Introduction, Paris, Éditions Universitaires (coll. «Philosophie européenne »), 1993, p. 145. Voir ID., «Saint Thomas et l'Éthique à Nicomaque», dans Sancti Thomae de Aquino, Opera Omnia, éd. Leon. t. 48, p. v-XXv. 
Quinze ans après le commentaire des Sentences, quand l'antiaverroïsme deviendra plus militant, Thomas, dans la $I I^{a}-I I^{a e}$, q. 180, a.1, ne reprendra pas l'expression amor sui, mais il ne changera pas sa doctrine et, dans la Q. disp. de uirtutibus, il n'hésitera pas à parler de désir naturel, et il commentera en toute liberté d'esprit le chapitre $13 \mathrm{du}$ livre X de l'Éthique à Nicomaque, cité à la note 49 (notons que ces textes ont été écrits dans la même période). Il commence, ici, par affirmer que la félicité dont il est question est d'ordre spéculatif, par opposition aux félicités d'ordre pratique, et qu'ainsi elle comporte une opération de l'intellect - ce en quoi les hommes et Dieu sont le plus semblables - avec sa double capacité, de connaître la vérité et de l'aimer. Cet amour de l'homme pour le bien de l'intellect lui attire l'amour de Dieu, dont il devient lui-même l'ami, par le don de soi que Dieu lui fait à travers la grâce. Rappelons que, pour Thomas, il n'y a pas le Dieu d'Aristote et le Dieu des chrétiens : c'est le même Dieu ; ce qui diffère, c'est la relation à cette unique divinité.

Ruedi Imbach a bien mis en valeur la notion de contemplation selon le Philosophe, en soulignant sa dimension religieuse; il montre aussi l'« accord parfait » entre Thomas et Aristote sur ce point. En reprenant le commentaire du P. Gauthier à l'Éthique à Nicomaque, R. Imbach écrit : «On peut donner raison à R.-A. Gauthier lorsqu'il affirme qu'il "n'y a pour Aristote de vraie contemplation que de Dieu" »104. Il reprend encore le P. Gauthier, qui écrit : «Faire le Dieu (athanatizeïn) comme Aristote nous y exhorte (1177 b 33), c'est donc le sommet, rarement atteint, de notre vie, c'est ce qui lui donne son sens et ce qui en fait le prix. Ce ne saurait en être la trame quotidienne : il faut, pour la remplir, faire autre chose: faire l'homme (anthrôpeuesthä̈, E.N., X, 8, 1178 b 7) ${ }^{105}$. En considérant cette double tâche de l'homme, Thomas distingue la vie contemplative et la vie active.

Nous pensons avoir montré qu'on ne peut nullement attribuer à Thomas d'Aquin l'idée d'une « déviation » chez Aristote et chez les

104. R. IмBACH, «Vie active et vie contemplative...», art. cit., p. 13, qui reprend R. A. GAuthiter et J. Y. Jolif, « Commentaire », dans ARISTOTE, L'Éthique à Nicomaque, op. cit., t. II, Commentaire, Deuxième partie. Livres VI-X, p. 855. Voir aussi ce qu'écrivait le P. Gauthier à propos de $S c G$, III, 25 et 50 : «Et saint Thomas, même s'il ne le cite pas explicitement, a toujours présent à l'esprit le texte du chapitre 5 du premier livre du traité Des parties des animaux, dans lequel Aristote affirme en termes presque mystiques que "nous désirons connaître" (eidénai pothoumen) les substances divines, à tel point que, comme un amant est plus joyeux d'entrevoir l'objet de son amour que de contempler à loisir le plus beau spectacle du monde, ainsi la moindre connaissance de Dieu est plus béatifiante pour l'esprit que la connaissance la plus achevée des choses d'ici-bas » R. A. GAUTHIER, «Introduction» à Saint Thomas d'Aquin, Contra Gentiles, Paris, P. Lethielleux, 1961, p. 113.

105. R.-A. GaUthIER, La Morale d'Aristote, op. cit., p. 106, [Paris, 1973, p. 112], repris dans R. IMBACH, «Vie active et vie contemplative... », art. cit., p. 15. 
maîtres ès arts d'avant 1255 dans leur compréhension de la contemplation philosophique ${ }^{106}$. Bien au contraire, Thomas est imbu des commentaires de l'Éthique d'Aristote élaborés pendant la première moitié du XIII ${ }^{\mathrm{e}}$ siècle. Ces commentaires, qui cherchent à harmoniser la doctrine du Philosophe avec la doctrine chrétienne, ont certainement contribué à la formation de l'interprétation «albertino-thomiste » de l'Éthique, dont parle le P. Gauthier (voir, ci-dessus, la note 102). En même temps toutefois, Thomas s'éloigne de cette tentative d'harmonisation qui vise à élaborer une «théologie éthique » à base aristotélicienne (voir ci-dessus, la note 90). Soucieux de bien comprendre la vraie doctrine d'Aristote sur le bonheur, Thomas prend soin de distinguer la position d'Aristote de celles d'autres philosophes, à commencer par Platon, dès son commentaire du IVe livre des Sentences, où il reconnaît également qu'Aristote «n'avait ni affirmé ni nié la béatitude qui est après la mort $\gg{ }^{107}$. Thomas, plutôt que dénoncer une déviation de celui-ci par rapport à la vérité, entend s'emparer de la doctrine aristotélicienne et se situer dans la droite ligne de celle-ci pour élaborer sa propre doctrine de la contemplation des saints. Son interprétation d'Aristote le lui permet ${ }^{108}$.

106. Voir J.-P. TORRELL, « Philosophie et théologie... », art. cit., p. 342 (cité, ci-dessus, à la note 65). Dans son commentaire de la solutio 1 qui nous retient, le P. Torrell écrit encore : «Comme tel ce passage du troisième livre des Sentences est un texte rare, unique peut-être chez Thomas, et on ne réduira pas à cela ce qu'il pense de la recherche philosophique » (ibid., p. 343 ; cité à la note 65 ). Si l'on interprète ce texte de Thomas avec exactitude, dans le mouvement même de la solutio où il se trouve et sans vouloir lui faire dire ce qu'il ne dit pas, on constate que ce passage est en parfaite harmonie avec la doctrine constante de Thomas sur la contemplation des philosophes. Il n'a rien de rare ni d'unique.

107. Voir In IV Sent., d. 49, q. 1, a. 1, sol. 4 (cité à la note 119). Dans ce texte, l'interprétation que Thomas donne de la doctrine d'Aristote sur le bonheur n'est pas naïve : le P. Gauthier la rejoint, dans son article de 1948 : «Concluons : Pourquoi Aristote n'a-t-il pas parlé du bonheur de l'autre vie ? Tout simplement parce que ce n'était pas de son sujet. Il avait, en effet, légitimement et sagement limité le sujet de son Éthique au bonheur imparfait, tel qu'il peut se trouver en cette vie» R. A. GAUTHIER, «Trois commentaires...», art. cit., p. 264, italiques dans le texte. Pour les autres positions philosophiques évaluées par Thomas, voir In IV Sent., d. 49, q. 2, a. 1 (éd. Vivès, t. 11, p. 481-487).

108. A propos de la complétude de l'acte de contemplation chez Aristote, voir R. A. GauthiER et J. Y. Jolif, « Commentaire », dans ARISTOTE, L'Éthique à Nicomaque, op. cit., t. II, Commentaire, Deuxième partie. Livres VI-X, p. $856:$ « [...] la contemplation aristotélicienne ne saurait être que strictement intellectuelle : son ambition est d'achever le sujet qu'est l'intellect, non de le dépasser pour atteindre, au-delà de lui, un objet transcendant. [...] Cependant, dans l'Éthique même, apparaît, quoiqu'incidemment, l'idée que ce qui fait de la contemplation l'activité la plus haute, ce n'est pas seulement la perfection de son sujet, l'intellect, mais aussi la perfection de son objet $(7,1177$ a 20-21) ».

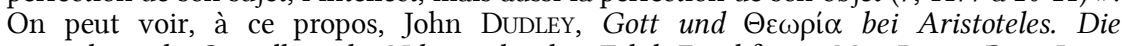
metaphysische Grundlage der Nikomachischen Ethik, Frankfurt a. M. - Berne, Peter Lang (coll. «Europäische Hochschulschriften. Reihe 20, Philosophie » 89), 1982 ; ID., « La contemplation $(\theta \varepsilon \omega \rho i \alpha)$ humaine selon Aristote », RPhL 80 (1982), p. 387-423, spéc. 
Ce que nous venons d'écrire à propos du Super III Sent., d. 35, q. 1, a. 2 , solutio 1 , nous permet aussi de comprendre la solutio 3 de ce même article. Thomas commence par y rappeler l'affirmation de la solutio 1 : «la vie contemplative des saints présuppose l'amour de ce que l'on contemple, et procède de lui » et, sur cette base, il soutient qu'il est nécessaire que leur vie contemplative « porte sur la contemplation de ce que l'on aime le plus, c'est-à-dire Dieu». Il ajoute toutefois, immédiatement à la suite : «c'est pourquoi la contemplation consiste principalement dans l'opération de l'intellect portant sur Dieu », en posant une distinction formelle, dans cette opération de l'intellect, entre la considération intellectuelle et l'acte d'amour ${ }^{109}$. Et c'est également en posant une distinction formelle entre la considération intellectuelle et la dilection amoureuse que Thomas, à la fin de la solutio 3 , dit que la contemplation des philosophes est semblable à celle des saints ${ }^{110}$. En effet, la distinction entre les deux concerne seulement l'ordre naturel et l'ordre surnaturel, et non l'acte même de contempler qui a pour objet Dieu. Selon Thomas, l'acte de contemplation des philosophes, en dehors de la foi chrétienne, ne peut surgir que de l'amour de soi, qui est la forme et la racine de toute amitié (voir $I I^{a}-I I^{a e}$, q. 25, a.4, resp., cité à la note 37). La contemplation des saints, en revanche, surgit de l'amour de charité, qui leur est accordé par Dieu, et informe l'amour de soi, en leur permettant d'aimer Dieu et soi-même dans la charité.

p. 409-411. On lira aussi, non sans profit, l'ouvrage original de Denis J. M. BRADLEY, Aquinas on the Twofold Human Good. Reason and Human Happiness in Aquinas's Moral Science, Washington, D. C., The Catholic University of America Press, 1997.

109. Cajetan exprimait ainsi cette distinction : « [Vita contemplativa] formaliter est in intellectu, quoniam est ipsa contemplatio, quae est actus intellectus. Causaliter autem et terminative est in affectu » THOMAS DE VIO, card. CAIETANUS, Commentaria in Summam theologicam, $I^{\mathrm{a}}$-II ${ }^{\mathrm{ae}}$, q. 180, a. 1 (cité d'après l'éd. Leon., t. 10, p. 425a).

110. «Ad tertiam quaestionem dicendum, quod vita contemplativa sanctorum praesupponit amorem ipsius contemplati, ex quo procedit. Unde cum vita contemplativa consistat in operatione quam quis maxime intendit, oportet quod sit circa contemplationem maxime amati: hoc autem Deus est: unde principaliter consistit in operatione intellectus circa Deum; unde Gregorius, super Ezech., dicit, quod contemplativa vita ad solum videndum principium anhelat, scilicet Deum. Nihilominus tamen et contemplativus considerat alia, inquantum ad Dei contemplationem ordinantur sicut ad finem, puta creaturas, in quibus admiratur divinam maiestatem et sapientiam et beneficia Dei, ex quibus inardescit in eius amorem; et peccata propria, ex quorum ablutione mundatur cor, ut Deum videre possit. Unde et nomen contemplationis significat illum actum principalem, quo quis Deum in seipso contemplatur; sed speculatio magis nominat illum actum quo quis divina in rebus creatis quasi in speculo inspicit. Et similiter etiam felicitas contemplativa, de qua philosophi tractaverunt, in contemplatione Dei consistit: quia, secundum Philosophum, consistit in actu altissimae potentiae quae in nobis est, scilicet intellectus, et in habitu nobilissimo, scilicet sapientia, et etiam obiecto dignissimo, quod Deus est. Unde enim philosophi ultimum tempus vitae suae reservabant, ut dicitur, ad contemplandum divina, praecedens tempus in aliis scientiis expendentes, ut ex illis habiliores fierent ad considerandum divina » In III Sent., d. 35, q. 1, a. 2, sol. 3 (éd. M. F. Moos, p. 1179-1180, n. 42-44 ; les italiques sont de nous). 


\section{PARTICULARITÉS DE LA CONCEPTION ARISTOTÉLICIENNE DE LA FÉLICITÉ CONTEMPLATIVE SELON THOMAS D'AQUIN}

En commentant le sermon sur la montagne selon l'Évangile de Matthieu, Thomas d'Aquin analyse les différentes conceptions de la béatitude; il montre les défauts de chacune et présente enfin celle du Philosophe : «D'autres [disent que la béatitude parfaite] consiste dans les vertus de la vie contemplative, c'est-à-dire dans la contemplation des réalités divines et intelligibles, comme Aristote. Mais toutes ces opinions sont fausses, quoique non pour la même raison. C'est pourquoi le Seigneur les rejette toutes ${ }^{111}$. Et voici pourquoi le Seigneur refuse la conception aristotélicienne de la béatitude : «Quant à l'opinion de ceux qui disent que la béatitude consiste dans la contemplation des réalités divines, le Seigneur la rejette quant au temps, car autrement elle est vraie: la félicité ultime consiste bien dans la vision du suprême intelligible, Dieu, et c'est pourquoi il dit : Ils verront... ${ }^{112}$. Ainsi, selon Thomas, la conception aristotélicienne de la béatitude est adéquate («vera est ») à celle de la conception révélée, sauf pour un seul élément : «quantum ad tempus». Que veut dire Thomas par cette dernière expression ? On peut proposer, semble-t-il, deux interprétations : ou bien Thomas entend affirmer qu'Aristote et certains autres philosophes ont dit que la béatitude parfaite est seulement de cette vie (ce en quoi ils se seraient trompés); ou bien il remarque seulement que ces philosophes, qui ont su déterminer avec exactitude la nature de la béatitude, n'ont pas été capables d'indiquer quand (en quel «tempus») celle-ci se réalise de manière parfaite. Si on lit la suite de la lectio, «Certains font consister la vision de Dieu dans la contemplation de la vérité ici-bas ; le Seigneur au contraire la promet dans la Patrie : Heureux les cours purs ${ }^{113}$, on pourrait penser que dans ce texte Thomas reproche à la conception aristotélicienne, partagée par d'autres auteurs, d'avoir affirmé que la béatitude parfaite est possible en cette vie. L'analyse des autres textes montre cependant que Thomas n'a jamais attribué cette idée à Aristote.

Pour bien interpréter ce passage du commentaire sur l'Évangile de Matthieu, considérons les différentes affirmations de Thomas sur la

111. « [...] Alii [dicunt quod perfecta beatitudo consistit] in virtutibus contemplativae vitae, scilicet divinorum et intelligibilium, sicut Aristoteles. Omnes autem istae opiniones falsae sunt : quamvis non eodem modo. Unde Dominus omnes reprobat » In Matth., 5, lect. 2 (éd. Marietti, 1951, n. 404).

112. « Illorum autem opinio qui dicunt quod beatitudo consistit in contemplatione divinorum, reprobat Dominus quantum ad tempus, quia alias vera est, quia ultima felicitas consistit in visione optimi intelligibilis, scilicet Dei, unde dicit Videbunt »Ibid. (n. 408).

113. «Aliqui ponunt visionem Dei in contemplatione veritatis in via; Dominus autem promittit in patria ; unde beati mundo corde etc. » Ibid. (n. 412). 
façon dont le Philosophe parle du bonheur ultime de l'homme. Dans le commentaire du De Trinitate de Boèce, Thomas exprime de façon très complète sa doctrine : il parle des objets de la contemplation (Dieu et les substances séparées), des moyens par lesquels nous les connaissons (l'habitus scientiae, ici-bas, et le lumen gloriae, dans la Patrie), des différentes connaissances que nous pouvons acquérir (le quia est et certaines perfections des objets ici-bas, leur quiditas dans la Patrie). Il en résulte donc une félicité parfaite dans la Patrie et une imparfaite ici-bas: c'est de cette dernière qu'a parlé le Philosophe ${ }^{114}$. Thomas se borne ici à une référence générique à la doctrine aristotélicienne sur le bonheur de l'homme, en incluant parmi les objets de contemplation les substances séparées et présentant les sciences spéculatives plutôt comme des moyens pour connaître leur existence et leurs perfections.

Dans la Somme contre les Gentils (III, 48), postérieure au Super Boetium, en traitant le thème « quod ultima hominis felicitas non sit in hac vita », Thomas, s'il s'abstient d'affirmer qu'Aristote supposait une béatitude dans une vie future, il explique cependant qu'Aristote dit qu'en cette vie l'homme n'atteint pas la félicité parfaitement, mais «suo modo $\gg 115$. Thomas compare cependant les positions d'Alexandre d'Aphrodise et d'Averroès avec celle d'Aristote et il précise que celui-ci n'envisageait pas la félicité en cette vie dans le contact avec les substances séparées, mais seulement dans l'exercice des sciences spéculatives et de l'habitus de sagesse, comme il l'avait dit dans le Super Boetium. Dans ces deux ouvrages Thomas ne change donc pas son interprétation de la doctrine du Philosophe.

Dans la I Pars, q. 62, a.1, Thomas affirme qu' « Aristote a dit que la contemplation la plus parfaite par laquelle l'intelligible suprême, c'est-àdire Dieu, puisse, en cette vie, être contemplé par l'homme, est la félicité suprême de l'homme » ${ }^{116}$. Pas plus que précédemment il n'exprime de réserves à l'égard de cette affirmation: il faut donc l'entendre en continuité avec la $S c G$, III, 48. D'autre part, dans ce texte, Thomas traite de la double béatitude de l'ange, naturelle et surnaturelle, et en instituant

114. « [...] duplex est felicitas hominis : una imperfecta, que est in uia ; de qua loquitur Philosophus, et hec consistit in contemplatione substantiarum separatarum per habitum sapientie, imperfecta tamen, et talis qualis in uia est possibilis, non ut sciatur ipsarum quiditas. Alia est perfecta in patria, in qua ipse Deus per essentiam uidebitur et alie substantie separate : set hec felicitas non erit per aliquam scientiam speculatiuam, set per lumen glorie »In Boet. De Trin., q. 6, a. 4, ad 3 (éd. Leon., t. 50, p. 171, 1. 176-185); voir aussi la responsio (Ibid., p. 170, l. 136-146).

115. Voir ScG, III, 48 (éd. Leon., t. 14, p. 131, 1. 42b-51b, cité ci-dessous à la note 125).

116. «Unde et Aristoteles perfectissimam hominis contemplationem, qua optimum intelligibile, quod est Deus, contemplari potest in hac vita, dicit esse ultimam hominis felicitatem. Sed super hanc felicitatem est alia felicitas, quam in futuro expectamus, qua videbimus Deum sicuti est » I Pars, q. 62, a. 1, resp. (éd. Leon., t. 5, p. 110) ; voir aussi un autre passage de cette responsio cité à la note 139, avec notre explication. 
un parallèle entre les deux béatitudes de l'ange et celles de l'homme, il veut montrer que la contemplation dont a parlé aussi le Philosophe est la suprême (ultimam) que l'homme puisse atteindre en cette vie.

Dans la $I^{a}-I I^{a e}$, q. 3, a. 7, resp., Thomas, en parlant de la contemplation d'ici-bas comme de la béatitude céleste, écrit : « il reste que Dieu seul est la vérité par essence et que le contempler rend parfaitement bienheureux. Rien n'empêche de voir dans la contemplation des anges une certaine béatitude imparfaite, plus profonde que celle que procurent les sciences spéculatives ${ }^{117}$; nous retrouvons ici la doctrine du Super Boetium, où Thomas faisait, de plus, référence à Aristote ; remarquons que dans l'ad 2 de ce même article, Thomas parle aussi du rôle de l'ange comme instrument (minister) de la contemplation de l'homme.

Le Super Matthaeum, dont l'interprétation nous pose problème, date du deuxième enseignement à Paris. On le date des années 1269-1270, en sorte qu'il serait contemporain de la $I^{a}-I I^{a e}$, mais un peu antérieur au Super Ethicam. Les textes que nous venons d'analyser ne comportent aucune réserve, de la part de Thomas, à propos de la doctrine aristotélicienne de la béatitude de l'homme. Le reproche du Super Matthaeum, selon lequel plusieurs philosophes, dont Aristote, se seraient trompés 《quant au temps (quantum ad tempus)» de la béatitude parfaite, peut faire penser que Thomas leur reproche d'avoir fait « consister la vision de Dieu dans la contemplation de la vérité ici-bas » (voir note 113), mais Thomas ne formule nulle part ce reproche à propos d'Aristote.

En commentant le II livre des Sentences, dans l'hiver 1253 ou 1254, Thomas avait utilisé l'expression «selon ce temps (secundum tempus illud) » pour désigner la contemplation imparfaite en cette vie, dont parle aussi le Philosophe au premier livre de l'Éthique ${ }^{118}$. Ensuite, dans le commentaire du IVe livre des Sentences, qui date de l'été 1254 ou 1255 , Thomas écrivait qu'Aristote «n'avait ni affirmé ni nié » la béatitude qui est après cette vie ${ }^{119}$. Enfin, dans le commentaire de l'Éthique, qui est de

117. «Unde relinquitur quod solus Deus sit veritas per essentiam, et quod eius contemplatio faciat perfecte beatum. Aliqualem autem beatitudinem imperfectam nihil prohibet attendi in contemplatione angelorum ; et etiam altiorem quam in consideratione scientiarum speculativarum » $I^{a}-I^{a e}$, q. 3, a. 7, resp. (éd. Leon., t. 6, p. 35).

118. « Augustinus nominat beatitudinem illam uisionem Dei naturalem. Per quam tamen non erant beati simpliciter, cum maioris perfectionis capaces essent, set secundum quid, scilicet secundum tempus illud. Sicut et Philosophus in I Etichorum dicit aliquos in hac vita beatos non simpliciter set ut homines » In II Sent., d. 4, a. 1, ad 1 (texte provisoire de la Commission Léonine, préparé par P.-M. Gils et A. Oliva; les italiques sont de nous ; voir éd. P. MANDONNET, p. 134).

119. «Et ideo simpliciter concedimus ueram hominis beatitudinem esse post hanc uitam. Non negamus tamen, quin aliqua beatitudinis participatio in hac uita esse possit, secundum quod homo est perfectus in bonis rationis speculatiue principaliter et practice secundario. Et de hac felicitate Philosophus in libro Eth. determinat, aliam que est post 
peu postérieur au Super Matthaeum, devant élucider l'expression d'Aristote «bienheureux comme des hommes », Thomas l'interprète comme si Aristote désignait une béatitude naturelle que l'homme atteint en cette vie. Toutefois, puisque cette béatitude ne correspond pas complètement (simpliciter) aux capacités de l'homme lui-même, il faut supposer une félicité parfaite, après cette vie ${ }^{120}$. Dans ce texte, il me semble que Thomas ne se limite pas à vouloir montrer que sa doctrine (et la doctrine révélée) n'est pas contraire à la doctrine d'Aristote, mais il veut montrer que la cohérence même de la doctrine d'Aristote postule cette actuation post mortem de la béatitude (le medium de la preuve étant l'axiome non est inane naturae desiderium).

Arrivé à ce point, après avoir mis en lumière la cohérence de l'enseignement de Thomas dans des textes écrits de sa propre main ou dictés, il semble possible de trancher sur le sens du reproche du Super Matthaeum, issu de notes d'auditeurs et dont le vocabulaire est moins contrôlé. Plutôt que d'une condamnation (reprobat), il s'agit d'un constat d'ignorance. Aristote, comme d'autres, n'a parlé que de la béatitude que l'homme peut atteindre «selon le temps» de cette vie et selon la perfection dont l'homme est capable par ses propres forces, suo modo. La

hanc uitam, nec asserens nec negans » In IV Sent., d. 49, q. 1, a. 1, sol. 4 (texte provisoire de la Commission Léonine, préparé par Winfried FAUSER ; voir éd. Vivès, t. 11, p. 464). Nous ne discutons pas dans cette étude les différentes affirmations de Thomas à propos d'une béatitude après la mort selon les philosophes : en plus de In II Sent., d. 4, a. 1, ad 1 (cité à la note précédente), il faut voir d. 18, q. 2, a. 2, resp. : « [...] a pluribus philosophis ponitur ultimam felicitatem hominis esse in continuatione intellectus possibilis, quo intelligimus, ad intelligentiam agentem, siue talis continuatio sit in uita secundum quosdam, siue post hanc uitam secundum alios » (texte provisoire de la Commission Léonine, préparé par P.-M. GILS et A. Oliva; les italiques sont de nous; voir éd. P. MANDONNET, p. 464); et aussi $I^{a}-I I^{a e}$, q. 3, a. 6 et 7 (éd. Leon., t. 6, p. 32-36). Sur ce point voir : R. A. GAUTHIER « Trois commentaires... », art. cit., p. 251-264, notamment les passages que nous citons aux notes 107 et 122 .

120. « Si autem ita, beatos dicemus vivencium quibus existunt et existent que dicta sunt, beatos autem ut homines » ARISTOTELES, Ethica Nicomachea, I, 1101a20-21, transl. R. Grosseteste, rec. pura (AL XXVI.1-3, p. 158, l. 6-7). Voici le commentaire de Thomas In Ethic. Nic., I (1101a20-21), lect. 16: «Et si ita est ut dictum est, <beatos dicemus> illos de numero viventium in hac vita quibus existunt in praesenti et existent in futuro ea quae dicta sunt; sed quia ista videntur non usquequaque attingere ad condiciones supra de felicitate positas, subdit quod tales dicimus beatos sicut homines, qui in hac vita mutabilitati subiecta non possunt perfectam beatitudinem habere. Et quia non est inane naturae desiderium, recte aestimari potest quod reservatur homini perfecta beatitudo post hanc vitam. Ultimo epilogat dicens quod de his in tantum dictum sit » (éd. Leon., t. 47-1, p. 60, 1. 215-226 ; les italiques sont de nous); voir également : In Ethic. Nic., X (1179a22), lect. 13 (éd. Leon., t. 47-2, p. 595, 1. 137-144, cité à la note 63). Comme nous l'avons déjà fait remarquer, le P. Gauthier commente ainsi l'expression beatos ut homines : «Voilà l'aveu, pense saint Thomas : le philosophe sent bien que le concept de béatitude tel qu'il l'a lui-même défini, ne peut se réaliser parfaitement ici-bas ; il reconnaît donc lui-même que le bonheur de cette vie ne saurait être le bonheur parfait mais seulement un bonheur imparfait » R. A. GAUTHIER, « Trois commentaires... », art. cit., p. 251. 
conception aristotélicienne ne dit en revanche rien de ce que le Seigneur a révélé en disant, au futur, Ils verront Dieu, dans la béatitude céleste ${ }^{121}$.

\section{LA NÉCESSITÉ DE LA DOCTRINA THEOLOGIE EN PLUS DE LA PHILOSOPHIE : LE PROBLĖME DE LA VISIO SVMME CAVSE}

\section{V.1 Une connaissance directement inspirée par la lumière divine}

En traitant de la relation entre philosophie et théologie, le raisonnement de Thomas se meut encore sur un plan éminemment philosophique. Nous nous référons à un texte qui, parmi d'autres, met bien en évidence la fonction «supplétive» de la sacra doctrina par rapport à la philosophie, mais surtout la continuité « essentielle » entre ces deux sciences.

Le chapitre 48 du livre III de la $S c G$, «Quod ultima hominis felicitas non sit in hac uita » (titre de la main de Thomas, dans Vat. lat. 9850, f. 49v, mg. inf.), commence par rappeler certaines données des chapitres précédents, où il a été démontré que la fin ultime de l'homme ne consiste pas dans une connaissance «générique» de Dieu, ni dans la connaissance qu'on peut en obtenir par voie de démonstration, selon les sciences spéculatives, ni même dans la connaissance par la foi. Il répète que cette félicité doit consister dans la connaissance de Dieu la plus parfaite pour l'homme, et il s'applique ensuite à montrer que celle-ci n'est pas réalisable en cette vie. Les raisons qu'il apporte sont premièrement la mutabilité de l'intelligence et de la volonté de l'homme en cette vie, qui l'empêchent de se reposer dans la fin. Il faut aussi prendre en compte la mort, qui, en tronquant cette vie, mettrait non seulement fin à cette félicité, mais la mêlerait de tristesse.

Les raisons énumérées jusqu'ici constituent des empêchements, qui, rappelons-le, sont communs tant à la contemplation philosophique qu'à celle selon la foi, comme Thomas l'a répété au début du chapitre.

Mais, au milieu du chapitre, Thomas fait une objection qui lui permet ensuite de changer le registre de son argumentation. Il objecte qu'en réalité seules les substances séparées possèdent une nature intellectuelle « parfaite », qui peut donc atteindre une félicité parfaite, adéquate à leur

121. La continuité entre la contemplation d'ici-bas et celle de la Patrie est exprimée de façon frappante dans un autre texte à peine postérieur au Super Matthaeum : «In hac etiam vita, purgato oculo per donum intellectus, Deus quodammodo videri potest» $I^{a}-I^{a e}$, q. 69, a. 2, ad 3 (éd. Leon., t. 6, p. 457). Comme me l'a fait remarquer aussi Luca Bianchi, dans les textes où Thomas compare béatitude imparfaite et parfaite, il use parfois de catégories temporelles, en parlant de la béatitude d'ici-bas, même philosophique, comme d'un commencement qui sera achevé dans la Patrie, ou comme une anticipation de celle de la Patrie, et parfois il se sert plutôt de la catégorie de la participation, qui comporte un prius ou primum et un post, comme par exemple dans $I^{a}-I I^{a e}$, q. 3, a. 6 et 7 (éd. Leon., t. 6, p. 32-36). 
nature. L'homme, à cause de sa nature intellectuelle qui procède par la recherche («per quendam inquisitionis motum »), ne pourra jamais atteindre une telle félicité en cette vie, mais seulement une félicité imparfaite et par participation ${ }^{122}$. C'est là, continue Thomas, ce qui semble avoir été l'opinion d'Aristote, quand il affirme que ceux qui parviennent, en cette vie, à obtenir une félicité parfaite de ce genre peuvent être dit « beatos ut homines, quasi non simpliciter ad felicitatem pertingentes, sed modo humano $»^{123}$.

Par les raisons qui suivent, Thomas s'emploie à montrer que cette réponse n'invalide pas les données précédemment acquises concernant l'impossibilité d'atteindre en cette vie le bonheur parfait. Thomas va insister sur la nécessité intrinsèque à l'homme de connaître la vérité selon son degré le plus haut, le seul qui puisse satisfaire le désir naturel de connaissance de l'homme et, en même temps, actualiser parfaitement sa faculté intellectuelle ${ }^{124}$. Il est important de remarquer que les arguments qui fondent le raisonnement de Thomas sont empruntés explicitement au Philosophe, comme pour souligner qu'il conçoit son raisonnement comme un prolongement cohérent de la doctrine aristotélicienne.

122. Après cette phrase on lit la suivante, rayée par Thomas : «Vnde non est necessarium ultimam hominis felicitatem esse in uita ista» (Autographa deleta, éd. Leon., t. 14, « Appendix », p. 16*, 1. 18a-19a ; voir Vat. lat. 9850, f. 49vb, 1. 53-54). À propos de la double béatitude des anges, voir I Pars, q. 62, a. 1, resp. (éd. Leon., t. 5, p. 110).

123. ScG, III, 48 (éd. Leon., t. 14, p. 131, 1. 44a-45a). Suivent immédiatement seize lignes, supprimées par Thomas, où il pose la question de savoir si Aristote a toujours maintenu cette opinion ou s'il a supposé aussi une félicité pour la vie future, comme l'affirme un commentateur grec du livre X de l'Éthique: Thomas ne veut cependant pas traiter de la question à cet endroit, ce qui le conduirait à étudier le problème de l'immortalité de l'âme chez Aristote, et l'éloignerait de son propos : voir Autographa deleta, éd. Leon., t. 14, « Appendix », p. 16*, 1. 22a-40a ; voir Vat. lat. 9850, f. 49vb, 1. $60-$ f. 50ra, l. 12.

124. Les textes ne manquent pas où Thomas a exprimé clairement et vigoureusement sa pensée : «Praeterea. Cuiuslibet effectus cogniti naturaliter homo scire causam desiderat. Intellectus autem humanus cognoscit ens universale. Desiderat igitur naturaliter cognoscere causam eius, quae solum Deus est, ut in secundo probatum est. Non est autem aliquis assecutus finem ultimum quousque naturale desiderium quiescat. Non sufficit igitur ad felicitatem humanam, quae est ultimus finis, qualiscumque intelligibilis cognitio, nisi divina cognitio adsit, quae terminat naturale desiderium sicut ultimus finis. Est igitur ultimus finis hominis ipsa Dei cognitio. [...] Huic etiam sententiae Aristoteles in ultimo Ethicorum, concordat, ubi ultimam hominis felicitatem dicit esse speculativam, quantum ad speculationem optimi speculabilis »ScG, III, 25 (éd. Leon., t. 14 , p. $67,1.24 \mathrm{a}-2 \mathrm{~b}$ et $1.30 \mathrm{~b}-33 \mathrm{~b})$; «Si igitur intellectus rationalis creaturae pertingere non possit ad primam causam rerum, remanebit inane desiderium naturae. Unde simpliciter concedendum est quod beati Dei essentiam videant»I Pars, q. 12, a. 1 (éd. Leon., t. 4, p. 115). Voir Gian Carlo GarfagninI, «Tommaso tra felicità e beatitudine », dans Maria BetTEtinI, Francesco D. PAPARElla (éd.), La felicità nel medioevo, Louvain-la-Neuve (coll. «Fédération Internationale des Instituts d'Études Médiévales. Textes et études du Moyen Âge » 31), 2005, p. 313-323. 
Thomas vient de prouver qu'en cette vie il est impossible à l'homme d'atteindre son parfait bonheur (Aristote lui aussi en convient). Restent alors deux possibilités : ou bien il faut admettre qu'il ne l'atteint jamais, ou bien il faut reconnaître qu'il l'atteint dans une vie future. Thomas s'emploie alors à démontrer, au moyen de deux raisonnements par l'absurde, qu'il n'est pas raisonnable que l'homme n'atteigne jamais son bonheur; puisqu'il ne peut l'atteindre en cette vie, ce sera donc dans la vie future.

Thomas, qui avait déjà pris en considération le cas des substances séparées, commence ici par l'autre bout de la hiérarchie des êtres créés et remarque que l'homme est supérieur aux animaux aussi bien qu'aux êtres inanimés. Or, aussi bien ces êtres que les animaux atteignent en cette vie leur bonheur parfait. Il faut donc que l'homme l'atteigne lui aussi ; ce sera par conséquent après cette vie.

Le deuxième raisonnement est fondé sur un passage du De celo d'Aristote : il est impossible que le désir naturel de l'homme soit vain, parce que «natura nihil facit frustra ». Si donc ce désir ne s'accomplit pas en cette vie, il faut qu'il se réalise après cette vie.

Les deux arguments qui suivent concluent encore qu'il est impossible que l'homme atteigne en cette vie sa fin ultime. Le premier considère que quelqu'un qui est en mouvement vers la perfection ne l'a pas atteinte. C'est la situation dans laquelle l'homme se trouve en cette vie; donc il n'atteint pas, en cette vie, la perfection. Et encore : tout ce qui est en puissance a pour fin (tendit) de devenir en acte. Notre intellect est en puissance ad omnia. Or cette actualité parfaite, l'intellect ne peut pas l'atteindre par les sciences spéculatives, en cette vie ; donc il ne peut pas, en cette vie, atteindre sa perfection.

Pour cette raison, écrit Thomas, Alexandre et Averroès ont dit que la perfection de l'homme ne peut pas être dans la contemplation des sciences spéculatives, mais «per continuationem cum substantia separata », qu'ils croyaient possible en cette vie. Tandis qu'Aristote, qui a bien vu qu'en cette vie ce sont les sciences spéculatives qui nous font connaître la vérité, «posuit hominem non consequi felicitatem perfectam, sed suo modo ${ }^{125}$. Thomas continue :

125. « Propter has autem et huiusmodi rationes, Alexander et Averroes posuerunt ultimam hominis felicitatem non esse in cognitione humana, quae est per scientias speculativas, sed per continuationem cum substantia separata, quam esse credebant possibilem homini in hac vita. Quia vero Aristoteles vidit quod non est alia cognitio hominis in hac vita quam per scientias speculativas, posuit hominem non consequi felicitatem perfectam, sed suo modo » $S c G$, III, 48 (éd. Leon., t. 14, p. 131, 1. 42b-51b). Thomas discute cette doctrine dans ScG, III, 41 et 42 (éd. Leon., t. 14, p. 102-104 et 106108). 
L'on voit par là combien grande était l'angoisse dont souffraient, à cause de cet état de choses, ces grands esprits. Nous en serons libérés si, comme on l'a démontré plus haut, nous tenons que l'homme peut accéder après cette vie à la vraie félicité, l'âme humaine étant immortelle [...]. La félicité ultime de l'homme consistera dans la connaissance de Dieu qu'a l'esprit humain après cette vie, connaissance semblable à celle qu'en ont les substances séparées ${ }^{126}$.

Il faut remarquer premièrement que Thomas formule sa conclusion sur la base de ce qu'il a démontré plus haut: il tient à prouver une nécessité d'ordre rationnel, fondée sur la doctrine du Philosophe, qu'il complète d'une donnée capitale. Selon ce qu'il écrit dans le passage supprimé, c'est cette donnée qui a probablement empêché le Philosophe d'arriver à placer après cette vie le bonheur parfait de l'homme : il s'agit de la doctrine de l'immortalité de l'âme humaine individuelle.

L'affirmation «Erit igitur ultima felicitas hominis in cognitione Dei quam habet humana mens post hanc vitam » ne surprend pas si l'on considère qu'elle sort de la plume d'un théologien. Ce sont les raisons et la façon de le démontrer qui nous surprennent: Thomas veut le faire « en philosophe ». Nous nous expliquons immédiatement.

Tout ce que nous avons exposé jusqu'ici permet de comprendre en quel sens on peut parler d'une duplex contemplatio Dei (In I Sent., prol., a.1, 1. 32-38). En effet, la contemplation de Dieu, à laquelle toute connaissance philosophique est de soi ordonnée, n'a pas d'autre fin que la connaissance de l'essence de Dieu. C'est le sens de $S c G$ III, 48, que nous avons commenté, et Thomas est explicite et toujours ferme sur ce point, comme par exemple dans $S c G$ III, 50, où il est question du désir naturel que les substances séparées ont de voir Dieu :

Nous ne pensons pas connaître telle chose si nous ne connaissons pas sa substance ; c'est pourquoi le principal de la connaissance d'une chose est la connaissance de ce qu'elle est. [...] Donc sachant que quelque chose est, par nature on désire savoir ce qu'elle est, c'est-à-dire connaître sa substance. Le désir naturel de savoir, quant à la connaissance de Dieu, n'est donc pas satisfait par le seul fait de savoir que Dieu est ${ }^{127}$.

126. «In quo satis apparet quantam angustiam patiebantur hinc inde eorum preclara ingenia. A quibus angustiis liberabimur si ponamus, secundum probationes praemissas, hominem ad veram felicitatem post hanc vitam pervenire posse, anima hominis immortali existente [...]. Erit igitur ultima felicitas hominis in cognitione Dei quam habet humana mens post hanc vitam, per modum quo ipsum cognoscunt substantiae separatae »ScG, III, 48 (éd. Leon., t. 14, p. 131, 1. 52b - p. 132, 1. 4a ; les italiques sont de nous).

127. « [...] non enim arbitramur nos aliquid cognoscere si substantiam eius non cognoscamus ; unde et praecipuum in cognitione alicuius rei est scire de ea quid est. [...] Ergo et cognoscentes an aliquid sit [est éd. 1.29a] naturaliter scire desiderant quid est ipsum, quod est intelligere eius substantiam. Non igitur quietatur naturale sciendi 
Si cette contemplation qui s'arrête au quia est imparfaite, elle l'est par rapport à la connaissance de Dieu dans son essence. Thomas le dit clairement dans l'a. $1 \mathrm{du}$ prologue des Sentences: «Il est une autre contemplation de Dieu, par laquelle on le voit immédiatement en son essence » (voir la note 7). C'est par rapport à cette contemplation que la contemplation du Philosophe est imparfaite, parce qu'en cette vie, par les seules capacités naturelles, la possibilité n'est pas donnée de dépasser la disproportion entre la créature et le créateur.

Or d'un côté, la contemplation du Philosophe, pour sublime qu'elle puisse être, est pour Thomas essentiellement frustrée, puisque, de soi, elle requiert la connaissance de l'essence de la cause, alors qu'elle doit se limiter à la contempler dans ses effets ${ }^{128}$. De l'autre côté, il est très important de souligner que Thomas semble avoir bien senti l'état d'âme dans lequel pouvaient se trouver les philosophes, quand il écrit : «L'on voit par là combien grande était l'angoisse dont souffraient, à cause de cet état de choses, ces grands esprits $\gg^{129}$. En lisant les textes concernant notre sujet, en particulier ceux dans lesquels la contemplation ou le bonheur des philosophes est mis en parallèle avec celui des saints in uia, il est facile de constater une sorte de respect admiratif et de profonde compréhension pour les premiers.

Si la fin que la philosophie peut atteindre par ses propres moyens est la contemplation imparfaite de Dieu, per creaturas, la philosophie est cependant, de soi, ordonnée à la vision de l'essence divine. C'est précisément ce qui justifie pour Thomas la nécessité de la sacra doctrina. Il n'y a pas pour Thomas deux fins dernières, l'une qu'on peut atteindre par la raison et l'autre par la Révélation : la doctrine «philosophique »

desiderium in cognitione Dei qua scitur de ipso solum quia est $\gg S c G$, III, 50 (éd. Leon., t. 14, p. 138, 1. 2a-33a). Et le chapitre se termine ainsi : « [...] in nullo alio quaerenda est ultima felicitas quam in operatione intellectus : cum nullum desiderium tam in sublime ferat sicut desiderium intelligendae veritatis. Omnia namque nostra desideria vel delectationis, vel cuiuscumque alterius quod ab homine desideratur, in aliis rebus quiescere possunt : desiderium autem praedictum non quiescit nisi ad summum rerum cardinem et factorem Deum pervenerit. Propter quod convenienter sapientia dicit, Eccli. 24, 7 : Ego in altissimis habitavi, et thronus meus in columna nubis. Et Proverb. 9, 3 dicitur quod Sapientia per ancillas suas vocat ad arcem. Erubescant igitur qui felicitatem hominis, tam altissime sitam, in infimis rebus quaerunt »Ibid. (1. 31b-45b). Cette phrase finale du chapitre 50 a un écho dans un sermon situé pendant le deuxième enseignement parisien, Beata gens : «Et uidete quod fuerunt aliqui et sunt, qui dixerunt felicitatem et beatitudinem esse in terrenis » Sermo XX, «Beata gens» (texte préparé par Louis Jacques BATAILLON, éd. Leon., t. 44, 1, l. 175-176 ; voir éd. Vivès, t. 32, p. 799b).

128. Il est impossible de ne pas penser ici à la figure d'Ulysse, idéal du philosophe, dont la présence au Moyen Âge a été étudiée par Ruedi IMBACH, Dante, la philosophie et les laïcs. Initiation à la philosophie médiévale I, Paris - Fribourg $(\mathrm{CH})$, Ed. du Cerf Éditions Universitaires (coll. «Vestigia » 21), 1996, spéc. p. 215 sqq.

129. ScG, III, 48 (éd. Leon., t. 14, p. 131, 1. 52b-53b, cité à la note 126); voir R. A. GAUTHIER, « Trois commentaires... », art. cit., p. 258. 
élaborée par Thomas suppose que la raison, per creaturas, aille vers la contemplation de Dieu et elle arrive même à affirmer qu'une telle contemplation est possible en soi ${ }^{130}$, mais surtout elle implique (oportet) que la cause première se dévoile et s'unisse elle-même à sa créature ${ }^{131}$.

La raison, en élaborant sa connaissance philosophique, peut arriver selon Thomas à identifier dans la contemplation de l'essence de Dieu luimême sa propre fin ultime, après la mort. Cette contemplation finale peut ainsi être supposée à juste titre, par la raison elle-même : on peut aussi supposer qu'elle comportera un acte d'intelligence parfaite et aussi un acte d'amour parfait (on a montré que ces deux éléments appartiennent bien, selon Thomas, à l'acte de contemplation de Dieu selon le Philosophe). Mais la raison reste seule, complètement démunie devant cette vérité, et même prisonnière de celle-ci.

Thomas, dans le chapitre 48 de $S c G$ III, a une expression qui n'a un sens complet qu'en supposant la foi. En effet, il conclut son raisonnement en disant que de l'angoisse éprouvée par les philosophes « nous serons libérés si, comme on l'a démontré plus haut, nous tenons que l'homme peut accéder après cette vie à la vraie félicité ». À s'en tenir aux seuls résultats de la réflexion philosophique, il ne s'agirait que d'une libération partielle, libération du problème spéculatif concernant le temps où il faut situer la contemplation parfaite de Dieu, tandis que reste entier le problème de savoir si effectivement cette contemplation se réalise, même si l'axiome natura nihil facit frustra conduit à supposer qu'elle devrait pouvoir se réaliser. Le pluriel liberabimur, par lequel Thomas fait sienne l'angoisse de ces grands esprits, ne peut se comprendre vraiment qu'en reconnaissant un lien sous-entendu avec la conclusion de ce chapitre, où se rencontrent la libération conditionnelle fournie par la raison et la libération effective promise par la Révélation : «Dominus mercedem nobis in celis promittit ».

En effet, la contemplation après la mort est un don, parce que l'effet (créature) n'est pas en mesure d'atteindre la cause première (créateur) selon sa vertu propre, en raison de la distance infinie entre les deux. De la même façon, la Révélation et la vie selon la foi se comprennent seulement comme des faits gratuits, proposés à l'homme comme tels. La raison ne peut pas même les postuler : la seule chose qu'elle puisse

130. «Cum autem impossibile sit naturale desiderium esse inane, quod quidem esset si non esset possibile pervenire ad divinam substantiam intelligendam, quod naturaliter omnes mentes desiderant; necesse est dicere quod possibile sit substantiam Dei videri per intellectum, et a substantiis intellectualibus separatis, et ab animabus nostris » $S c G$, III, 51 (éd. Leon., t. 14, p. 139, 1. 1a-2b, les soulignements sont de nous).

131. Cette convenance avait déjà été exprimée par certains maîtres ès Arts de la première moitié du XIII siècle, dans leurs commentaires de l'Éthique et leurs introductions à la philosophie : voir les textes cités par I. ZAVATTERO, « Le bonheur parfait... », art. cit., p. 316 avec la note 29, p. 318 et 320. 
postuler et supposer c'est la contemplation de Dieu parfaite après la mort.

C'est à partir de ce donné qu'il faut interpréter la suite de l'a.1 du prologue des Sentences: «Il est une autre contemplation de Dieu, par laquelle on le voit immédiatement en son essence, et qui est parfaite : elle aura lieu dans la Patrie et, selon ce que croit la foi, elle est possible à l'homme » (1. 40-42, cité à la note 7). C'est la foi qui nous assure que cette contemplation, postulée et supposée par la philosophie, est possible et réalisable, après la mort, dans la Patrie. « Et ainsi il convient que les moyens soient proportionnés à la fin, et que l'homme soit conduit à cette contemplation ici-bas par une connaissance qui n'est pas tirée des créatures, mais qui est directement inspirée par la lumière divine. Telle est la doctrine théologique » (1. 42-46, cité à la note 7). La foi, et la doctrina theologie qui en découle, a aussi pour rôle de nous préparer à cette contemplation ici-bas, mais la foi et toute connaissance qui en dérive, y compris la contemplation des saints in uia, sont elles aussi imparfaites par rapport à la contemplation de Dieu dans la Patrie. La foi, de soi, ne procure pas la vision de Dieu en son essence ni ne la rend nécessairement possible: c'est Dieu lui-même qui intervient, en nous procurant, en cette vie, une connaissance qui est directement inspirée par la lumière divine et en nous donnant, dans la Patrie, de le connaître luimême, tel qu'il est, immédiatement en son essence ${ }^{132}$.

Le rôle propre de la sacra doctrina est un rôle «nécessaire », mais dans la mesure où l'on peut parler de «nécessité » dans le domaine de la connaissance gratuite inspirée par Dieu. La raison qui s'exerce en théologie est certainement la même raison qui permet au Philosophe d'identifier dans la contemplation de Dieu le but de toute connaissance philosophique; mais les principes à partir desquels elle raisonne sont reçus dans la foi et Thomas parle donc plutôt de convenance, oportet (In I Sent., prol., a.1, 1. 38, cité à la note 7).

\section{V.2 La contemplation de Dieu : fin de toute vie humaine}

Avant d'étudier le rôle de la doctrina philosophie par rapport à celui de la doctrina theologie, il faut avoir présent à l'esprit que cette dernière, pour Thomas, ne représente pas la fin à laquelle la philosophie est ordonnée. On a bien vu que la philosophie, pour Thomas, a sa propre fin dans la contemplation de Dieu : «toute la connaissance philosophique

132. Voir Jean-Pierre ToRRell, «La vision de Dieu "per essentiam" selon saint Thomas d'Aquin », dans Views and Vision in the Middle Ages - Micrologus. Nature, Science and Medieval Societies 5 (1997), p. 43-68; repris dans ID., Recherches thomasiennes. Études revues et augmentées, Paris, Vrin (coll. «Bibliothèque thomiste » 52), 2000, p. 177-197. 
qui procède de la considération de ce que sont les créatures lui est entièrement ordonnée » (In I Sent., prol., a.1, 1. 35-36, cité à la note 7).

Sur la base de telles affirmations, on a voulu faire dire à Thomas qu'il existe deux fins pour la nature humaine: une fin naturelle, qui consisterait dans la félicité naturelle et une fin surnaturelle, la contemplation de Dieu en son essence. Thomas n'a jamais dit cela, ce qui serait d'ailleurs totalement incohérent avec la doctrine que nous venons d'exposer.

Nous touchons cependant à une question qui, selon Thomas, a occupé constamment la pensée humaine au cours de l'histoire, et pas seulement durant l'ère chrétienne: la question du désir naturel de voir Dieu («omnes qui recte senserunt posuerunt finem humane uite Dei contemplationem»In I Sent., prol., a.1, 1.31-32, cité à la note 7). L'ampleur d'un tel sujet dépasse le but de ce travail ${ }^{133}$; cependant, il nous a semblé utile de présenter les observations suivantes, en commençant par considérer l'historiographie et l'exégèse d'un mouvement philosophique important pendant la seconde moitié du XIII ${ }^{e}$ siècle.

Il n'est pas permis d'affirmer que la doctrine de Thomas à propos de la contemplation de Dieu selon le Philosophe est intrinsèquement opposée aux thèses de ce mouvement philosophique désigné par plusieurs noms, dont celui d' « aristotélisme intégral », qu'a retenu R. A. Gauthier. C'est aussi l'avis de ce dernier dans la conclusion du fameux article «Trois commentaires "averroïstes" sur l'Éthique à Nicomaque», pour peu qu'on le lise sereinement (p. 335-336; voir, ci-dessus, la note 102). Il faut cependant tenir compte du fait qu'en interprétant la doctrine thomiste du « désir naturel de voir Dieu », R. A. Gauthier s'était senti obligé de faire intervenir la «potentia obedientialis» ${ }^{134}$, qui à proprement parler n'a strictement rien à voir ici, comme nous le montrons ci-dessous. Il est dès lors opportun de tenir compte de cela pour saisir la portée exacte des rapports qui, selon l'article du P. Gauthier, interviennent entre la doctrine de Thomas et celle de

133. Pour Thomas cette doctrine est capitale et elle intervient là où on ne s'y attendrait pas : «Cum autem creaturae rationali sit naturaliter appetibilis gloria, non potest in voluntatem humanam cadere, quod auctorem gloriae interimat »In I Cor., 2, lect. 2 (éd. Marietti, 1953, p. 250, n. 91) ; voir aussi In II Cor., 13, lect. 2 (éd. Marietti, 1953, p. 559, n. 534).

134. À propos de cette thèse, voir R. A. GAUTHIER, « Trois commentaires... », art. cit., p. 264, n. 2, qui doit être complété par ID., «Introduction» à Saint Thomas d'Aquin, Contra Gentiles, Paris, 1961, p. 108-112. Les textes cités dans ID., «Trois commentaires... », art. cit., p. 288-293, doivent être interprétés à la lumière de ce que nous venons de dire à propos de la conception de la contemplation élaborée par Thomas luimême. 
l'« aristotélisme intégral » ${ }^{135}$. Il faut aussi se rappeler que l'article du P. Gauthier est paru à un moment où le débat sur ces thèmes était très agité : $\mathrm{H}$. de Lubac venait de publier sa première édition de Surnaturel et son article « Duplex hominis beatitudo » ${ }^{136}$.

Si la littérature théologique sur ce point est imposante ${ }^{137}$, nous nous en tiendrons ici à un seul auteur rarement cité à ce sujet, le P. Daniel Ols, qui a commenté ainsi le texte suivant «Est igitur ultimus finis hominis ipsa Dei cognitio » $(S c G$, III, 25) :

Pour saint Thomas, il est clair que Dieu était libre de créer ou non l'homme (ou l'ange), mais à partir du moment où l'homme existe (ou que l'ange existe), ceux-ci ne peuvent pas ne pas désirer (consciemment ou pas) Dieu, en vertu de leur propre nature. Le désir de Dieu, de voir l'essence divine, est présent en l'homme non parce que Dieu l'aurait surajouté, mais parce qu'il procède nécessairement de la nature de l'homme. «Connaitre Dieu est la fin de toute substance intellectuelle », enseigne Thomas dans un chapitre célèbre de la Summa contra Gentiles ( $S c G$, III, 25), et les démonstrations qu'il donne de cette affirmation montrent surabondamment qu'il s'agit d'une fin voulue nécessairement par la nature (même si, du point de vue de son acquisition, elle est en

135. Parmi les exemples d'interprétation correcte de ces rapports on peut citer : Ruedi IMBACH, « Notule sur le commentaire du Liber de causis de Siger de Brabant et ses rapports avec Thomas d'Aquin », FZPhTh 43 (1996), p. 304-323; et aussi : Luca BIANCHI, « Filosofi, uomini e bruti. Note per la storia di un'antropologia 'averroista' », dans Rinascimento, sec. ser., 32 (1992), p. 185-201, spéc. p. 188 ; D. J. M. BRADLEY, Aquinas on the Twofold Human Good..., op. cit., p. 395-423. Ces mêmes rapports sont interprétés dans une autre optique par: Christian TrotTMAnN, La Vision béatifique. Des disputes scolastiques à sa définition par Benoît XII, Rome, École française de Rome (coll. «Bibliothèque de l'École française de Rome» 289), 1995, p. 264-282; et ID., Théologie et noétique au XIII siècle. À la recherche d'un statut, Paris, Vrin (coll. «Études de philosophie médiévale »78), 1999, p. 133.

136. Henri DE LUBAC, Surnaturel. Études historiques, Paris, Aubier-Montaigne (coll. «Théologie. Études publiées sous la direction de la faculté de théologie s. j. de Lyon-Fourvière » 8), 1946 ; ID., Surnaturel. Études historiques, nouvelle édition avec la traduction intégrale des citations latines et grecques, Édition préparée et préfacée par Michel Sales, Paris, Desclée de Brouwer (coll. « Théologie »), 1991 ; ID., « Duplex hominis beatitudo (Saint Thomas, $1^{\text {a }} 2^{\text {ae }}$, q. 62, a. 1) », Recherches de Science Religieuse 35 (1948), p. 290-299; voir aussi: ID., Le Mystère du surnaturel, Paris, Aubier-Montaigne (coll. «Théologie. Études publiées sous la direction de la faculté de théologie s. j. de Lyon-Fourvière » 64) 1965, repris, avec traductions et errata, dans ID., Euvres complètes, t. XII, Paris, Éd. du Cerf, 2000. Les thèses fondamentales exprimées par H. de Lubac dans ces ouvrages demeurent à notre avis toujours valables; on lira avec intérêt à leur propos les précisions historiques et certaines observations doctrinales présentées dans: Surnaturel. Une controverse au cœur du thomisme au $X X^{e}$ siècle, Actes du colloque organisé par l'Institut Saint-Thomas d'Aquin les 26-27 mai 2000 à Toulouse, Revue Thomiste 101 (2001), p. 5-351.

137. Pour les ouvrages plus récents, à propos desquels nous exprimons ici de fortes réserves, on peut voir les recensions plus favorables de Serge-Thomas BonINo, «Thomistica (X). Raison et foi face au mystère de Dieu », Revue Thomiste 111 (2011), p. 281-295. 
dehors de sa portée) [...]. Il ne s'agit donc pas d'une fin que Dieu dans sa toute gracieuse bonté donnerait de surcroît à l'homme en le surélevant à l'ordre surnaturel, mais il s'agit de la fin qui appartient à l'homme du seul fait qu'il est homme : cette fin est la fin de la nature (I Pars, q. 62, a.1, resp.). Certes cette fin qui est la fin de la nature, ne peut être atteinte par les seules forces de la nature et donc saint Thomas précise : « cette béatitude n'est pas une composante de la nature, mais la fin de la nature $\gg(\text { Ibid. })^{138}$.

Le texte de I pars, q. 62, a. 1 ne doit pas insinuer de doutes sur la doctrine de Thomas : «La perfection ultime de la nature rationnelle ou intellectuelle est double. L'une qu'elle peut acquérir en vertu de sa nature, que l'on dit être béatitude ou félicité d'une certaine manière [...] mais au-dessus de cette félicité, il en est une autre, que nous attendons pour plus tard, et par laquelle nous verrons Dieu tel qu'il est ${ }^{139}$. Pour bien comprendre en quel sens Thomas peut parler de duplex perfectio, on peut se limiter à considérer trois textes: les deux premiers nous apprennent que la perfection de la créature rationnelle (et intellectuelle) « est ratio ultimi finis » $\left(I^{a}-I I^{a e}\right.$, q. 1 , a. 7 et aussi a. 5$)$, et il ne peut $\mathrm{y}$ avoir qu'une seule fin dernière, la contemplation de l'essence de Dieu ${ }^{140}$. Ainsi, pour que Thomas puisse parler ici de duplex perfectio il faut qu'il donne au mot perfectio deux extensions différentes. On peut considérer aussi un troisième texte dans lequel est examiné le rapport de l'homme (effet) à Dieu (cause) :

Or l'effet est double : le premier est adéquat à la vertu de sa cause, et par un tel effet on connait entièrement la vertu de la cause, et donc sa quiddité. Le second n'égale pas cette vertu, et par un tel effet on ne peut

138. Daniel OLS, Le cristologie contemporanee e le loro posizioni fondamentali al vaglio della dottrina di S. Tommaso, Città del Vaticano, Libreria editrice vaticana (coll. «Studi tomistici» 39), 1991, p. 40 ; voir p. 39-44. Dans cette même ligne, voir : Stanislas DockX, «Du désir naturel de voir l'essence divine selon saint Thomas », dans Archives de Philosophie 27 (1964), p. 49-96; Jorge LAPORTA, La Destinée de la nature humaine selon Thomas d'Aquin, Paris, Vrin (coll. «Études de philosophie médiévale » 55), 1965 ; ID., « Pour trouver le sens exact des termes... », art. cit., p. 37-95. Voir I Pars, q. 62 , a. 1 , resp. : « [...] ultimam beatitudinem, quae facultatem naturae excedit, angeli non statim in principio suae creationis habuerunt : quia haec beatitudo non est aliquid naturae, sed naturae finis; et ideo non statim eam a principio debuerunt habere » (éd. Leon., t. 5, p. 110 ; c'est nous qui soulignons).

139. «Ultima autem perfectio rationalis seu intellectualis naturae est duplex. Una quidem, quam potest assequi virtute suae naturae, et haec quodammodo beatitudo vel felicitas dicitur. Unde et Aristoteles perfectissimam hominis contemplationem, qua optimum intelligibile, quod est Deus, contemplari potest in hac vita, dicit esse ultimam hominis felicitatem. Sed super hanc felicitatem est alia felicitas, quam in futuro expectamus, qua videbimus Deum sicuti est » I Pars, q. 62, a. 1, resp. (éd. Leon., t. 5, p. 110 ; les italiques sont dans l'édition; les soulignements sont de nous); voir H. DE LUBAC, « Duplex hominis beatitudo... », art. cit., p. 290-299.

140. Voir H. DE LUBAC, Surnaturel..., op. cit., p. 449-471 ; D. J. M. BradLEY, Aquinas on the Twofold Human Good..., op. cit., p. 514-534. 
comprendre la vertu de l'agent, et par conséquent pas non plus son essence. On sait seulement de cette cause qu'elle existe [...]. C'est un tel rapport que tout effet entretient avec Dieu ${ }^{141}$.

Nous avons déjà eu occasion de nous référer à ce texte du Super Boetium, qui nous permet de comprendre correctement l'expression duplex perfectio de la I Pars. La perfection que la créature rationnelle ou spirituelle obtient en vertu de sa nature n'est pas en mesure d'arriver à la contemplation de l'essence de la cause, contemplation qui seule peut amener l'intelligence à sa perfection ultime ${ }^{142}$. Cette seconde perfection, c'est la fin de la nature : «non est aliquid naturae, sed naturae finis ». Nous le voyons une fois encore, pour que l'expression duplex perfectio soit acceptable, il faut que Thomas emploie le mot perfectio selon deux extensions différentes : dans le cas de la béatitude virtute naturae, la perfectio ne porte pas sur la fin dernière, mais sur la contemplation de Dieu en cette vie ${ }^{143}$.

Le désir naturel de s'unir à la cause première, Dieu, est un désir intrinsèque à toute créature et conforme à la nature de celle-ci ${ }^{144}$. Pour la créature de nature intellectuelle, l'ange et l'homme, ce désir est de connaître l'essence de la cause première, c'est-à-dire « voir Dieu ». Cela ne relève pas seulement de la Révélation : certains philosophes ont dit

141. «Effectus autem est duplex : quidam qui adequatur uirtuti sue cause, et per talem effectum cognoscitur plenarie uirtus cause, et per consequens quiditas ipsius. Alius effectus est qui deficit a predicta equalitate, et per talem effectum non potest comprehendi uirtus agentis, et per consequens nec essentia eius, set cognoscitur tantum de causa quod est ; et sic se habet cognitio effectus ut principium ad cognoscendum de causa an est, sicut se habet quiditas ipsius cause cum per suam formam cognoscitur. Hoc autem modo se habet omnis effectus ad Deum » In Boet. De Trin., q. 1, a. 2, resp. (éd. Leon., t. 50, p. 84, 1. 82-93 ; les soulignements sont de nous).

142. Cette doctrine est aussi celle de Thomas dans une prédication: après avoir exposé l'opinion de ceux qui disent que la béatitude de l'homme « est in hiis que sunt iuxta nos » et avoir exclu qu'elle soit dans la fréquentation des hommes, pour écarter ensuite qu'elle puisse résider dans la contemplation des anges, il dit « constituitur intellectus noster ad uisionem summe cause »Sermo XX, «Beata gens » (texte préparé par L. J. BATAILLON, éd. Leon., t. 44, 1, 1. 204-205 ; éd. Vivès, t. 32, p. 799b).

143. Un exemple intéressant se trouve dans le commentaire de la béatitude «Beati mundo corde quoniam ipsi Deum videbunt ». Thomas réfute l'opinion de ceux qui nient qu'on puisse jamais voir Dieu dans son essence et commence par apporter deux autorités scripturaires puis une autorité fondée sur la raison, qui convient bien ici à notre propos : «Item rationi, quia beatitudo hominis est ultimum bonum hominis, in quo quietatur desiderium eius. Naturale autem desiderium est, quod homo videns effectus inquirat de causa: unde etiam admiratio philosophorum fuit origo philosophiae, quia videntes effectus admirabantur, et quaerebant causam. Istud ergo desiderium non quietabitur, donec perveniat ad primam causam, quae Deus est, scilicet ad ipsam divinam essentiam. Videbitur ergo per essentiam » In Matth., 5, lect. 2 (éd. Marietti, 1951, n. 434). Voir aussi : III ${ }^{a}$ Pars, q. 5, a. 4, resp. (éd. Leon., t. 11, p. 91).

144. Voir De uer., q. 22, a. 1 et 2 (éd. Leon., t. 22, 3, p. 611-617) ; In De diu. nomin., IV, lect. 3 (éd. Marietti, 1950, p. 104, n. 318); $I^{a}-I I^{a e}$, q. 1, a. 2, resp. et a. 8, resp. (éd. Leon., t. 6, p. 9 et p. 16), avec les lieux parallèles. 
que la contemplation la plus haute à laquelle l'homme puisse aspirer est celle de Dieu, c'est-à-dire la vision l'essence de la cause première ${ }^{145}$. Thomas dit explicitement que ce désir est inné (inditum, innatum) chez l'ange et chez l'homme ${ }^{146}$, il appartient en propre à leur nature intellectuelle, «tout intellect désire par nature la vision de l'essence divine », et il ne peut pas être vain ${ }^{147}$.

145. Voir In III Sent., d. 35, q. 1, a. 2, sol. 3, cité à la note $110 ; S c G$, III, 25, cité à la note $124 ; S c G$, III, 50, cité aux notes 127 et $146 ; S c G$, III, 51, cité à la note 130 ; In Matth., 5, lect. 2, cité à la note 143; In Matth., 5, lect. 2, cité à la note 111; In Ethic. Nic., I (1101a20-21), lect. 16, cité à la note 120, avec notre commentaire ; voir aussi In II Sent., d. 18, q. 2, a. 2, resp., cité à la note 119. Voir D. J. M. BRADLEY, Aquinas on the Twofold Human Good..., op. cit., p. 424-439 et p. 455-471.

146. « Ex cognitione effectuum incitatur desiderium ad cognoscendum causam : unde homines philosophari incoeperunt causas rerum inquirentes. Non quiescit igitur sciendi desiderium, naturaliter omnibus substantiis intellectualibus inditum, nisi, cognitis substantiis effectuum, etiam substantiam causae cognoscant. Per hoc igitur quod substantiae separatae cognoscunt omnium rerum quarum substantias vident, esse Deum causam, non quiescit desiderium naturale in ipsis, nisi etiam ipsius Dei substantiam videant » ScG, III, 50 (éd. Leon., t. 14, p. 138). Le passage suivant est une explication très claire de ce que Thomas entend par desiderium naturale (et on y trouve aussi la référence à la disproportion entre la créature et le créateur, à partir de laquelle, dans le Super I Sent., prol., a. 1, Thomas postule la nécessité de la doctrina theologie) : «Vnde anima rationalis, que immediate a Deo causatur, excedit capacitatem sue materie, ita quod materia corporalis non totaliter potest comprehendere et includere ipsam; set remanet aliqua uirtus eius et operatio in qua non communicat materia corporalis. Quod non contingit de aliqua aliarum formarum que causantur ab agentibus naturalibus. Sicut autem homo suam primam perfectionem, scilicet animam, acquirit ex actione Dei, ita et ultimam suam perfectionem, que est perfecta hominis felicitas, immediate habet a Deo et in ipso. Quod ex hoc patet quod naturale hominis desiderium in nullo alio quietari potest, nisi in solo Deo : innatum est homini ut ex causatis desiderio quodam moueatur ad inquirendum causas; nec quiescit istud desiderium quousque peruentum fuerit ad primam causam, que Deus est. Oportet igitur quod sicut prima perfectio hominis, que est anima rationalis, excedit facultates materie corporalis, ita ultima perfectio ad quam homo potest peruenire, que est beatitudo uite eterne, excedat facultatem totius humane nature. Et quia unumquodque ordinatur ad finem per operationem aliquam, ea autem que sunt ad finem oportet esse aliqualiter fini proportionata, necessarium est esse aliquas hominis perfectiones quibus ordinetur ad finem supernaturalem, que excedunt facultatem principiorum naturalium hominis. Hoc autem esse non posset, nisi supra principia naturalia aliqua supernaturalia operationum principia homini infundantur a Deo » Q. disp. de uirtutibus, a. 10, resp. (d'après le texte provisoire établi par É. DERONNE; les italiques sont de nous; voir éd. Marietti, 1965, p. 735); voir aussi : In Ioh., 12, lect. 2 : «Ps. 138 [14] : Mirabilia opera tua, et anima mea cognoscet nimis, idest laborabit ad cognoscendum. [... homines] sperabant, Lazaro referente, aliquod de alia vita perpendere et audire ; cuius cognitionis desiderium innatum est hominibus »(éd. Marietti, 1952, p. 302, n. 1613).

147. «Supra probatum est quod omnis intellectus naturaliter desiderat divinae substantiae visionem »ScG, III, 57 (éd. Leon., t. 14, p. 161; les soulignements sont de nous) : il s'agit d'une conclusion tirée des chapitres précédents ; voir en particulier, $S c G$, III, 50 (cité aux notes 127 et 146) et 51 (cité à la note 130). « Naturale desiderium nihil aliud est quam inclinatio inhaerens rebus ex ordinatione primi moventis, quae non potest esse supervacua »In Ethic. Nic., I (1094a18-21), lect. 2 (éd. Leon., t. 47, 1, p. 8, 1. 44-47). 
Pour bien comprendre ce que Thomas entend par désir naturel de voir l'essence divine, il faut partir d'abord de l'étude des textes et non de la problématique élaborée par ses commentateurs. La plupart des fausses interprétations actuelles de l'enseignement de Thomas à ce propos ne proviennent pas du fait qu'on ne distingue pas entre désir naturel et désir élicite de la volonté (dans le système de Thomas il ne peut aucunement y avoir de désir élicite : seuls les actes des facultés de l'âme peuvent être élicites ${ }^{148}$ ), mais proviennent de ce que l'on fonde premièrement dans la volonté ce désir naturel et de la manière dont on le fonde dans la volonté. Le Père Stanislas Dockx, que nous suivons ici, l'a bien montré ${ }^{149}$. Comme il ressort des textes que nous avons déjà cités, ce désir appartient en propre et d'abord à l'intelligence de l'homme ainsi qu'à l'appétit naturel de l'intelligence, qu'est la volonté, mais de deux manières différentes. Dans la volonté, enseigne Thomas, ce désir connaît deux stades successifs : «Bien que la vision divine soit la béatitude elle-même il ne s'en suit pas que tout homme qui désire (appetit) la béatitude désire la vision de Dieu, car la béatitude en tant que telle est de soi (importat per se) l'objet propre de la volonté, mais non la vision divine elle-même $\gg^{150}$. «L'objet de la volonté est le bien universel (in communi), perçu en tant

148. Dans ce texte de la $I^{a}-I I^{a e}$, q. 6, a. 4, resp., qui institue une comparaison (« sicut ») entre l'acte de la volonté («ab interiori principio cognoscente ») et le désir naturel («ab interiori principio et sine cognitione »), la distinction de ces deux inclinations ne peut pas être exprimée plus clairement : «Duplex est actus voluntatis : unus quidem qui est eius immediate, velut ab ipsa elicitus, scilicet velle; alius autem est actus voluntatis a voluntate imperatus, et mediante potentia exercitus [...]. Actus voluntatis nihil est aliud quam inclinatio quaedam procedens ab interiori principio cognoscente : sicut appetitus naturalis est quaedam inclinatio ab interiori principio et sine cognitione » (éd. Leon., t. 6, p. 59); voir aussi : In III Sent., d. 27, q. 2, a. 4, sol. 3 (éd. F. M. Moos, p. 888, n. 173) ; et le passage de la $Q$. disp. de spe cité à la note 169 .

149. S. DockX, « Du désir naturel... », art. cit., p. 52-55 et 65-72. Cette erreur, entre autres, mine les fondements du livre de L. Feingold et fausse son interprétation de Thomas; même sa reconstruction historique des textes de Thomas relatifs au désir naturel de voir Dieu est fautive : Lawrence FeINGOLD, The Natural Desire to See God according to St. Thomas Aquinas and His Interpreters, Second Edition, Naples (Florida), Sapientia Press of Ave Maria University (Faith and Reason : Studies in Catholic Theology and Philosophy), $2010^{2}$.

150. «Quamuis diuina uisio sit ipsa beatitudo, non tamen sequitur quod quicumque appetit beatitudinem, appetat diuinam uisionem, quia beatitudo inquantum huiusmodi importat per se obiectium uoluntatis, non autem ipsa diuina uisio; sicut aliquis appetit dulce qui tamen non appetit mel »In IV Sent., d. 49, q. 1, a. 3, sol. 1, ad 2 (texte provisoire de la Commission Léonine, préparé par W. FAUSER ; voir éd. Vivès, t. 11, p. 473) ; et aussi : «Quamuis autem ex naturali inclinatione uoluntas habeat ut in beatitudinem feratur secundum communem rationem, tamen quod feratur in beatitudinem talem uel talem, hoc non est ex inclinatione nature, set per discretionem rationis que adinuenit in hoc uel in illo summum bonum hominis constare. Et ideo, quandocumque aliquis beatitudinem appetit, actualiter coniungitur ibi appetitus naturalis et appetitus rationalis. Et ex parte appetitus naturalis semper est ibi rectitudo. Set ex parte appetitus rationalis quandoque est ibi rectitudo, quando scilicet appetitur ibi beatitudo, ubi uere est ; quandoque autem peruersitas, quando appetitur, ubi uere non est » Ibid., sol. 3 (p. 474 ; nous soulignons). 
que fin » et non la vision de l'essence divine : les passages où Thomas exprime cette idée sont nombreux et son enseignement est constant ${ }^{151}$. Ce désir ne peut donc pas être fondé comme tel dans la volonté (dans la uoluntas ut natura), car, dans ce cas, la volonté devrait avoir pour objet le bien de voir Dieu comme son acte premier et tous les hommes devraient le désirer nécessairement, sans possibilité de se tromper, et Dieu serait obligé de donner à l'homme accès à la vision de son essence. $\mathrm{Au}$ contraire, cette identification est un acte second de la volonté (de la uoluntas ut ratio ou deliberata), qui suit une délibération de la raison et ne comporte donc aucune nécessité absolue, ni de la part de l'homme ni de la part de Dieu ${ }^{152}$. Cependant, le fait d'être fondé dans la volonté en acte second, n'implique pas l'existence de deux désirs naturels dans la volonté, l'un de la béatitude et l'autre de voir l'essence divine (« actualiter coniungitur ibi appetitus naturalis et appetitus rationalis »). C'est le même et unique désir naturel de la béatitude, inné dans la voluntas ut natura, qui, à la suite d'une délibération de l'intellect concernant l'objet de la béatitude et à une electio de la volonté, porte directement sur l'essence divine ${ }^{153}$.

Il faut ensuite considérer que Thomas enseigne constamment que le désir naturel de voir l'essence de la cause première, Dieu, est enraciné par nature dans l'intelligence de l'homme, comme désir inné. Pour bien comprendre la nature de ce désir, il faut analyser comment il peut être enraciné dans l'intelligence.

Dans toute intelligence, comme dans toute puissance de l'âme, on peut distinguer deux aspects différents: son rapport à son opération (puissance opérative) et son rapport à son objet (puissance informée par sa forme).

En tant que puissance opérative, elle peut être passive (intellectus possibilis) ou active (intellectus agens). Or, «dans aucun genre la puissance naturelle passive ne peut s'étendre au delà de ce à quoi s'étend la puissance active du même genre. [...] L'intellect possible est ainsi en

151. «Bonum autem in communi, quod habet rationem finis, est obiectum voluntatis » $I^{a}-I I^{a e}$, q. 9, a. 1, resp. (éd. Leon., t. 6, p. 74); « Obiectum voluntatis est finis et bonum in universali »Ibid., q. 1, a. 2, ad 3 (p. 9) ; Ibid., q. 10, a. 1, resp. (p. 83) ; voir aussi, ci-dessus, la note 150 et les lieux parallèles de tous ces textes.

152. Voir, par exemple, Super II Sent., d. 39, q. 2, a. 2, ad 2 (éd. P. MANDONNET, p. 994); In III Sent., d. 17, a. 1, sol. 3, ad 1 (éd. F. Moos, p. 532-533, n. 27); Ibid., a. 2, sol. 1 (ibid., p. 537, n. 45-46) ; III ${ }^{a}$ Pars, q. 18, a. 3, resp. et a. 4, resp. (éd. Leon., t. 11, p. 233 et 234).

153. À propos du fonctionnement de la volonté : «Voluntas non exit in actum suum per aliquas species ipsam informantes, sicut intellectus possibilis. Et ideo non requiritur aliquis naturalis habitus in uoluntate ad naturale desiderium; et precipue cum ex habitu naturali intellectus moueatur uoluntas, in quantum bonum intellectum est obiectum uoluntatis »Q. disp. de uirtutibus, a. 8, ad 13 (d'après le texte provisoire établi par É. DERONNE ; les italiques sont de nous ; voir éd. Marietti, 1965, p. 728). 
puissance seulement à ce que peut faire en lui l'intellect agent, bien que cela n'exclue pas que certaines autres choses puissent être faites en lui par action divine, comme dans les natures corporelles par l'action du miracle ${ }^{154}$. Cette dernière puissance est la puissance obédientielle, « qui est dans toute créature, en tant qu'elle obéit à Dieu pour recevoir en ellemême tout ce que Dieu aura voulu $\gg^{155}$.

Or, puisque par ses propres forces naturelles la puissance opérative active ne peut pas s'unir à l'essence divine, il ne peut pas y avoir dans l'intelligence une puissance opérative passive naturelle par rapport à l'acte de la vision de l'essence divine. Et en ce qui concerne la puissance obédientielle, celle-ci n'est pas déterminée, de par sa nature, à un objet particulier, comme l'est l'acte de voir l'essence divine, mais elle est ouverte à tout ce que Dieu voudra y opérer. Aucune de ces trois puissances ne peut donc être le sujet du désir naturel de voir l'essence divine. En plus, si l'on voulait identifier ce désir naturel avec la puissance obédientielle, il serait absurde que Thomas dise que ce désir ne peut pas être vain, car, la puissance obédientielle est naturellement ordonnée à des actions divines qui sont infinies et pour lesquelles le sujet n'a aucune disposition naturelle nécessaire : « la puissance obédientielle est celle qui fait que toute créature puisse recevoir quelque chose de Dieu. Et cette capacité ne peut être remplie, car quoi que Dieu fasse de la créature, celle-ci reste toujours en puissance à recevoir quelque chose de la part de Dieu ${ }^{156}$. C'est tout le contraire pour le désir naturel de voir Dieu : «Si Dieu seul était vu, qui est la source et le principe de tout l'être et de toute la vérité, alors il remplirait le désir naturel de connaître, car il ne

154. « In nullo enim genere potentia passiva naturalis se extendit ultra id ad quod se extendit potentia activa eiusdem generis [...]. In animae autem humanae intellectu duplex potentia invenitur, una quasi passiva, scilicet intellectus possibilis, et alia quasi activa, scilicet intellectus agens. Unde intellectus possibilis naturaliter non est in potentia ut in eo fiant nisi ea quae intellectus agens natus est facere, quamvis per hoc non excludatur quin aliqua alia in eo fieri possint operatione divina, sicut et in natura corporali per operationem miraculi »De uer., q. 18, a. 5, resp. (éd. Leon., t. 22, 2, p. 546, 1. 142-157). À propos de la «puissance obédientielle» voir: Étienne GILSON, «Sur la problématique thomiste de la vision béatifique », AHDLMA 31 (1964), p. 67-88, spéc. p. 82-88 ; S. DocKX, « Du désir naturel... », art. cit., p. 56-57 ; Marie-Michel LABOURDETTE, « Anthropologie théologique et péché originel », RT 73 (1973), p. 643-663, spéc. p. 646647 ; D. Ols, Le Cristologie contemporanee..., op. cit., p. 30-38 ; D. J. M. BradLEY, Aquinas on the Twofold Human Good..., op. cit., p. 448-471.

155. «In tota creatura est quedam obedientialis potentia, prout tota creatura obedit Deo ad suscipiendum in se quicquid Deus uoluerit »Q. disp. de uirtutibus, a. 10, ad 13 (d'après le texte provisoire établi par É. DeRonNe ; voir éd. Marietti, 1965, p. 737); voir III ${ }^{a}$ Pars, q. 11, a. 1, resp. (éd. Leon., t. 11, p. 157).

156. «Est potentia obedientiae, secundum quod potest [creatura] recipere aliquid a Deo ; et talis capacitas non potest impleri, quia quicquid Deus de creatura faciat, adhuc remanet in potentia recipiendi a Deo » De uer., q. 29, a. 3, ad 3 (éd. Leon., t. 22, 3, p. 856, 1. 233-238). 
chercherait nulle autre chose et il serait bienheureux $\gg^{157}$. On peut ajouter encore trois considérations.

La puissance obédientielle, par rapport à l'étant concerné, reste, d'une certaine façon, dans le domaine de la proportio et de l'adaequatio de l'effet à la cause, puisque la toute-puissance divine peut causer n'importe quel effet, alors que le problème à dépasser ici est celui de la disproportion entre l'effet et la cause. Deuxièmement, par rapport à l'agent, qui est Dieu, toute créature est en puissance obédientielle infinie par rapport au Créateur et donc elle ne donne aucun moyen pour surmonter la difficulté spécifique d'un désir naturel inné. Troisièmement, Thomas nie explicitement que la justification implique la puissance obédientielle ${ }^{158}$. Or, c'est précisément par la justification que l'homme est surélevé à l'état de grâce et mis en mesure d'atteindre la vision de l'essence divine qu'il désire d'un désir naturel inné, ce qui n'implique donc pas la puissance obédientielle.

Ayant ainsi vu de quelle façon le désir naturel de voir l'essence divine peut être l'inclination de la voluntas ut natura et ayant exclu qu'il puisse être enraciné dans les puissances opérationnelles de l'âme et dans la puissance obédientielle, on peut alors considérer l'âme selon son rapport de materia-forma, en fonction de son actuation par son objet propre. Par rapport à son objet, l'intelligence peut être considérée selon sa nature essentielle ou selon son mode d'opération. La manière d'opérer de l'intelligence est différente chez l'homme, l'ange et Dieu, en raison de leur être. Seul l'intellect de Dieu a une relation à l'être universel en tant qu'il est l'acte de tout l'être, qui est aussi son essence, dans laquelle tout être préexiste originairement et virtuellement comme dans la cause première. L'intelligence divine n'est donc pas en puissance par rapport à son objet, mais actus purus. L'intelligence humaine et l'intelligence angélique ont une relation comme de la puissance à l'acte, par rapport à leur objet, bien que de façon diversifiée : chez l'ange cette puissance est toujours perfectionnée par l'acte et son intellect est toujours en acte par rapport à ses objets intelligibles; chez l'homme, l'intellect est en

157. « Si tamen solus Deus videretur, qui est fons et principium totius esse et veritatis, ita repleret naturale desiderium sciendi, quod nihil aliud quaereretur, et beatus esset » $I^{a}$ Pars, q. 12, a. 8, ad 4 (éd. Leon., t. 4, p. 129).

158. Voir $I^{a}-I I^{a e}$, q. 113 , a. 10 , set c. et resp. : «Iustificatio impii non est supra potentiam naturalem » et «In quibusdam miraculosis operibus invenitur quod forma inducta est supra naturalem potentiam talis materiae : sicut in suscitatione mortui vita est supra naturalem potentiam corporis. Et quantum ad hoc, iustificatio impii non est miraculosa : quia naturaliter anima est gratiae capax ; eo enim ipso quod facta est ad imaginem Dei, capax est Dei per gratiam, ut Augustinus dicit» (éd. Leon., t. 7, p. 342 ; italiques dans l'édition); et déjà In IV Sent., d. 17, q. 1, a. 5, III, resp. : « Ordo naturalis inest animae ad iustitiae rectitudinem consequendam » (éd. F. Moos, p. 851, n. 157). 
puissance par rapport à ses objets intelligibles ${ }^{159}$. Mais puisque l'intelligence passive de l'homme est mesurée par la puissance active, qui ne peut pas atteindre par ses seules forces naturelles la vision de l'essence divine, la puissance passive de l'homme et celle de l'ange sont différentes et ne peuvent pas être la racine du désir naturel de voir Dieu.

L'intelligence angélique et humaine, cependant, ne se distinguent pas par nature quant à la faculté d'abstraire de leur objet intelligible propre la notion d'être en acte, principe de tout être et fin de toute intelligence, bien que par leurs forces naturelles elles ne puissent l'atteindre réellement en lui-même. Seul Dieu, qui est l'être subsistant en acte, a une relation toujours en acte par rapport à son objet d'intelligence, en tant qu'il est l'acte de tout l'être. La distinction se pose donc entre intelligence créée et intelligence incréée. L'intelligence créée ne peut atteindre sa perfection que si elle est informée par sa forme ultime, qui est l'essence divine : «La mens rationnelle est formée immédiatement par Dieu, soit comme une image par son modèle, car elle n'est faite qu'à l'image de Dieu, soit comme un sujet par sa forme ultime (completiva), car la mens créée est considérée informe si elle n'adhère pas à la vérité première ellemême. Les autres connaissances (illuminationes) que la mens [de l'ange] reçoit de l'homme ou d'un ange, sont comme des dispositions à recevoir la forme ultime » ${ }^{160}$. Pour Thomas, « l'intellect créé est proportionné à la vision de l'essence divine, en tant qu'il est en rapport à cette essence comme à une forme intelligible ${ }^{161}$. Et puisque l'essence divine est, seule, la forme de la potentialité de l'intelligence créée, elle est aussi la fin de cette intelligence : «ultima forma completiva », « ultima perfectio ». En raison de la « distance infinie » entre l'essence divine et l'intelligence créée, celle-ci n'est pas en puissance à cette «ultima forma » selon un rapport d'opération, mais selon un rapport de matière à

159. Voir I Pars, q. 79, a. 2, resp. (éd. Leon., t. 5, p. 259).

160. «Rationalis mens formatur immediate a Deo, vel sicut imago ab exemplari, quia non est facta ad alterius imaginem quam Dei : vel sicut subiectum ab ultima forma completiva, quia sempre mens creata reputatur informis, nisi ipsae primae veritati inhaereat. Aliae autem vero illuminationes, quae sunt ab homine vel angelo, sunt quasi dispositiones ad ultimam formam »I Pars, q. 106, a. 1, ad 3 (éd. Leon., t. 5, p. 482). Et aussi : « Potentia passiva est perfectibilis pluribus perfectionibus ordinatis ; si perfecta sit sua ultima perfectione, non dicitur imperfecta etiam si aliquae dispositiones praecedentes ei desint. Omnis autem cognitio qua intellectus creatus perficitur, ordinatur, sicut ad finem, ad Dei cognitionem. Unde videns Deum per essentiam, etiam si nihil aliud cognosceret, perfectum intellectum haberet; nec est perfectior ex hoc quod aliquid aliud cognoscit, nisi quatenus ipsum plenius videt »In IV Sent., d. 49, q. 2, a. 5, ad 5 (éd. Vivès, t. 11, p. 495).

161. «Intellectus creatus est proportionatus ad videndam divinam essentiam in quantum se habet ad ipsam quodam modo ut ad formam intelligibilem, quamvis secundum quantitatem virtutis nulla possit esse proportio propter distantiam infinitam » De uer., q. 8, a. 1, ad 7 (éd. Leon., t. 22, 2, p. 219, l. 280-285). Voir aussi : III ${ }^{a}$ Pars, q. 9, a. 2, resp. et ad 3, cités à la note 167 . 
forme : «l'appétit de la forme n'est pas une action de la matière, mais une certaine relation de la matière à la forme en tant qu'elle est en puissance à celle-ci ${ }^{162}$. Or, «bien que Dieu soit la fin ultime dans l'obtention (in consecutione) et le premier dans l'intention de l'appétit naturel, il n'est cependant pas nécessaire qu'il soit le premier dans la connaissance de la mens humaine, qui est ordonnée à la fin, mais dans la connaissance de celui qui l'ordonne à sa fin ; comme dans les autres choses qui tendent à la fin par un appétit naturel ${ }^{163}$. Le désir naturel de voir l'essence divine est enraciné, innatum, dans cet appétit naturel de l'intelligence envers sa forme, fin de la nature intellectuelle. « À chacune des puissances de l'âme revient de désirer son bien propre par un appétit naturel, qui ne suit pas une appréhension ${ }^{164}$. Toutes les puissances de l'âme, en plus de leur bien propre et particulier, poussées par la nature même de l'âme, désirent naturellement atteindre la forme ultime qui complète la nature intelligente de celle-ci. Et l'appétit naturel n'est pas seulement en puissance à sa forme, mais aussi à l'union à cette forme : « ad videndam divinam essentiam ».

Ce désir naturel, inclination de la puissance intellectuelle vers sa perfection (tant objectivement que subjectivement), se manifeste dans toutes les puissances opérationnelles de l'âme, qui ainsi sont orientées vers l'objet de ce désir. Dans l'intelligence opérationnelle : «Le désir naturel de l'homme tend dans sa connaissance (in sciendo) à une fin déterminée. Celle-ci ne peut être autre que le connaissable le plus noble (nobilissimum scibile), qui est Dieu ${ }^{165}$; dans la volonté ut natura : «Id quod voluntas de necessitate vult, quasi naturali inclinatione in ipsum determinata, est finis ultimus, ut beatitudo et ea quae in ipso includuntur, ut esse, cognitio veritatis et aliqua huiusmodi » ${ }^{166}$; et dans la volonté ut ratio, mais seulement avec l'aide de Dieu : «Videre Deum per essentiam est supra naturam cuiuslibet intellectus creati. Unde nulla creatura rationalis potest habere motum voluntatis ordinatum ad illam

162. « Appetitus forme non est aliqua actio materie, set quedam habitudo materie ad formam secundum quod est in potencia ad ipsam »Q. disp. de pot., q. 4, a. 1, ad 2 in contrario (texte provisoire de la Commission Léonine, préparé par René Antoine GAUTHIER ; voir éd. Marietti, 1965, p. 109).

163. «Quamuis Deus sit ultimus finis in consecutione et primus in intentione appetitus naturalis, non tamen oportet quod sit primus in cognitione mentis humane, que ordinatur in finem, set in cognitione ordinantis ; sicut et in aliis que naturali appetitu tendunt in finem » In Boet. De Trin., q. 1, a. 3, ad 4 (éd. Leon., t. 50, p. 88, 1. 180-186).

164. «Unicuiquae potentiae animae competit appetere proprium bonum appetitu naturali, qui non sequitur apprehensionem $I^{a}-I^{a e}$, q. 30, a. 1, ad 3 (éd. Leon., t. 6, p. 209).

165. «Tendit igitur desiderium naturale hominis in sciendo ad aliquem determinatum finem. Hoc autem non potest esse aliud quam nobilissimum scibile, quod est Deus »ScG, III, 25 (éd. Leon., t. 14, p. 67) ; voir aussi : In IV Sent., d. 49, q. 2, a. 5, ad 5 (cité à la note 160); $I^{a}-I^{a e}$, q. 3, a. 8, resp. (éd. Leon., t. 6, p. 35-36).

166. De uer., q. 22, a. 5, resp. (éd. Leon., t. 22, 3, p. 624, 1. 196-201). 
beatitudinem, nisi mota a supernaturali agente ${ }^{167}$. Et «pour que l'intelligence puisse s'unir effectivement à l'essence divine comme à sa forme, il lui faut une disposition surnaturelle ; surnaturelle parce que la disposition ultime à la forme est du même ordre que la forme ellemême » ${ }^{168}$, écrivait le P. Dockx, qui concluait ainsi :

Le désir naturel de voir l'essence divine n'est pas un désir résultant d'un jugement sur la désirabilité d'une telle connaissance, ni un désir de la volonté en tant qu'elle tend vers sa béatitude, mais un désir de l'intelligence, non pas en tant que puissance opérative passive, considérée par rapport à ses forces naturelles de connaissance, ni en tant que puissance obédientielle, considérée par rapport à un agent supérieur, mais de l'intelligence en tant que puissance appétitive résultant de sa nature de "matière première", dans l'ordre intelligible, par rapport à la forme intelligible qu'est l'essence divine. [...] Il s'en suit [sic] que ce désir est nécessairement universel, [...] un tel désir peut servir de fondement à un raisonnement basé sur l'axiome "desiderium naturale non potest esse inane", car un désir qui est inscrit dans la nature même des choses permet d'invoquer la sagesse de l'ordinateur de l'univers ${ }^{169}$.

Le fait que ce désir ne soit enraciné ni dans l'intelligence opérationnelle ni simpliciter dans la voluntas ut natura, comme on l'a vu ci-dessus, enlève tout fondement à l'idée d'une obligation de la part de Dieu à réaliser la fin ultime de l'homme, ce qui relève, en revanche, de l'ordre de sa sagesse créatrice et de sa libéralité gratuite. L'étude du P. Dockx développe ensuite, de manière très juste, la façon dont ce désir naturel de voir l'essence divine se répercute sur la volonté humaine et le rôle de celle-ci dans la réalisation de ce désir ${ }^{170}$.

167. I $I^{a}$ Pars, q. 12, a. 2, resp. Sans oublier la III ${ }^{a}$ Pars, q. 9, a. 2, resp. et ad $3:$ « Homo autem est in potentia ad scientiam beatorum, quae in visione Dei consistit, et ad eam ordinatur sicut ad finem » et «Visio seu scientia beata est quodammodo supra naturam animae rationalis : inquantum scilicet propria virtute ad eam pervenire non potest. Alio vero modo est secundum naturam ipsius : inquantum scilicet per naturam suam est capax eius, prout scilicet ad imaginem Dei facta est » (éd. Leon., t. 11, p. 141 ; nous soulignons).

168. S. DockX, « Du désir naturel... », art. cit., p. 74. Voir In Boet. De Trin., q. 6, a. 4, ad $5:$ : Quamuis enim homo naturaliter inclinetur in finem ultimum, non tamen potest naturaliter illum consequi set solum per gratiam; et hoc est propter eminentiam illius finis » (éd. Leon., t. 50, p. 171, 1. 193-196); et aussi : Super IV Sent., d. 49, q. 2, a. 6, resp. (éd. Vivès, t. 11, p. 497-498); Q. disp. de uirtutibus, q. 10, resp. (citée à la note 146).

169. S. DocKX, « Du désir naturel... », art. cit., p. 64-65. Dans la $Q$. disp. de spe, q. un., a. 1, resp., Thomas parle du désir absolu du bien, sans considération de son asséquibilité : «Differt tamen spes a desiderio in duobus. [...] Secundo, quia desiderium est alicuius boni absolute, absque consideratione possibilitatis uel impossibilitatis illius; set spes tendit in aliquod bonum sicut in id quod est possibile adipisci : importat enim in sui ratione quamdam securitatem adipiscendi » (d'après le texte provisoire établi par Émile DERONNE ; les italiques sont de nous ; voir éd. Marietti, 1965, p. 804).

170. On peut considérer au moins ce texte de Thomas : «Non enim per voluntatem appetimus solum ea quae pertinent ad potentiam voluntatis; sed etiam ea quae pertinent ad singulas potentias, et ad totum hominem. Unde naturaliter homo vult non solum 
Comme nous l'avons montré plus haut, cet excursus sur le désir naturel de voir l'essence divine nous semble capital, malgré sa concision, pour comprendre exactement l'articulation entre la philosophie et la théologie chez Thomas d'Aquin.

\section{LE RAPPORT ENTRE DOCTRINA PHILOSOPHIE ET DOCTRINA THEOLOGIE}

Nous pouvons ici reprendre quelques données générales sur la relation entre ces deux doctrines, telle qu'elle est apparue dans les pages précédentes. Il faut premièrement remarquer que les deux doctrines, sous un certain aspect, ont un même et unique but : la contemplation de Dieu. Deuxièmement, nous avons vu que c'est la raison naturelle qui pose le fondement de la nécessité d'une autre doctrine : elle la postule. La raison elle-même requiert que cette doctrine ait son propre principe en dehors d'elle-même, dans la cause première, en raison de l'inadéquation des puissances de l'intellect naturel à atteindre la cause première elle-même.

Il en résulte que, pour Thomas, le rôle subsidiaire de la philosophie par rapport à la sacra doctrina est affirmé par la théologie ${ }^{171}$, alors que la philosophie postule la nécessité de la théologie. C'est là le signe de la dignité que Thomas reconnaît à la philosophie : être mesure de soimême, sans être suffisante à soi-même.

Cette doctrine de Thomas manifeste une certaine affinité avec les positions de ses collègues de la faculté des Arts, qui revendiquaient, à cette époque, une certaine autonomie par rapport à la théologie dans l'élaboration de leur discipline ${ }^{172}$.

C'est pour que les rapports entre théologie et philosophie soient ainsi compris que Thomas évite constamment d'utiliser l'image de la domina et de l'ancilla ${ }^{173}$, image invoquée par les théologiens traditionalistes de

obiectum voluntatis, sed etiam alia quae conveniunt aliis potentiis : ut cognitionem veri, quae convenit intellectui; et esse et vivere et alia huiusmodi, quae respiciunt consistentiam naturalem; quae omnia comprehenduntur sub obiecto voluntatis, sicut quaedam particularia bona $» I^{a}-I I^{a e}$, q. 10, a. 1, resp. (éd. Leon., t. 6, p. 83 ; nous soulignons).

171. Voir les textes cités à la note 185. À propos de la notion de sacra doctrina chez Thomas : voir Adriano Oliva, « Doctrina et sacra doctrina chez Thomas d'Aquin », dans Philippe Buttgen, Ruedi Imbach, Ulrich Johannes Schneider, Herman J. Selderhuis (éd.), Vera doctrina. Zur Begriffsgeschichte der Lehre von Augustinus bis Descartes. L'idée de doctrine d'Augustin à Descartes, Wiesbaden, Harrassowitz Verlag (coll. «Wolfenbütteler Forschungen » 123), 2009, p. 35-61.

172. Voir les notes 77 et 91.

173. Le seul emploi de cette image que nous ayons repéré est dans la I Pars, q. 1, a. 5, ad 2 (éd. Leon., t. 4, p. 16), où Thomas présente les sciences philosophiques comme des « servantes », mais il précise qu'il le fait à la manière d'Aristote. C'était aussi le cas dans le Super Boet. De Trinitate, q. 2, a. 2, ad 1 (éd. Leon., t. 50, p. 96, 1. 95-98) : bien que Thomas cite l'expression d'Aristote qui fait de la métaphysique la « déesse des sciences », il n'applique pas cette qualification à la théologie et se limite à en tirer argument pour 
son époque ${ }^{174}$. Il faut encore remarquer que dans l'a. $1 \mathrm{du}$ prologue des Sentences, Thomas a écrit : «ipsa [theologia] utitur in obsequium sui omnibus aliis scientiis, quasi usualis, ... » (1. 43-44, avec les sources), alors que toutes les éditions qui suivent celle de J. Nicolai de $1660{ }^{175}$, à la place de « usualis », ont le mot «vassallis », ce qui implique un changement non seulement de mot, mais également de sujet d'attribution «ipsa [theologia] utitur in obsequium sui omnibus aliis scientiis, quasi vassallis ». En revanche, Thomas, en disant que la « doctrina theologie » a le rôle «usualis » par rapport aux autres sciences (humaines), reprend un texte d'Aristote (Phys. II, 194b1-5) qui présente la science architectonique comme usualis $^{176}$, parce qu'elle ordonne à sa propre fin plusieurs autres sciences, qui possèdent cependant leur fin particulière. fins :

Cette expression fait bien ressortir le principe de la subordination des

[...] comme il apparaît dans tous les arts ordonnés entre eux, dont la fin de l'un est subalternée à la fin de l'autre [...]. Ainsi le médecin passe commande (imperat) au pharmacien et il se sert, pour sa propre fin, des médicaments que celui-ci lui prépare. Puisque la fin de toute philosophie est inférieure à la fin de la théologie et lui est subordonnée, la théologie

montrer combien la théologie, plus encore que la métaphysique, mérite le nom de sagesse.

174. Voir Louis Jacques BATAILLON, «Problèmes philosophiques dans les œuvres théologiques », dans Olga WeIJERS et Louis HolTz (éd.), L’Enseignement des disciplines à la Faculté des arts (Paris et Oxford, XIII-XV siècles), Turnhout, Brepols (coll. «Studia Artistarum » 4), 1997, p. 449-453; le regretté P. Bataillon nous avait fourni un autre texte à ajouter à ceux qu'il citait dans cette contribution, un sermon prêché le 12 avril 1262 par LATINO MALABRANCA : «Qui in tenebris ambulare debet querit sibi lumen. Diligite igitur lumen sapiencie quia in tenebris estis. Omnes homines natura scire desiderant. Studium multorum conuertitur ad sciendum que parum ualent ad salutem : nisi homo habeat scientiam de diuinis, nihil est quod $\mathrm{s}<\mathrm{c}>\mathrm{it}$. Vnde Salomon : 'Vbi non est sapiencia, ibi non est bonum'. Dicet aliquis : 'Oportet nos ista inferiora addiscere ut postea proficiamus in sapiencia diuina'. Ergo est accessorium audire ista. Caueas ne principale dimittas propter accessorium. Prouisum est ut sapiencia diuina proponetur uobis in sermone quia non omnes potestis audire diuinam sapienciam. Et multi non ueniunt ad sermonem propter lectionem Aristotilis. Philosofi [!] fuerunt omnes obtenebrati, dicentes se sapientes stulti facti sunt $\gg$ (Sermo in III dominica quadragesime f. latini de festo beati gregorii, Oxford, Merton Coll. 237, f. 43vb).

175. Voir A. Oliva, Les Débuts..., op. cit., p. 97-98.

176. À propos de l'expression «quasi usualis», qu'on nous permette de remarquer qu'ici, comme souvent (et même presque toujours), quasi ne veut pas dire «quasi, presque », mais « dans la mesure où, en tant que ». Voir ce texte qui explique les deux emplois du mot: «Hic diffamatus est quasi dissipasset [LC 16,11], quasi dicat, diffamatus est quasi dissipator, et hec dictio 'quasi' nota est ueritatis, non similitudinis, sicut 'quasi unigenitus a Patre' » Guillaume PEYRAUT, Sermo I in dom. IX post Trinitatem, Homo quidam, ms. Vat. lat. 10910, f. 60rb ; cit. par Louis Jacques BATAILLON, « L'influence d'Hugues de Saint-Cher», dans Louis Jacques BATAILlon, Gilbert DaHAN, Pierre-Marie Gy (éd.), Hugues de Saint-Cher († 1263), bibliste et théologien, Turnhout, Brepols (coll. « Bibliothèque d'histoire culturelle du Moyen Âge » 1), 2004, p. 497-502, ici p. 501. 
doit commander (imperat) toutes les autres sciences et se servir de leurs contenus ${ }^{177}$.

Dans ce texte, d'une part, est expliqué que chaque science a sa propre fin, laquelle peut être ordonnée à celle d'une science supérieure; de l'autre, est reconnu à la doctrina theologie la faculté de procurer une connaissance supérieure, qui « utilise » les autres sciences pour expliciter et approfondir ce qu'elle reçoit de la Révélation, pour mettre l'homme en état d'accueillir l'inspiration divine.

La relation entre la philosophie et la théologie est cependant particulière, par rapport aux autres sciences subordonnées. D'une part, car c'est la philosophie elle-même qui reconnaît la nécessité de la doctrina theologie et la fonction directrice que celle-ci exerce ; de l'autre, car la fin de la philosophie est la même que celle de la théologie, mais autres sont les principes à partir desquels la philosophie procède.

La doctrina theologie oriente toutes les autres sciences, mais elle n'est pas la science ultime, car elle est elle-même au service de la sagesse suprême qui consiste, pour l'homme, dans la vision de l'essence divine. La doctrina theologie est ainsi servante, à la fois, au service de l'homme et au service de Dieu : d'une part, elle conduit l'homme à dépasser la connaissance accessible par les seules forces de sa raison en ouvrant à son esprit les richesses de la Révélation; d'autre part (mais c'est en réalité la même chose), Dieu se sert d'elle pour communiquer à l'homme qui vit dans la foi une première approche de la connaissance qui le rendra bienheureux, en le conduisant vers sa fin «par une connaissance qui n'est pas tirée des créatures, mais qui est directement inspirée par la lumière divine » (Ibid., 1. 39-40). C'est ainsi que Thomas nous présente ici cette doctrine : «Et hec est doctrina theologie ».

177. «[...] sicut patet in omnibus artibus ordinatis quarum finis unius est sub fine alterius [...]. Vnde medicus imperat pigmentario et utitur pigmentis ab ipso factis ad suum finem. Item cum finis totius philosophie sit infra finem theologie et ordinatus ad ipsum, theologia debet omnibus aliis scientiis imperare et uti hiis que in eis traduntur » In I Sent., prol. a. 1 (éd. A. OlivA, p. 313, 1. 44-49). En plus des sources données dans l'édition, où l'on constate que le verbe « imperare » reprend le participe «principantes » d'Aristote, on peut voir cet autre texte: «Et quia res referuntur in finem ultimum communem mediante fine proprio, ideo secundum diuersitatem finis proprii efficitur diuersa relatio rerum ad finem ultimum. Sic ergo dicendum est, quod sicut rerum omnium unus est finis ultimus, scilicet Deus, ita et uoluntatum omnium unus est finis ultimus, scilicet Deus; nichilominus tamen sunt alii fines proximi. Et si secundum illos fines seruatur debita relatio uoluntatis in finem ultimum, est recta uoluntas, si autem non, uoluntas erit peruersa. Debita autem relatio uoluntatis ad finem ultimum saluatur secundum illum finem quo uoluntas nata est ultimum finem participare, in quo distinguitur a rebus aliis que alio modo finem participant» In II Sent., d. 38, q. 1, a. 1, resp. (texte provisoire de la Commission Léonine, préparé par P.-M. GILS et A. OLIVA ; voir éd. P. MANDONNET, p. 968-969) ; voir Ibid., a. 2, resp. (p. 970-971) ; Ibid., d. 41, q. 1, a. 1, resp. (éd. P. MANDONNET, p. 1035-1036) ; et In Metaph., XII (1075a11-1075a25), lect. 12 (éd. Marietti, 1950, p. 612-613, n. 2628-2634). 
La fin de la philosophie est subordonnée à celle de la théologie en raison de cette première et fondamentale ordination de la philosophie elle-même à la connaissance de l'essence de la cause première, fin aussi de la théologie. On peut reconnaître là, semble-t-il, les conditions pour un échange fructueux entre les deux sciences.

Le premier article du prologue du commentaire des Sentences nous montre comment Thomas conçoit la place de la théologie par rapport aux sciences philosophiques et comment il comprend leurs rapports réciproques ${ }^{178}$. Nous avons vu, en particulier, comment la théorie de la subalternation des fins permet à Thomas de réunir philosophie et théologie en une unité articulée et «hiérarchisée », où chacune d'elles conserve sa spécificité («autonomie »), mais où toutes deux travaillent en vue de la même fin dernière. Dans les articles suivants du même prologue, Thomas déterminera les principes et la méthode propres de la théologie, au moyen, cette fois, de la théorie de la «quasi» subalternation des principes $^{179}$ par rapport à la science de Dieu lui-même. Cela permettra de déterminer les lieux et les conditions des rapports entre la philosophie et la théologie, en tenant toujours compte des fondements établis dans le premier article.

\section{CONCLUSION : CONTEMPLATIO ACCIPIT RATIONEM VITAE}

Cette étude s'inspire de l'article $1 \mathrm{du}$ prologue du commentaire des Sentences, où Thomas conclut à la nécessité de la doctrina theologie en plus et au-delà des disciplines philosophiques, qui, au temps de Thomas, couvraient un champ beaucoup plus vaste qu'aujourd'hui, des sciences naturelles aux mathématiques appliquées et aux différents arts. Je crois que dans l'esprit de Thomas tout savoir scientifique, pour spécialisé qu'il soit, est conçu comme pouvant servir au développement de la sacra doctrina et il est de soi orienté à la contemplation de Dieu. En effet, il part du fait que la vie humaine a pour but dernier la contemplation de Dieu et cela tant pour les philosophes que pour les fidèles. Dans notre étude, nous nous sommes d'abord demandé ce que Thomas veut dire quand il parle de la «contemplation de Dieu à partir des créatures, en

178. Voir à ce propos les pages éclairantes de R. Imbach, qui situent bien l'idéal de sagesse formulé par Thomas : Ruedi IMBACH, « Autonomie des philosophichen Denkens? Zur historischen Bedingtheit der mittelalterlischen Philosophie, dans Jan A. AERTSEN et Andreas SPEER (éd.), Was ist Philosophie im Mittelalter? Qu'est-ce que la philosophie au Moyen Âge? What is Philosophy in the Middle Ages?, Berlin - New York, Walter de Gruyter (coll. « Miscellanea mediaevalia » 26), 1998, p. 125-137.

179. In I Sent., prol., a. 3, ad 2.2.B (éd. A. OlivA, p. 323-324, 1. 67-90 ; étude historique de cette doctrine aux p. 139-158). 
laquelle consiste selon le Philosophe la félicité contemplative » (In I Sent., prol., a.1, 1. 33-34, cité à la note 7).

Après avoir constaté que Thomas, au long de toute sa carrière d'enseignant, a parlé d'une contemplation des philosophes, parfois de façon générale et parfois selon tel ou tel auteur, il nous a paru important d'étudier en quoi consiste cette contemplation et en quoi elle se distingue de la contemplation selon la foi. Cela nous a permis de constater une identité essentielle entre l'acte de contemplation des philosophes et celui des fidèles ou sancti in uia. La différence originelle entre les deux contemplations est que l'une commence par considérer les créatures et de celles-ci parvient à contempler Dieu, tandis que l'autre commence par considérer d'abord Dieu par la foi et ne considère les créatures qu'en fonction de Dieu (voir $S c G$ II, 4, cité à la note 7). Rappelons-nous que, tant pour la philosophie que pour la théologie, «connaître les réalités divines par le miroir des créatures et énigmatiquement par ressemblance est un mode de connaissance connaturel à la nature humaine » (In III Sent., d. 34, q. 1, a.1, resp., cité à la note 13).

La contemplation, pour Thomas, est essentiellement une activité de l'intellect, une vision, mais pas seulement : elle est aussi « une affaire de vie ». Cela vaut pour les philosophes autant que pour les fidèles. En effet, dès l'a. $1 \mathrm{du}$ prologue des Sentences Thomas avait parlé de la contemplation de Dieu comme fin de la «vie humaine» («omnes qui recte senserunt posuerunt finem humane uite Dei contemplationem » 1. 31-32, cité à la note 7). Dans la distinction 35 du III' Livre, il parle de la contemplation des philosophes et de celle des saints sous cet aspect. L'idée de la contemplation comme « affaire de vie » est sous-jacente à la plupart des textes où Thomas parle de la contemplation philosophique selon différents philosophes. La contemplation comme « affaire de vie » comporte un double mouvement de la volonté. D'abord, un acte d'amour préalable, qui perfectionne la faculté cognitive du sujet: dans la contemplation des philosophes, ceux-ci sont mus préalablement par l'« amour de soi », tandis que, dans la contemplation des fidèles, ceux-ci sont mus par l'«amour de charité ». Le deuxième mouvement de la volonté est «le désir de la contemplation [qui] provient de l'amour de l'objet, car, là où se trouve l'amour, là est le regard » (voir note 36) et cet objet est Dieu et les réalités divines, tant pour les philosophes que pour les sancti in uia.

Le mouvement à partir duquel les philosophes contemplent et aiment Dieu part d'un amour de soi, de sa propre vie, car, comme l'exprime Thomas : «sicut unitas est principium unionis, ita amor quo quis diligit seipsum est forma et radix amicitiae » $\left(I I^{a}-I I^{a e}\right.$, q. 25 , a.4, resp., cité à la note 37). Ils aimeront cependant Dieu pour lui-même, conformément aux exigences de la simple nature, et même plus qu'eux-mêmes, sans ou avec 
le secours de la grâce, comme Thomas l'affirme dès son commentaire des Sentences: «amore amicitiae naturaliter Deus ab homine plus quam seipso diligitur » (Super III Sent., d. 29, a.3, resp., cité à la note 43, et dans la $I^{a}-I I^{a e}$, q. 109 , a.3, avec notre explication au $\left.\S I I I .2\right)$. Le mouvement par lequel les fidèles contemplent Dieu et l'aiment est en revanche inspiré par Dieu lui-même et, à son origine, il a Dieu qui infuse la charité dans les fidèles, et il a Dieu pour objet ultime. Cela n'empêche pas que les fidèles, dans cet amour surnaturel pour Dieu, ne s'aiment aussi eux-mêmes d'amour de charité, lequel n'évacue cependant pas l'amour naturel d'eux-mêmes, qui est radical en l'homme, comme l'est l'unité de l'être humain ${ }^{180}$. Cette distinction de deux types de contemplation correspond parfaitement à la distinction entre connaissance philosophique et théologique, telle que nous venons de la voir exprimée dans la $S c G$ II, 4 (voir la note 7).

La contemplation aimante de Dieu que même les philosophes peuvent pratiquer, en aimant Dieu par-dessus tout et plus qu'eux-mêmes, éventuellement de leurs seules forces naturelles, arrive à créer, selon Thomas, les conditions d'une vraie amitié entre «Dieu, les dieux et les hommes ${ }^{181}$, mais cela seulement à travers la grâce, le don surnaturel de sa vie, que Dieu fait aux sages païens (voir ci-dessus, § III.2).

Il est évident que, pour Thomas, cette contemplation naturelle des philosophes, « en tant qu'elle est une affaire de vie», n'a de sens que pour « les gentils et les infidèles ». Les croyants ont accès, par la foi, à une autre contemplation de Dieu et des réalités divines, qui a son point de départ, non dans la considération des créatures pour elles-mêmes, mais dans celle de Dieu lui-même, qui se révèle. Chez le croyant, la considération des créatures est illuminée et régie par la foi : il les étudie à partir de Dieu et en référence à lui. Est-ce qu'alors, selon Thomas, pour le croyant sous le régime de la foi, il n'y aurait plus d'exercice possible de la philosophie mais seulement de la théologie? Il n'apparait pas que ce soit la position de Thomas.

Il semble au contraire que, pour lui, la philosophie peut avoir, en régime chrétien, toute sa place et jouer un rôle important : d'abord pour l'élaboration de la théologie elle-même; deuxièmement, parce que c'est le lieu propre du débat avec ceux qui n'admettent pas la Révélation chrétienne comme principe de vie (voir $S c G, I, 2){ }^{182}$.

180. $I I^{a}-I I^{a e}$, q. 25, a. 4 (éd. Leon., t. 8, p. 200, cité à la note 37).

181. In Ethic. Nic., X (1179a22), lect. 13 (éd. Leon., t. 47, 2, p. 595, 1. 109-137, cité à la note 49).

182. Pasquale Porro, dans le très beau livre qu'il vient de publier, exprime à ce propos une position plus mitigée que la nôtre : «Ai suoi occhi [à savoir de Thomas], la filosofia in generale rappresentava anzi una stagione forse gloriosa ma ormai chiusa, circoscritta essenzialmente ai Greci e agli Arabi - una esperienza di cui parlare coniugando i verbi al passato. [...] La filosofia è per Tommaso una stagione chiusa, perché la rivelazione ha 
Il faut d'abord considérer les disciplines elles-mêmes, la philosophie et la théologie, et voir comment elles s'articulent entre elles selon Thomas. Il en parle déjà dans l'a. 1 du prologue des Sentences : «Puisque la fin de toute philosophie est inférieure à la fin de la théologie et lui est subordonnée (Cum finis totius philosophie sit infra finem theologie et ordinatus ad ipsum) » (voir la note 177). Rappelons encore que la fin de la philosophie n'est pas ordonnée à la théologie comme à sa fin, mais à la fin même de la théologie (ad ipsum) ! Il n'y a donc pas deux fins ultimes pour l'homme qui est à la fois philosophe et croyant, mais une seule : la vision immédiate de Dieu dans son essence. «Cette béatitude n'est pas une composante de la nature humaine, mais la fin de la nature ellemême (haec beatitudo non est aliquid naturae, sed naturae finis) » (I Pars, q. 62, a.1, resp., cité à la note 138). La façon dont l'une et l'autre discipline atteignent cette fin unique n'est cependant pas la même : si ni l'une ni l'autre ne l'atteignent parfaitement, la théologie s'en approche toutefois beaucoup mieux quant au contenu et à la certitude. En raison des principes dont elle découle, la philosophie est inférieure à la théologie ( « infra finem theologie ») dans sa manière d'accéder à la même fin.

Sous le régime de la foi chrétienne, la recherche philosophique, selon Thomas, ne perd pas la spécificité qui lui est imposée par ses principes, sa méthode et sa fin. Il est indéniable que Thomas admet, même sous le régime de la foi chrétienne, l'élaboration d'une science proprement philosophique, qui, à partir des créatures, étudiées à la lumière des principes de la raison naturelle, élabore une connaissance du monde créé, et de sa destinée, dont la théologie, en raison de la faiblesse de l'intellect humain, peut se servir pour approfondir ses propres connaissances et mieux comprendre la Révélation ${ }^{183}$.

C'est dans le cadre de la subalternation des fins, dont nous venons de parler, que Thomas comprend la façon dont un chrétien philosophe peut pratiquer sa discipline. Selon Thomas, pour un chrétien il n'y a pas deux fins dernières, une naturelle et une surnaturelle, et donc son élaboration philosophique a pour fin la contemplation du Dieu de la Révélation chrétienne. La philosophie qu'élabore le philosophe chrétien n'a pas pour lui ce caractère de sagesse suprême qu'elle conserve pour le philosophe non croyant (voir I Pars, q. 1, a. 6). La contemplation de Dieu que pratique le chrétien philosophe est celle même des sancti in uia, car la fin

cambiato scenario e ha fornito nuovi principî di conoscenza, non è tuttavia una stagione morta o dimenticata : ciò che ha prodotto conserva una funzione vitale, al punto che Tommaso non ha cessato di servirsene, e di confrontarsi con essa, finché è stato intellettualmente attivo, fino cioè a poche settimane dalla morte» Pasquale PorRo, Tommaso d'Aquino. Un profilo storico-filosofico, Roma, Carocci editore (coll. « Frecce »), 2012, p. 13 et 15.

183. Voir I Pars, q. 1, a.5, ad 2, cité ci-dessous à la note 185 ; voir aussi la note 77 . 
de sa philosophie est la même que celle qu'il aime par l'inspiration de la charité. Le chrétien philosophe ne pratique donc pas la contemplation philosophique de Dieu, mais sa philosophie, qui procède ex creaturis et selon la raison naturelle, n'en est pas rendue par cela moins authentique, car l'amor sui, principe de toute contemplation, joue toujours son rôle, même informé par la charité, et la fin de sa philosophie est la même que celle de sa foi.

Cela est possible grâce au fait que, comme on a essayé de le montrer, l'acte de contemplation propre au philosophe en tant que tel, selon Thomas, a la même structure que celui des fidèles et que la fin de la philosophie est la même que la fin de la théologie : c'est la vision face à face, dans la Patrie ${ }^{184}$. C'est à cette vision que sont ordonnées en même temps la philosophie et la théologie. Les deux, pour Thomas, se tiennent, et nous tiennent, vraiment par la main: la philosophie, par sa connaturalité avec l'intelligence humaine, conduit par la main les fidèles à la compréhension des réalités surnaturelles ${ }^{185}$, mais seule la théologie peut conduire par la main à l'unique Patrie.

184. Thomas l'affirme en prenant ensemble la contemplation des philosophes et celle selon la foi : «Oportet igitur quod ultima felicitas hominis quae in hac vita haberi potest, consistat in consideratione primarum causarum, quia illud modicum quod de eis sciri potest, est magis amabile et nobilius omnibus his quae de rebus inferioribus cognosci possunt, ut patet per Philosophum in $I^{\circ}$ De partibus animalium; secundum autem quod haec cognitio in nobis perficitur post hanc vitam, homo perfecte beatus constituitur secundum illud Evangelii : "Haec est vita aeterna ut cognoscant te Deum verum unum." Et inde est quod philosophorum intentio ad hoc principaliter erat ut, per omnia quae in rebus considerabant, ad cognitionem primarum causarum pervenirent. », dans In De causis, prooem. (éd. Henri Dominique SAfrReY, p. 2, 1.5-24). Voir également: II ${ }^{a}-I^{a e}$, q. 180, a. 7, ad 3 (éd. Leon., t. 10, p. 433).

185. «Et hoc ipsum quod sic utitur eis [à savoir, le fait que la théologie se sert des sciences philosophiques], non est propter defectum vel insufficientiam eius [de la théologie], sed propter defectum intellectus nostri; qui ex his quae per naturalem rationem (ex qua procedunt aliae scientiae) cognoscuntur, facilius manuducitur in ea quae sunt supra rationem, quae in hac scientia traduntur»IPars, q. 1, a. 5, ad 2 (éd. Leon., t. 4, p. 16 ; nous soulignons). Voir aussi In Boet. De Trin., q. 2, a. 3, ad 7 (éd. Leon., t. 50, p. 100, 1. 223-233) ; Ibid., q. 5, a. 1, ad 9 (p. 141, 1. 347-381). Â propos de la manuductio, voir : In I Sent., prol., a. 1, (éd. A. OlivA, p. 313, 1. 39-41) ; Ibid., a. 3, resp. 3 (p. 325, 1. 106); Ibid., a. 4, resp. (p. 330, 1. 33). 

OLIVA.

RÉsumÉ. - La contemplation des philosophes selon Thomas d'Aquin. Par Adriano

Après avoir vérifié l'existence d'une «contemplation des philosophes » dans l'œuvre de Thomas, l'article se propose d'en étudier la nature et de la comparer avec celle de la «contemplation des saints», ici-bas et dans la patrie. La notion de contemplation est analysée comme acte de l'intellect spéculatif en tant qu'il est choisi au préalable par la volonté : il s'agit de la contemplation qui «devient une affaire de vie » (contemplatio accipit rationem uite), pour le chrétien comme pour «le païen et l'infidèle». Le rôle de l'amour dans la contemplation est structurellement identique chez les philosophes et chez les saints, bien que dans le premier cas il s'agisse d'un amour naturel et dans le second d'un amour surnaturel, la charité. L'étude attentive conduite sur les textes manifeste que, selon Thomas, l'homme, pour aimer Dieu plus que soi-même et par-dessus tout, n'a pas un besoin absolu de la grâce sanctifiante, qui est nécessaire seulement pour lui faciliter l'exercice de cette capacité naturelle $\left(I^{a}-I^{a e}, q .109\right.$, a.3). En revanche, l'amitié entre le sage païen et Dieu ne peut se réaliser que par le don de la grâce sanctifiante. La contemplation des philosophes sert à Thomas pour expliquer l'articulation entre la philosophie et la théologie, et la notion du désir naturel de voir l'essence divine joue un rôle capital dans l'élucidation de cette articulation : l'article analyse de manière détaillée les textes de Thomas sur ce sujet, sans négliger la littérature ancienne et récente.

MOTS-CLEFS : contemplation des philosophes - contemplation des saints - amour de soi dans la contemplation - amour naturel de Dieu plus que soi-même - amitié entre le sage païen et Dieu - nature et grâce - rapport philosophie et théologie - philosophes chrétiens - désir naturel de voir Dieu - puissance obédientielle - commentaires médiévaux à l'Ethica vetus et à l'Ethica nova - aristotélisme intégral - averroüsme médiéval - interprétations médiévales d'Aristote.

Abstract. - The Contemplation of the Philosophers according to Thomas Aquinas. By Adriano Oliva.

After verifying the existence of a "contemplation of the philosophers" in the work of Thomas, the article proposes to study it and compare it to the "contemplation of the saints", in this life and in patria. The notion of contemplation is analyzed as an act of the speculative intellect as chosen beforehand by the will. Such contemplation "becomes a matter of life" (contemplatio accipit rationem uite), for the Christian as well as for "the pagan and the infidel". For philosophers and saints alike, the role of love in contemplation is structurally identical, though for the former it is a matter of natural love, whereas for the latter it is a matter of supernatural love, charity. Attentive study of the texts shows that, according to Thomas, to love God more than oneself and above all else, man does not have an absolute need for sanctifying grace, which is necessary only for facilitating the exercise of this natural capacity $\left(I^{a}-I I^{a e}, q .109, a .3\right)$. On the other hand, friendship between the wise pagan and God can only be realized by the gift of sanctifying grace. Thomas makes use of the philosophers' contemplation to explain the relation between philosophy and theology. In the elucidation of this relation, the notion of natural desire for seeing the divine essence plays a crucial role. The article engages in a detailed analysis of Thomas' texts on the subject, without neglecting classical and recent literature.

KEYWORDS : contemplation of the philosophers - contemplation of the saints - love of oneself in contemplation - natural love of God more than of oneself - friendship between the wise pagan and God - nature and grace - relation between philosophy and theologychristian philosophers - natural desire to see God - obediential potency - medieval commentaries on the Ethica vetus and the Ethica nova - integral Aristotelianism medieval Averroism - medieval interpretations of Aristotle. 